\title{
BCC-CSM2-HR: a high-resolution version of the Beijing Climate Center Climate System Model
}

\author{
Tongwen Wu ${ }^{1}$, Rucong Yu ${ }^{1}$, Yixiong Lu ${ }^{1}$, Weihua Jie ${ }^{1}$, Yongjie Fang ${ }^{1}$, Jie Zhang ${ }^{1}$, Li Zhang ${ }^{1}$, Xiaoge Xin ${ }^{1}$, \\ Laurent $\mathbf{L i}^{1,2}$, Zaizhi Wang ${ }^{1}$, Yiming Liu ${ }^{1}$, Fang Zhang ${ }^{1}$, Fanghua $\mathbf{W u}^{1}$, Min $\mathbf{C h u}^{1}$, Jianglong $\mathbf{L i}^{1}{ }^{1}$, Weiping $\mathbf{L i}^{1}$, \\ Yanwu Zhang ${ }^{1}$, Xueli Shi ${ }^{1}$, Wenyan Zhou ${ }^{1}$, Junchen Yao ${ }^{1}$, Xiangwen Liu ${ }^{1}$, He Zhao ${ }^{1}$, Jinghui Yan ${ }^{1}$, Min Wei ${ }^{3}$, \\ Wei Xue ${ }^{4}$, Anning Huang ${ }^{5}$, Yaocun Zhang ${ }^{5}$, Yu Zhang ${ }^{6}$, Qi Shu ${ }^{7}$, and Aixue $\mathrm{Hu}^{8}$ \\ ${ }^{1}$ Beijing Climate Center, China Meteorological Administration, Beijing 100081, China \\ ${ }^{2}$ Laboratoire de Météorologie Dynamique, IPSL, CNRS, Sorbonne Université, Ecole Normale Supérieure, \\ Ecole Polytechnique, Paris 75005, France \\ ${ }^{3}$ National Meteorological Information Center, China Meteorological Administration, Beijing 100081, China \\ ${ }^{4}$ Tsinghua University, Beijing 100084, China \\ ${ }^{5}$ Nanjing University, Nanjing 210023, China \\ ${ }^{6}$ Chengdu University of Information Technology, Chengdu 610225, China \\ ${ }^{7}$ The First Institute of Oceanography of the Ministry of Natural Resources, Qingdao 266061, China \\ ${ }^{8}$ National Center for Atmospheric Research, P.O. Box 3000, Boulder, Colorado 80307-3000, USA
}

Correspondence: Tongwen Wu (twwu@cma.gov.cn)

Received: 24 August 2020 - Discussion started: 26 October 2020

Revised: 3 April 2021 - Accepted: 19 April 2021 - Published: 26 May 2021

\begin{abstract}
BCC-CSM2-HR is a high-resolution version of the Beijing Climate Center (BCC) Climate System Model (T266 in the atmosphere and $1 / 4^{\circ}$ latitude $\times 1 / 4^{\circ}$ longitude in the ocean). Its development is on the basis of the mediumresolution version $\mathrm{BCC}-\mathrm{CSM} 2-\mathrm{MR}$ (T106 in the atmosphere and $1^{\circ}$ latitude $\times 1^{\circ}$ longitude in the ocean) which is the baseline for BCC participation in the Coupled Model Intercomparison Project Phase 6 (CMIP6). This study documents the high-resolution model, highlights major improvements in the representation of atmospheric dynamical core and physical processes. BCC-CSM2-HR is evaluated for historical climate simulations from 1950 to 2014, performed under CMIP6-prescribed historical forcing, in comparison with its previous medium-resolution version BCC-CSM2-MR. Observed global warming trends of surface air temperature from 1950 to 2014 are well captured by both BCC-CSM2-MR and BCC-CSM2-HR. Present-day basic atmospheric mean states during the period from 1995 to 2014 are then evaluated at global scale, followed by an assessment on climate variabilities in the tropics including the tropical cyclones (TCs), the El Niño-Southern Oscillation (ENSO), the Madden-Julian Oscillation (MJO), and the quasi-biennial oscillation (QBO)
\end{abstract}

in the stratosphere. It is shown that BCC-CSM2-HR represents the global energy balance well and can realistically reproduce the main patterns of atmospheric temperature and wind, precipitation, land surface air temperature, and sea surface temperature (SST). It also improves the spatial patterns of sea ice and associated seasonal variations in both hemispheres. The bias of the double intertropical convergence zone (ITCZ), obvious in BCC-CSM2-MR, almost disappears in BCC-CSM2-HR. TC activity in the tropics is increased with resolution enhanced. The cycle of ENSO, the eastward propagative feature and convection intensity of $\mathrm{MJO}$, and the downward propagation of QBO in BCC-CSM2-HR are all in a better agreement with observations than their counterparts in BCC-CSM2-MR. Some imperfections are, however, noted in BCC-CSM2-HR, such as the excessive cloudiness in the eastern basin of the tropical Pacific with cold SST biases and the insufficient number of tropical cyclones in the North Atlantic. 


\section{Introduction}

Accurately modelling climate and weather is a major challenge for the scientific community and needs high spatial resolution. However, many climate models, such as those involved in the Coupled Model Intercomparison Project Phase 5 (CMIP5, Taylor et al., 2012) and the more recent CMIP6 (Eyring et al., 2016), still use a spatial resolution of hundreds of kilometres (Flato et al., 2013). This nominal resolution is suitable for global-scale applications that run simulations for centuries into the future but fails to capture small-scale phenomena and features that influence local or regional weather and climate events. This resolution is fine enough to simulate mid-latitude weather systems which evolve in thousands of kilometres, but insufficient to describe convective cloud systems that rarely extend beyond a few tens of kilometres. The study of Strachan et al. (2013) showed that while the average tropical cyclone number can be well simulated at a resolution of around $130 \mathrm{~km}$, grids finer than $60 \mathrm{~km}$ are needed to properly simulate the inter-annual variability of cyclone counts. Higher horizontal resolutions (e.g. $50 \mathrm{~km}$ ) can further improve the simulated climatology of tropical cyclones (e.g. Oouchi et al., 2006; Zhao et al., 2009; Murakami et al., 2012; Manganello et al., 2012; Bacmeister et al., 2014; Wehner et al., 2015; Reed et al., 2015; Zarzycki et al., 2016). Growing evidence shows that high-resolution models $(50 \mathrm{~km}$ or finer in the atmosphere) can reproduce the observed intensity of extreme precipitation (Wehner et al., 2010; Endo et al., 2012; Sakamoto et al., 2012). Some phenomena are sensitive to increasing resolution such as ocean mixing (Small et al., 2015), diurnal cycles of precipitation (Sato et al., 2009; Birch et al., 2014; Vellinga et al., 2016), the quasi-biennial oscillation QBO; Hertwig et al., 2015), the Madden-Julian Oscillation (MJO; Peatman et al., 2015), and monsoons (Sperber et al., 1994; Lal et al., 1997; Martin, 1999; Yao et al., 2017; Zhang et al., 2018). Some small-scale processes associated with mid-latitude storms and tropical cyclones as well as ocean eddies also feed back on the simulated large-scale circulation, climate variability, and extremes (Smith et al., 2000; Masumoto et al., 2004; Mizuta et al., 2006; Shaffrey et al., 2009; Masson et al., 2012; Doi et al., 2012; Rackow et al., 2016). Many studies (e.g. Ohfuchi et al., 2004; Zhao et al., 2009; Walsh et al., 2012; Bell et al., 2013; Strachan et al., 2013; Kinter et al., 2013; Demory et al., 2014; Schiemann et al., 2014; Small et al., 2014; Shaevitz et al., 2014; Hertwig et al., 2015; Murakami et al., 2015; Roberts et al., 2016; Hewitt et al., 2016; Roberts et al., 2018, 2019) show that enhanced horizontal resolution in atmospheric and ocean models has many beneficial impacts on model performance and helps to reduce model systematic biases.

High-resolution climate system modelling becomes a key activity within the climate research community, although increasing model resolution needs considerable computational resources. In 2004, the first high-resolution global climate model produced its first simulations using the Japanese Earth
Simulator (Ohfuchi et al., 2004; Masumoto et al., 2004). In the present day, performing high-resolution climate simulations with model grids smaller than $50 \mathrm{~km}$ in the atmosphere and $0.25^{\circ}$ in the ocean is still a very costly effort, but a growing number of research centres can do it (e.g. Shaffrey et al., 2009; Delworth et al., 2012; Mizielinski et al., 2014; Bacmeister et al., 2014; Satoh et al., 2014; Roberts et al., 2018; Zhou et al., 2020). The High Resolution Model Intercomparison Project (HighResMIP, Haarsma et al., 2016) is a CMIP6-endorsed MIP (Model Intercomparison Project), which aimed to investigate the impact of model resolution on climate simulation fidelity and systematic model biases.

As a major climate modelling centre in China (Wu et al., 2010, 2013, 2014, 2019b, 2020a; Xin et al., 2013, 2019; Li et al., 2019; Lu et al., 2020a, b), Beijing Climate Center (BCC), China Meteorological Administration, also put important efforts into developing high-resolution fully coupled Beijing Climate Center Climate System Model (BCC-CSM-HR) (Yu et al., 2016). The currently released version (BCC-CSM2$\mathrm{HR}$, Table 1) is one of the three BCC model versions ( Wu et al., 2019b) involved in CMIP6 to run HighResMIP experiments. It is now in its pre-operational phase to become the next-generation Beijing Climate Center Climate Prediction System to produce forecasts at leading times of 2 weeks to 1 year. The purpose of this paper is to evaluate its performance by comparing it with the medium-resolution version (BCC-CSM2-MR, Wu et al., 2019b). In particular, we assess their performance to simulate large-scale mean climate and some important phenomena such as the ITCZ, tropical cyclones (TCs), MJO, and QBO which are expected to be improved with enhanced resolution. A relevant description of BCC-CSM2-HR is shown in Sect. 2, and the experiment design is shown in Sect. 3. The main results of model performance are presented in Sect. 4.

\section{Model description at high-resolution configuration}

Due to the diversity of research and operational needs in $\mathrm{BCC}$, a basic rule that we imposed on ourselves in the development of BCC-CSMs (Wu et al., 2019b) is the construction of a traceable hierarchy of model versions running from a coarse grid (T42, approximately $280 \mathrm{~km}$ ) to a medium grid (T106, approximately $110 \mathrm{~km} \times 110 \mathrm{~km}$ ), and to a fine grid (T266, around $45 \mathrm{~km} \times 45 \mathrm{~km}$ ). Actually, we fulfilled our target with an achievement to deliver all of these model versions. All of them are fully coupled models with four components (atmosphere, ocean, land, and sea ice) interacting with each other (Wu et al., 2013, 2019b, 2020a). They are physically coupled through fluxes of momentum, energy, and water at their interfaces. The ocean-atmosphere coupling frequency is $30 \mathrm{~min}$, which is sufficient to account for the diurnal cycle. As shown in Table 1, the medium resolution of BCC-CSM2-MR is at T106 for the atmosphere and has 46 layers with its model lid at $1.459 \mathrm{hPa}$. The resolution of the 
Table 1. Constituents and configurations of BCC-CSM2-MR and BCC-CSM2-HR.

\begin{tabular}{|c|c|c|c|}
\hline & & BCC-CSM2-MR & BCC-CSM2-HR \\
\hline \multirow{10}{*}{$\begin{array}{l}\text { Atmosphere } \\
\text { component } \\
\text { (BCC-AGCM3) }\end{array}$} & Resolution & $\begin{array}{l}\text { T106 }(\sim 110 \mathrm{~km}), 46 \text { layers with top layer at } \\
1.979 \mathrm{hPa} \text { and model lid at } 1.459 \mathrm{hPa}\end{array}$ & $\begin{array}{l}\text { T266 }(\sim 45 \mathrm{~km}), 56 \text { layers with top layer at } \\
0.156 \mathrm{hPa} \text { and model lid at } 0.092 \mathrm{hPa}\end{array}$ \\
\hline & Dynamical core & Spectral framework described in Wu et al. (2008) & $\begin{array}{l}\text { Same as in BCC-CSM2-MR but including } \\
\text { spatially varying divergence damping }\end{array}$ \\
\hline & Deep convection & $\begin{array}{l}\text { A modified Wu (2012) scheme described in Wu et } \\
\text { al. (2019b) }\end{array}$ & $\begin{array}{l}\text { Revised Wu et al. (2019b) scheme, including the ef- } \\
\text { fects of convective downdraft in neighbouring grids }\end{array}$ \\
\hline & $\begin{array}{l}\text { Shallow/middle tropospheric } \\
\text { moist convection }\end{array}$ & Hack (1994) & $\begin{array}{l}\text { Modified Hack (1994) scheme described in Lu et } \\
\text { al. (2020b), incorporating a trigger based on lower } \\
\text { tropospheric stability }\end{array}$ \\
\hline & Cloud macrophysics & $\begin{array}{l}\text { Diagnosed cloud fraction described in } \\
\text { Wu et al. (2019b) }\end{array}$ & $\begin{array}{l}\text { Revised Wu et al. ( } 2019 \mathrm{~b} \text { ) scheme, excluding the } \\
\text { special treatment for the marine stratocumulus }\end{array}$ \\
\hline & Cloud microphysics & $\begin{array}{l}\text { Modified scheme of Rasch and Kristjánsson (1998) } \\
\text { by Zhang et al. (2003), but included the aerosol in- } \\
\text { direct effects in which liquid cloud droplet num- } \\
\text { ber concentration is diagnosed using the aerosols } \\
\text { masses }\end{array}$ & Same as in BCC-CSM2-MR \\
\hline & Gravity wave drag & $\begin{array}{l}\text { Gravity wave drag generated by both orography } \\
\text { (Mcfarlane, 1987) and convection (Beres et al., } \\
\text { 2004) }\end{array}$ & $\begin{array}{l}\text { Same as in BCC-CSM2-MR, but using tuned pa- } \\
\text { rameters related to model resolutions }\end{array}$ \\
\hline & Surface orographic drag & No treatment & $\begin{array}{l}\text { The turbulent mountain stress scheme as in Richter } \\
\text { et al. (2010) }\end{array}$ \\
\hline & Radiative transfer & $\begin{array}{l}\text { Radiative transfer scheme used in CAM3 (Collins et } \\
\text { al., 2004), but including the aerosol indirect effects, } \\
\text { and the effective radius of the cloud droplet for liq- } \\
\text { uid clouds is diagnosed using liquid cloud droplet } \\
\text { number concentration }\end{array}$ & Same as in BCC-CSM2-MR \\
\hline & Boundary layer & $\begin{array}{l}\text { Parameterization of Holtslag and Boville (1993), } \\
\text { but modified PBL height computation as in Zhang } \\
\text { et al. (2014) }\end{array}$ & $\begin{array}{l}\text { The University of Washington Moist Turbulence } \\
\text { scheme (Bretherton and Park, 2009) }\end{array}$ \\
\hline \multirow[t]{3}{*}{$\begin{array}{l}\text { Land surface } \\
\text { component } \\
\text { (BCC-AVIM2) }\end{array}$} & Resolution & $\begin{array}{l}\text { Horizontal resolution same as in the atmosphere } \\
\text { component; } 10 \text { layers for soil and up to five layers } \\
\text { for snow }\end{array}$ & $\begin{array}{l}\text { Horizontal resolution same as in the atmosphere } \\
\text { component; } 10 \text { layers for soil and up to five layers } \\
\text { for snow }\end{array}$ \\
\hline & Biophysical process & CLM3 (Oleson et al., 2004) & CLM3 (Oleson et al., 2004) \\
\hline & $\begin{array}{l}\text { Plant physiological and Soil } \\
\text { carbon- nitrogen dynamical } \\
\text { processes }\end{array}$ & BCC-AVIM2 (Li et al., 2019) & BCC-AVIM2 (Li et al., 2019) \\
\hline \multirow[t]{6}{*}{$\begin{array}{l}\text { Ocean } \\
\text { component } \\
(\mathrm{MOM})\end{array}$} & Resolution & $\begin{array}{l}1^{\circ} \times 1^{\circ} \text { with a tri-pole grid, but } 1 / 3^{\circ} \text { latitude be- } \\
\text { tween } 30^{\circ} \mathrm{S} \text { and } 30^{\circ} \mathrm{N} \text { to } 1.0^{\circ} \text { at } 60^{\circ} \text { latitude, } 40 \\
\text { layers in vertical }\end{array}$ & $\begin{array}{l}1 / 4^{\circ} \times 1 / 4^{\circ} \text { with a tri-pole grid at north to } 60^{\circ} \mathrm{N} \text {, } \\
50 \text { layers in vertical }\end{array}$ \\
\hline & Tracer advection scheme & $\begin{array}{l}\text { MOM4 (Griffies et al., 2005), } \\
\text { Sweby advection scheme (Sweby, 1984) }\end{array}$ & $\begin{array}{l}\text { MOM5 (Griffies, 2012), multi-dimensional piece- } \\
\text { wise parabolic method }\end{array}$ \\
\hline & Neutral diffusion scheme & $\begin{array}{l}\text { Griffies et al. (1998) with a constant diffusivity of } \\
600 \mathrm{~m}^{2} \mathrm{~s}^{-1}\end{array}$ & None \\
\hline & $\begin{array}{l}\text { Surface boundary layer } \\
\text { processes }\end{array}$ & $\begin{array}{l}K \text {-profile parameterization (KPP, Large et al., } \\
1994)\end{array}$ & Same as in MOM4 \\
\hline & $\begin{array}{l}\text { Submesoscale parameterization } \\
\text { scheme }\end{array}$ & None & Fox-Kemper et al. (2008) \\
\hline & Shortwave penetration & $\begin{array}{l}\text { Morel and Antoine (1994), with the maximum } \\
\text { depth of } 100 \mathrm{~m}\end{array}$ & $\begin{array}{l}\text { Manizza et al. (2005), with the maximum depth of } \\
300 \mathrm{~m}\end{array}$ \\
\hline \multirow[t]{4}{*}{$\begin{array}{l}\text { Sea ice } \\
\text { component } \\
\text { (SIS) }\end{array}$} & Resolution & $\begin{array}{l}\text { Same as in the ocean component MOM } 4 \text {, } \\
3 \text { vertical layers including } 1 \text { snow cover and } 2 \text { ice } \\
\text { layers of equal thickness }\end{array}$ & $\begin{array}{l}\text { Same as in the ocean component MOM5, } 3 \text { vertical } \\
\text { layers including } 1 \text { snow cover and } 2 \text { ice layers of } \\
\text { equal thickness }\end{array}$ \\
\hline & Model physics & $\begin{array}{l}\text { SIS4 (Winton, 2000), Elastic-viscous-plastic dy- } \\
\text { namical processes, Semtner's thermodynamic pro- } \\
\text { cesses }\end{array}$ & $\begin{array}{l}\text { SIS5 (Delworth et al., 2006), } \\
\text { Elastic-viscous-plastic dynamical processes, Semt- } \\
\text { ner's thermodynamic processes }\end{array}$ \\
\hline & Snow albedo & 0.80 & 0.85 \\
\hline & Ice albedo & 0.5826 & 0.68 \\
\hline
\end{tabular}




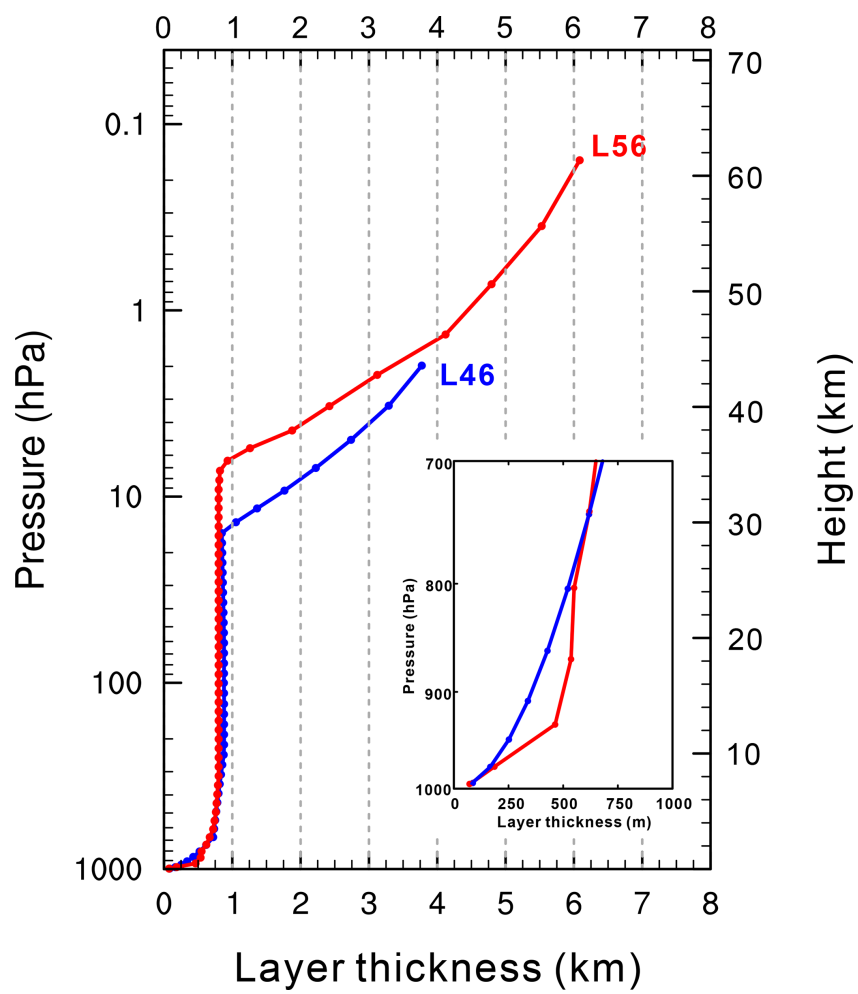

Figure 1. The profiles of layer thickness against height for 46 vertical layers in BCC-CSM2-MR (blue) and 56 vertical layers in BCCCSM2-HR (red).

global ocean is of $1^{\circ}$ latitude $\times 1^{\circ}$ longitude on average, but $1 / 3^{\circ}$ latitude $\times 1^{\circ}$ longitude for the tropical oceans. BCCCSM2-MR was described in detail in Wu et al. (2019b). The atmosphere resolution of BCC-CSM2-HR is T266 on the globe and has 56 layers with the top layer at $0.156 \mathrm{hPa}$ (Fig. 1) and model lid at $0.092 \mathrm{hPa}$ (Table 1). The ocean and sea-ice resolution in BCC-CSM2-HR is $1 / 4^{\circ}$ latitude $\times 1 / 4^{\circ}$ longitude and has 40 layers in depth. Compared to BCCCSM2-MR, BCC-CSM2-HR is updated for its dynamical core and model physics in the atmospheric component (Table 1). The ocean and sea-ice components are also updated from Modular Ocean Model version 4 (MOM4) and Sea Ice Simulator version 4 (SIS4) in BCC-CSM2-MR to their version 5 (MOM5 and SIS5), respectively. The land component in the two versions of BCC-CSMs is the Beijing Climate Center Atmosphere-Vegetation Interaction Model version 2 (BCC-AVIM2, Li et al., 2019).

\subsection{Atmosphere model}

The atmospheric component of BCC-CSM2-MR is Beijing Climate Center Atmospheric General Circulation Model version 3 (BCC-AGCM3) at medium resolution (BCCAGCM3-MR), with details being described in $\mathrm{Wu}$ et al. (2019b) and in a series of relevant publications (Wu et al., 2008, 2010; Wu, 2012; Wu et al., 2013; Lu et al., 2013; Wu et al., 2019a; Lu et al., 2020a; Wu et al., 2020a). The dynamical core in BCC-AGCM3-MR uses the spectral framework as described in Wu et al. (2008), in which an explicit time difference scheme is applied to vorticity equations, semiimplicit time difference schemes for divergence, temperature, and surface pressure equations, and a semi-Lagrangian tracer transport scheme is used for water vapour, liquid cloud water, and ice cloud water. The main model physics in BCCAGCM3-MR was described in Wu et al. (2019b), which includes the modified scheme of deep convection suggested by $\mathrm{Wu}$ (2012), a new diagnostic scheme of cloud amount (Wu et al., 2019b), the shallow convection transport scheme of Hack (1994), the stratiform cloud microphysics following the framework of non-convective cloud processes in NCAR Community Atmosphere Model version 3 (CAM3, Collins et al., 2004) but with a different treatment for indirect effects of aerosols affecting clouds and precipitation, the radiative transfer parameterization that was originally implemented in CAM3, a modified boundary layer turbulence parameterization based on the eddy diffusivity approach (Holtslag and Boville, 1993), and a treatment of gravity waves that are generated by a variety of sources related to orography and convection ( $\mathrm{Lu}$ et al., 2020a).

The atmospheric component in BCC-CSM2-HR is the newly developed version of BCC-AGCM3 with high resolution (BCC-AGCM3-HR). The main differences between BCC-AGCM3-HR and BCC-AGCM3-MR are listed in Table 1 and detailed in the following sub-sections. Actually, the high-resolution atmospheric component has incorporated a spatially varying divergence damping scheme, amelioration of Wu's deep convective scheme (Wu, 2012), and an integrated consideration for shallow convection and boundary layer processes.

\subsubsection{Spatially varying divergence damping}

The performance of a climate model is largely determined by complex motions at different spatio-temporal scales and interactions between them. Subgrid-scale motions are generally caused by high-frequency waves, and they can exert impacts on the computational stability, especially for a highresolution model. Horizontal divergence damping is often needed to control numerical noise in weather forecast models and for numerical stability reasons (Dey, 1978; Bates et al., 1993; Whitehead et al., 2011).

In BCC-AGCM3-HR, second-order and fourth-order horizontal Laplacians $\left(\nabla^{2}\right.$ and $\left.\nabla^{4}\right)$ are used to realize the damping operation on the divergence field $D$ :

$$
\frac{\partial D}{\partial t}=\ldots+k_{2} \nabla^{2} D
$$

and

$$
\frac{\partial D}{\partial t}=\ldots-k_{4} \nabla^{4} D
$$


where $k_{2}$ and $k_{4}$ express the damping coefficients for the second-order and fourth-order dissipation operators, respectively. They are generally set as constant parameters. The second-order damping is used for the top three layers and the fourth-order damping for other layers.

Whitehead et al. (2011) proposed a horizontal divergence damping scheme that works on a latitude-longitude grid by using a linear von Neumann analysis. Here, we extended their idea to the spectral dynamical core in our highresolution model BCC-AGCM3-HR, and we use a secondorder horizontal damping operator with a spatially varying damping coefficient. In order to express the grid spacing dependence of the dissipation, an additional term is introduced in Eqs. (1) and (2) as follows:

$$
\frac{\partial D}{\partial t}=\ldots+k_{2} \nabla^{2} D+k_{v} \nabla^{2} D
$$

and

$$
\frac{\partial D}{\partial t}=\ldots-k_{4} \nabla^{4} D+k_{v} \nabla^{2} D
$$

where

$k_{v}=C_{s} \frac{\left[A_{\mathrm{E}} \Delta \varnothing\right] \cdot\left[A_{\mathrm{E}} \Delta \lambda\right]}{\Delta t}$.

$k_{v}$ is dependent on the time step $\Delta t$ and grid spacing. $A_{\mathrm{E}}$ in Eq. (5) is the radius of the Earth. $\Delta \varnothing$ and $\Delta \lambda$ stand for the latitudinal and longitudinal mesh sizes, respectively. The parameter $C_{s}$ is designed to depend on vertical position as

$C_{s}=C_{s 0} \max \left\langle 1,8\left\{1+\tanh \left[\ln \left(\frac{p_{\text {top }}}{p_{k}}\right)\right]\right\}\right\rangle$,

where $C_{s 0}$ is a constant and related to model resolution, and $p_{\text {top }}$ and $p_{k}$ are the pressures at the top and the $k$ th layers of the model, respectively. Equation (6) provides a rather flat vertical profile until the final two to three model levels, where the damping coefficient is increased rapidly by up to a factor of 8 (Whitehead et al., 2011). This dependence introduces a diffusive sponge layer near the model top to absorb rather than reflect outgoing gravity waves (Whitehead et al., 2011). Equation (5) implies the damping coefficient increases with latitude for BCC-AGCMs spectral grid. This spatially varying damping scheme can improve the atmospheric temperature simulation in the stratosphere, especially at polar areas of both hemispheres, which is possibly due to the more efficient damping of small-scale meridional waves as Whitehead et al. (2011) pointed out.

\subsubsection{Deep convection}

In BCC-AGCM3-MR, as well as in BCC-AGCM3-HR, a modified scheme of the deep cumulus convection developed by $\mathrm{Wu}$ (2012) is used (Wu et al., 2019b). It is characterized by the following points:
1. Deep convection is initiated at the level of maximum moist static energy above the boundary layer, and convection is triggered only when the boundary layer is unstable or there exists updraft velocity in the environment at the lifting level of convective cloud, and simultaneously there is positive convective available potential energy (CAPE).

2. A bulk cloud model is used to calculate the convective updraft with consideration of budgets for mass, dry static energy, moisture, cloud liquid water, and momentum, and the entrainment or detrainment amount for the updraft cloud parcel is determined according to the increase or decrease in updraft parcel mass with altitude.

3. The convective downdraft is assumed to be saturated and originated from the level of minimum environmental saturated equivalent potential temperature within the updraft cloud.

4. The closure scheme determines the mass flux at the base of convective cloud and depends on the decrease or increase in CAPE resulting from large-scale processes.

Along with increasing resolution in BCC-AGCM3-HR, the detrained cloud water can be transported to its adjacent grid boxes, which is accomplished in the dynamical core. Part of the horizontally transported cloud water is permitted to be transferred downward to the lower troposphere, and the amount of downward transferred water vapour is determined by the horizontally transported convective cloud water increment with time. These modifications of the deep convection scheme only in BCC-CSM2-HR are found to be in favour of improving the simulation of eastward propagation of MJO in the tropics, and their details will be presented in another paper.

\subsubsection{Boundary layer turbulence}

BCC-AGCM3-HR employs the University of Washington Moist Turbulence (UWMT) scheme as proposed in Bretherton and Park (2009) to replace the dry turbulence scheme of Holtslag and Boville (1993). The latter was used in BCCAGCM3-MR. In UWMT, the first-order $K$ diffusion is used to represent all turbulence values, by which the turbulent fluxes of a variable $\chi$ are written as

$\overline{w^{\prime} \chi^{\prime}}=-K_{\chi} \frac{\partial \chi}{\partial z}$.

The eddy diffusivity, $K \chi$, is calculated based on the turbulent kinetic energy $e$ and proportional to the stability-corrected length scale $L$, given by

$K_{\chi}=L \sqrt{e}$.

In the case of an entrainment layer at the top of convective boundary layers (BLs), the diffusivity is parameterized with

$K_{\chi}=w_{\mathrm{e}} \Delta z_{\mathrm{e}}$, 
where $\Delta z_{\mathrm{e}}$ is the thickness of the entrainment layer, and $w_{\mathrm{e}}$ is the entrainment rate which uses the expression in Nicholls and Turton (1986):

$w_{\mathrm{e}}=A \frac{w_{*}^{3}}{\left(g \Delta^{\mathrm{E}} S_{\mathrm{vl}} / s_{\mathrm{vl}}\right)\left(z_{\mathrm{t}}-z_{\mathrm{b}}\right)}$.

Here, $w_{*}$ is the convective velocity, $z_{\mathrm{t}}$ and $z_{\mathrm{b}}$ are the top and bottom heights of the entrainment layer, $\Delta^{\mathrm{E}}$ denotes a jump across the entrainment layer, and $s_{\mathrm{vl}}$ is the liquid virtual static energy. $A$ is a nondimensional entrainment efficiency, which is affected by evaporative cooling of mixtures of cloud-top and above-inversion air.

Compared to that of dry convective BLs over land, which is mainly forced by the surface heating, the structure of marine stratocumulus-topped BLs depends strongly on a dominant turbulence-generating mechanism resulting from both evaporative and radiative cooling at cloud top. The UWMT scheme aims to provide a more physical and realistic treatment of marine stratocumulus-topped BLs, and it has been demonstrated that the observed patterns of low-cloud amount with maxima in the subtropical stratocumulus decks can be well reproduced by UWMT in the Community Atmosphere Model (Park and Bretherton, 2009). The implementation of the UWMT scheme in BCC-AGCM3-HR aims to improve the simulation of the low-level clouds over subtropical eastern oceans, and these improvements are found to be critical to reducing the double-ITCZ bias of precipitation (Lu et al., 2020b).

\subsubsection{Shallow convection}

BCC-AGCM3-HR basically inherits the shallow convection parameterization used in BCC-AGCM3-MR, which is a stability-dependent mass-flux representation of moist convective processes with the use of a simple bulk three-level cloud model, as in Hack (1994). Specifically, in a vertically discrete model atmosphere where the level index $k$ decreases upward and considering the case where layers $k$ and $k+1$ are moist and adiabatically unstable, the Hack scheme assumes the existence of a non-entraining convective element with roots in level $k+1$, condensation and rain-out processes in level $k$, and limited detrainment in level $k-1$. By repeated application of this procedure from the bottom of the model to the top, the thermodynamic structure is locally stabilized.

The Hack shallow cumulus scheme can also be active in moist turbulent mixing, such as stratocumulus entrainment, which has different physical characteristics than cumulus convection. Shallow cumulus is usually regarded as a decoupled BL regime in which the vertical mixing processes do not achieve a single well-mixed layer, while the stratocumulus regime represents a well-mixed BL up to cloud top. The decoupling criterion to distinguish between the two regimes is of great importance for simulating the stratocumulus-tocumulus transition (Bretherton and Wyant, 1997; Wood and Bretherton, 2004). A number of these decoupling criteria have been explored, such as static stability (Klein and Hartmann, 1993) and the buoyancy flux integral ratio (Turton and Nicholls, 1987). In light of its robustness, the stability criterion with a threshold of $17.5 \mathrm{~K}$ is introduced into the Hack scheme. The lower tropospheric stability (LTS) is defined as

$\mathrm{LTS}=\theta_{700 \mathrm{hPa}}-\theta_{\text {sfc }}$,

where $\theta_{700 \mathrm{hPa}}$ and $\theta_{\mathrm{sfc}}$ are potential temperatures at $700 \mathrm{hPa}$ and at surface, respectively. In BCC-CSM2-HR, the modified Hack scheme is activated only in the decoupled BL regimes with LTS $<17.5 \mathrm{~K}$ below $700 \mathrm{hPa}$ to remove adiabatically moist instability, and the original Hack scheme (Hack, 1993) is still retained above $700 \mathrm{hPa}$ to remove any local instability as long as the two adjacent model layers are moist and adiabatically unstable. This modification to the triggering of shallow convection is found to be very useful to improve the simulation of the ITCZ precipitation (Lu et al., 2020b).

\subsection{Land surface model}

BCC-AVIM2 is a comprehensive land surface model developed and maintained in BCC. Its previous version BCCAVIM1 was used as the land component in BCC-CSM1.1m participating in CMIP5 (Wu et al., 2013), which includes major land surface biophysical processes treated similarly to in the Community Land Model version 3.0 (CLM3, Oleson et al., 2004) developed at the National Center for Atmospheric Research (NCAR) as well as plant physiological processes (Ji, 1995; Ji et al., 2008), with 10 layers for soil and up to 5 layers for snow. The land component in BCC-CSM2MR and BCC-CSM2-HR is BCC-AVIM version 2 (Li et al., 2019). Updates in BCC-AVIM2 from its precedent version BCC-AVIM1 include a replacement of the water-only lake module by the common land model lake module (CoLMlake) with a more realistic snow-ice-water-soil framework, a parameterization scheme for rice paddies added in the vegetation module, renewed parameterizations of snow cover fraction and snow surface albedo to accommodate the varied snow ageing effect during different stages of a snow season, a revised parameterization to calculate the threshold temperature to initiate freeze (thaw) of soil water (ice) rather than being fixed at $0^{\circ} \mathrm{C}$ in BCC-AVIM1, a prognostic phenology scheme for vegetation growth instead of empirically prescribed dates for leaf onset and fall, and a renewed scheme to depict solar radiation transfer through the vegetation canopy. Details of the updates are given in Li et al. (2019). BCCAVIM2 is implemented in BCC-CSM2-MR and is identical to what is implemented in BCC-CSM2-HR, except for horizontal resolution (same as in their atmosphere component) and the corresponding sub-grid surface classification.

\subsection{Ocean and sea-ice models}

The ocean component of BCC-CSM2-MR is MOM4-L40, developed by the Geophysical Fluid Dynamics Laboratory 
(GFDL; Griffies et al., 2005). It has a nominal resolution of $1^{\circ} \times 1^{\circ}$ with a tri-pole grid, and the actual resolution is from $1 / 3^{\circ}$ latitude between $10^{\circ} \mathrm{S}$ and $10^{\circ} \mathrm{N}$ to $1^{\circ}$ at $60^{\circ}$ latitude. There are 40 levels in the vertical. More details of its implementation can be found in Wu et al. (2019b).

The ocean component of BCC-CSM2-HR is MOM5, also developed by GFDL (Griffies, 2012). The model is based on the hydrostatic primitive equations and uses the Boussinesq approximation. The model uses Arakawa B grid in the horizontal, with a globally uniform $0.25^{\circ}$ resolution. The quasihorizontal rescaled height coordinate, namely the $z^{*}$ vertical coordinate, is employed to enhance flexibility of model applications, which allows for the free surface to fluctuate to values as large as the local ocean depth. There are 50 levels in the vertical, with a resolution of $10 \mathrm{~m}$ in the upper ocean and $367 \mathrm{~m}$ at the bottom. The tracer advection scheme used in both the horizontal and vertical is the multidimensional piecewise parabolic method (MDPPM, Marshall et al., 1997), which is of higher order and more accurate (less dissipative).

MOM5 has a complete set of physical processes with advanced parameterization schemes. The effect of mesoscale eddies through the neutral diffusion scheme of Griffies et al. (1998) is not included in this work. The $K$-profile parameterization (KPP) is used to parameterize ocean surface boundary layer processes (Large et al., 1994). MOM5 uses the optical scheme of Manizza et al. (2005) to define the light attenuation exponentials. SeaWiFS chlorophyll $a$ monthly climatology is used in the calculation of the attenuation of shortwave radiation entering the ocean layers with a maximum depth set at $200 \mathrm{~m}$. The re-stratification effect of submesoscale eddies in the ocean surface mixed layer are parameterized with the sub-mesoscale scheme of Fox-Kemper et al. $(2008,2011)$.

The sea-ice component of BCC-CSM2-HR and BCCCSM2-MR is SIS4 (Winton, 2000) and SIS5 (Delworth et al., 2006), respectively, both developed by GFDL. Both SIS4 and SIS5 are the sea-ice component of MOM4 and MOM5, respectively, and have three vertical layers including one snow cover and two ice layers of equal thickness. They operate on the same oceanic grid of MOM4 in BCC-CSM2-MR and MOM5 in BCC-CSM2-HR, respectively. There are up to five categories of sea ice on each model grid for SIS4 and SI5 according to the thickness of sea ice, and the mutual transformation from one category to another are taken into account under thermodynamic conditions. Both SIS4 and SIS5 employ the scheme of Semtner (1976) for the vertical thermodynamics and contains full dynamics with internal ice forces calculated using an elastic-viscous-plastic rheology.

\section{Experimental design and data used}

\subsection{Historical simulation}

The principal simulation to be analysed is the CMIP6 historical run (hereafter referred to as historical) with prescribed forcings from 1850 to 2014 for BCC-CSM2-MR and from 1950 to 2014 for BCC-CSM2-HR. All historical forcings are from the CMIP6-recommended data (https://esgf-node. llnl.gov/search/input4mips/, last access: 1 April 2018) including (1) greenhouse gases concentrations such as $\mathrm{CO}_{2}$, $\mathrm{N}_{2} \mathrm{O}, \mathrm{CH}_{4}, \mathrm{CFC} 11$, and CFC12 with zonal-mean values and updated monthly; (2) annual means of total solar irradiance derived from the CMIP6 solar forcing; (3) stratospheric aerosols from volcanoes; (4) CMIP6-recommended tropospheric aerosol optical properties due to anthropogenic emissions that are formulated in terms of nine spatial plumes associated with different major anthropogenic source regions using version 2 of the Max Planck Institute Aerosol Climatology Simple Plume model (MACv2-SP, Stevens et al., 2017); (5) time-varying gridded ozone concentrations; and (6) yearly global gridded land-use forcing. In addition, aerosol masses based on CMIP5 (Taylor et al., 2012) are also used for the on-line calculation of cloud droplet effective radius in our models.

The historical simulation of BCC-CSM2-MR follows the requirement of CMIP6, with the preindustrial initial state obtained after a 500-year piControl simulation. It covers the whole period from 1850 to 2014 (Wu et al., 2019b). The simulation of BCC-CSM2-HR covers a shorter historical period from 1950 to 2014. Its initial state is the final state from a 50-year control simulation with fixed historical forcing of the year 1950, following the HighResMIP protocol. The control run itself is initiated from the states of individual components with their uncoupled mode. That is, the states of atmosphere and land are obtained from a 10-year AMIP run forced with monthly climatology of sea surface temperature (SST) and sea-ice concentration, while the states of ocean (MOM5) and sea ice (SIS5) are derived from a 1000-year forced run with a repeating annual cycle of monthly climatology of atmospheric state from the Coordinated Ocean-Ice Reference Experiment (CORE) dataset version 2 (Danabasoglu et al., 2014).

\subsection{Data used for evaluations}

We choose the same period of 1950-2014 from both BCCCSM2-MR and BCC-CSM2-HR historical simulations to evaluate their performance against observation-based or reanalysis data.

The 1950-2014 monthly global $1^{\circ} \times 1^{\circ}$ gridded surface temperature from the Hadley Centre-Climatic Research Unit (HadCRUT version 4.6.0.0, available at https://www. metoffice.gov.uk/hadobs/hadcrut4/, last access: 1 May 2019) is used to evaluate the global warming trend from BCC- 
CSM2-MR and BCC-CSM2-HR. HadCRUT (Morice et al., 2012) is a dataset combining land surface air temperature from the Climatic Research Unit (CRUTEM) and Hadley Centre Sea Ice and Sea Surface Temperature (HadISST). CRUTEM is derived from air temperatures near the land surface recorded at weather stations across the globe (Harris and Jones, 2017). HadISST contains global $1^{\circ} \times 1^{\circ}$ sea-ice concentration and SST, including in situ measurements from ships and buoys (Rayner et al., 2003).

For the evaluation of present-day mean climate over the globe and major climate variabilities in the tropics, we choose the recent past 20 years of 1995-2014 as our reference period, which will be observed as close as possible for observation-based or reanalysis data, described as follows.

The 2001-2014 monthly global $1^{\circ} \times 1^{\circ}$ gridded net radiations at the top of the atmosphere (TOA) from CERESEBAF version 4.1 products (Loeb et al., 2018; available at https://asdc.larc.nasa.gov/project/CERES/CERES_ EBAF_Edition4.1, last access: 1 May 2020) are used to evaluate the global energy budget in models. CERES-EBAF data are derived on the basis of satellite observation from CERES (Clouds and Earth's Radiant Energy System) and synthesized with EBAF (Energy Balanced and Filled) data. Satellite observation is a direct monitoring of the net radiation at TOA, and a primary source of data for estimating Earth's energy balance (Wielicki et al., 1996).

The $1995-2014$ monthly global $0.25^{\circ} \times 0.25^{\circ}$ gridded atmospheric temperature and wind from the fifth generation of ECMWF (the European Centre for Medium-Range Weather Forecasts) atmospheric reanalyses (ERA5, Hersbach and Dee, 2016) and the climatological data of global zonal mean temperature and wind above the $1 \mathrm{hPa}$ level to $0.1 \mathrm{hPa}$ at $5^{\circ}$ latitude interval from the COSPAR (Committee on Space Research) International Reference Atmosphere (CIRA86) are used to evaluate the vertical structure of atmospheric temperature and wind. The 1995-2014 monthly global gridded wind data from ERA5 are also used to evaluate the quasi-biennial oscillation (QBO) of the equatorial zonal wind between easterlies and westerlies in the tropical stratosphere. CIRA-86 (available at https://catalogue.ceda.ac. uk/uuid/4996e5b2f53ce0b1f2072adadaeda262, last access: 1 May 2020) includes a global climatology of zonal atmospheric temperature and velocity extending from pole to pole on a $5^{\circ}$ latitude grid and approximately $0-120 \mathrm{~km}$ at $2 \mathrm{~km}$ vertical resolution. It is derived from a combination of satellite, radiosonde, and ground-based measurements (Fleming et al., 1990).

The 1995-2014 monthly global observed precipitation at $2.5^{\circ}$ resolution is taken from the Global Precipitation Climatology Project (GPCP version 2.2; Adler et al., 2003) dataset and used to evaluate the global distribution of precipitation climatology.

The $2001-2014$ quasi-global $\left(60^{\circ} \mathrm{N}-60^{\circ} \mathrm{S}\right) 0.1^{\circ} \times 0.1^{\circ}$ gridded half-hourly precipitation estimates of Global Precipitation Measurement (GPM) Integrated Multi-satellitE
Retrievals for GPM (IMERG) products (available at https://gpm1.gesdisc.eosdis.nasa.gov/data/GPM_L3/GPM_ 3IMERGHH.06/, last access: 1 May 2020) are used to derive 3-hourly data and then to evaluate the spectrum of precipitation intensity. IMERG uses inter-calibrated estimates from the international constellation of precipitation-relevant satellites and other data sources, including surface precipitation gauge analyses (Huffman et al., 2019).

Two datasets (CRUTEM and HadISST) of the 1995-2014 monthly global $1^{\circ} \times 1^{\circ}$ gridded surface temperature for the land (Jones et al., 2012) and ocean (Rayner et al., 2003) and gridded sea-ice concentration are used to evaluate the model biases of land and ocean temperatures as well as seaice cover. For the assessment of the ENSO cycle variation, a longer period of 1950-2014 is used from the global monthly HadISST dataset.

The 1995 to 2014 daily global $0.25^{\circ} \times 0.25^{\circ}$ wind from ERA5, daily global $2.5^{\circ} \times 2.5^{\circ}$ outgoing longwave radiation (OLR) from NOAA (Liebmann and Smith, 1996), and daily global $2.5^{\circ} \times 2.5^{\circ}$ precipitation from GPCP (Adler et al., 2003) are used to diagnose the Madden-Julian Oscillation (MJO), which is the dominant mode of sub-seasonal variability in the tropical troposphere (Madden and Julian, 1971). All the data firstly undergo the $20-100 \mathrm{~d}$ band-pass filter. An analysis of multivariate empirical orthogonal functions (EOFs) and principal components (PCs) is then performed on intra-seasonal OLR, 850 , and $200 \mathrm{hPa}$ zonal wind anomalies averaged over $10^{\circ} \mathrm{S}-10^{\circ} \mathrm{N}$. Eight MJO phases defined by the inverse tangent of the ratio of $\mathrm{PC} 2$ to $\mathrm{PC} 1$ as in Wheeler and Hendon (2004) are also reconstructed.

The 1995-2014 6-hourly tropical cyclone observations from International Best Track Archive for Climate Stewardship (IBTrACS; Knapp et al., 2010) provide information of all tropical cyclones, including latitude-longitude position, minimum central pressure, and maximum sustained winds (instantaneous values) at a time frequency of every $6 \mathrm{~h}$. We use the multiple criteria reported by Murakami (2014) to detect TCs with 6-hourly outputs from models (instantaneous values from BCC-CSM2-HR, but accumulated values from BCC-CSM2-MR). (1) The maximum of relative vorticity of a TC-like vortex at $850 \mathrm{hPa}$ exceeds $15 \times 10^{-5} \mathrm{~s}^{-1}$ (a threshold that can vary from $1 \times 10^{-5}$ to $15 \times 10^{-5} \mathrm{~s}^{-1}$ as a function of resolution (Murakami, 2014). (2) The warmcore above the TC-like vortex, which is presented as the sum of the air temperature deviations (subtracting the maximum temperature from the mean temperature within the TClike vortex centre for an area of $10^{\circ} \times 10^{\circ}$ ) at 300,500 and $700 \mathrm{hPa}$, exceeds $0.8 \mathrm{~K}$, a threshold falling in the range $0.6-$ $1.0 \mathrm{~K}$ that is recommended in Murakami (2014). (3) the maximum wind speed at $850 \mathrm{hPa}$ is higher than that at $300 \mathrm{hPa}$. (4) The maximum wind speed at $10 \mathrm{~m}$ within the TC-like vortex centre for an area of $3^{\circ} \times 3^{\circ}$ grid is higher than $10 \mathrm{~m} \mathrm{~s}^{-1}$. (5) The genesis position of the TC-like vortex is over the ocean. (6) The duration of the TC-like vortex that satisfied above conditions exceeds $48 \mathrm{~h}$. 


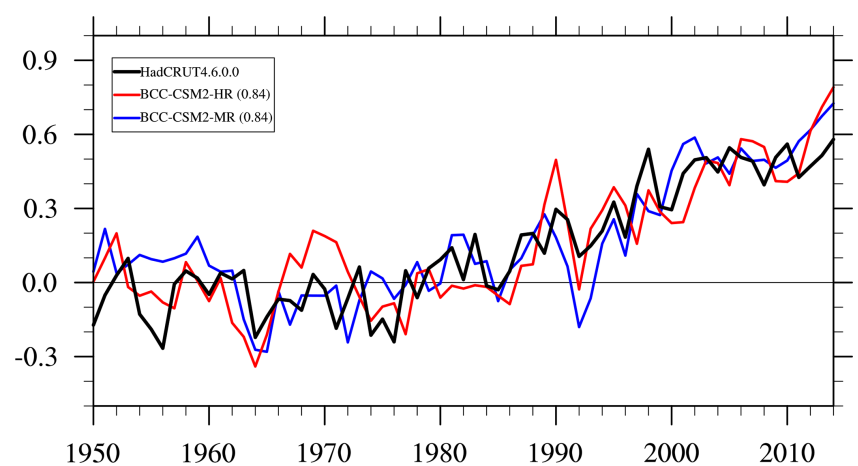

Figure 2. Time series of anomalies in the global mean surface air temperature from 1950 to 2014 . The reference climate to deduce anomalies is for each individual curve from 1961 to 1990. The numbers in the parentheses denote the correlation coefficient of 11-year smoothed simulations with HadCRUT4.6.0.0 (Morice et al., 2012) observations.

\section{Results}

Data analysis and visualization are generally on the original or native grid of observation and models. An exception is the assessment of models' biases in contrast to observation. In this case, simulations are re-gridded onto the grid of corresponding observation.

\subsection{Global mean surface air temperature variations from 1950 to 2014}

The historical simulation from 1950 to 2014 allows us to evaluate the ability of models to reproduce the global warming of near-surface temperature. Figure 2 presents globalmean surface air temperature evolutions for HadCRUT4 data and the two BCC models, in which the climatological mean is calculated for the reference period 1961-1990 and removed from the time series to better reveal long-term trends. The interannual variability of both simulations is qualitatively comparable to that observed, and the correlation coefficients reach 0.84 in both models. A remarkable feature in Fig. 2 is the presence of a global warming hiatus or pause for the period from 1998 to 2013 when the observed global surface air temperature warming slowed down. It is interesting that both models reproduce a hiatus, from 2002 to 2010 in BCC-CSM2-MR and from 2004 to 2012 in BCC-CSM2HR. This warming hiatus is a hot topic (e.g. Fyfe et al., 2016; Medhaug et al., 2017; Wu et al., 2019a), largely debated in the scientific research community. The reason why the BCC models simulate the recent global warming hiatus is beyond the scope of this paper and will be explored in other works.

\subsection{Global energy budget}

It is to be noted that only the period 2001-2014 is available for CERES-EBAF. For the consistency of comparison, we also shortened data from models and kept the same time interval as in CERES-EBAF. As shown in Table 2, the globally averaged TOA net energy is $2.12 \pm 0.40 \mathrm{~W} \mathrm{~m}^{-2}$ in BCC-CSM2-MR and $1.51 \pm 0.57 \mathrm{~W} \mathrm{~m}^{-2}$ in BCC-CSM2-HR for the same period from 2001 to 2014. The energy equilibrium of the whole Earth system in BCC-CSM2-HR is slightly improved. The TOA shortwave and longwave components for clear sky in BCC-CSM2-HR are also much closer to CERES-EBAF than in BCC-CSM2-MR. We noted that the TOA shortwave and longwave components for all sky in BCC-CSM2-HR are lower than CERES-EBAF data and are not improved from BCC-CSM2-MR. This is related to cloud radiative forcing. Clouds constitute a major modulator of the radiative transfer in the atmosphere, and their radiative properties exert strong impacts on the equilibrium and variation of the radiative budget at TOA. The globally averaged shortwave cloud radiative forcing in BCCCSM2-HR is slightly stronger than that in CERES-EBAF $\left(-47.16 \pm 0.24 \mathrm{~W} \mathrm{~m}^{-2}\right)$, about $3 \mathrm{~W} \mathrm{~m}^{-2}$ of the cooling effect, and the globally averaged longwave cloud radiative forcing in BCC-CSM2-HR is also stronger than the CERESEBAF data $\left(25.99 \pm 0.25 \mathrm{~W} \mathrm{~m}^{-2}\right)$ near $2 \mathrm{~W} \mathrm{~m}^{-2}$ of warming effect (biases). The globally averaged shortwave and longwave cloud radiative forcing in BCC-CSM2-MR are much closer to CERES-EBAF.

The obvious biases of the model in contrast to CERESEBAF are mainly located at the mid-latitudes and subtropics. Figure 3 shows the annual and zonal mean of shortwave, longwave, and net cloud radiative forcing for the two model versions and observations. The longwave and net cloud radiative forcing are overall consistent with CERES-EBAF at most latitudes. In the mid-latitudes of both the hemispheres, the shortwave cloud radiative forcing from BCC-CSM2-HR is much closer to CERES-EBAF than that from BCC-CSM2MR. But at low latitudes between $30^{\circ} \mathrm{S}$ and $30^{\circ} \mathrm{N}$, BCCCSM2-HR simulates excessive cloud shortwave radiative forcing which mainly comes from evident biases over the eastern tropical Pacific and tropical Atlantic oceans (Fig. 4). These biases are possibly attributable to new treatments for boundary layer processes.

\subsection{Present-day mean climate}

\subsubsection{Vertical structure of the atmospheric temperature and wind}

Figure 5 presents zonally averaged vertical profiles of air temperature and zonal wind for December-JanuaryFebruary (DJF) and June-July-August (JJA) as simulated by BCC-CSM2-MR and BCC-CSM2-HR, in contrast to the ERA5 reanalysis below the $1 \mathrm{hPa}$ level (Hersbach and Dee, 2016) and climatological values above the $1 \mathrm{hPa}$ level from CIRA86 (Fleming et al., 1990). The observed vertical profile of atmospheric temperature shows a clear structure of stratification, with an evident seasonal transition. In DJF, it is characterized as cool layers over broader latitudes span- 
Table 2. Energy balance and cloud radiative forcing at the top of the atmosphere (TOA) in the models in contrast to CERES-EBAF observations. Units: $\mathrm{W} \mathrm{m}^{-2}$.

\begin{tabular}{lrrr}
\hline & BCC-CSM2-MR & BCC-CSM2-HR & CERES-EBAF \\
\hline Net energy at TOA & $2.12 \pm 0.40$ & $1.51 \pm 0.57$ & $0.84 \pm 0.33$ \\
TOA outgoing longwave radiative flux & $239.18 \pm 0.20$ & $237.85 \pm 0.18$ & $239.69 \pm 0.25$ \\
TOA net shortwave radiative flux & $241.29 \pm 0.35$ & $239.35 \pm 0.49$ & $240.53 \pm 0.19$ \\
TOA outgoing longwave radiative flux in clear sky & $265.10 \pm 0.20$ & $265.28 \pm 0.22$ & $265.67 \pm 0.37$ \\
TOA net shortwave radiative flux in clear sky & $291.13 \pm 0.25$ & $290.06 \pm 0.15$ & $287.68 \pm 0.14$ \\
TOA incoming shortwave radiation & $340.34 \pm 0.09$ & $340.35 \pm 0.09$ & $340.14 \pm 0.09$ \\
Shortwave cloud radiative forcing & $-49.83 \pm 0.27$ & $-50.71 \pm 0.48$ & $-47.16 \pm 0.24$ \\
Longwave cloud radiative forcing & $25.92 \pm 0.08$ & $27.43 \pm 0.11$ & $25.99 \pm 0.25$ \\
\hline
\end{tabular}

Notes: mean value and standard deviation are calculated from 2001-2014 yearly global means of the simulations for BCC-CSM2-MR, BCC-CSM2-HR, and the CERES-EBAF Ed4.1 dataset.

ning the transition from troposphere to stratosphere over the Northern Hemisphere, and warm layers spanning from the top of the stratosphere to the mesosphere over the Southern Hemisphere. Those different vertical structures in both hemispheres during DJF are almost reversed in JJA. BCC-CSM2HR is capable of capturing the structure of the upper stratosphere and the transition to mesosphere while BCC-CSM2MR cannot.

Figure 6 shows biases of the zonally averaged annual air temperature, relative to ERA5. Only model data from 5 to $1000 \mathrm{hPa}$ are evaluated as there are spare station-based observations above $5 \mathrm{hPa}$ and it is generally recognized that most of the stations do not reach their best-practice altitude of $5 \mathrm{hPa}$ (https://gcos.wmo. int/en/atmospheric-observation-panel-climate, last access: 1 May 2020). Temperature biases in the lower to middle troposphere are relatively small, about -2 to $2 \mathrm{~K}$ in BCCCSM2-MR and -1 to $1 \mathrm{~K}$ in BCC-CSM2-HR at most latitudes, except in the southern polar region where temperature below $700 \mathrm{hPa}$ are extrapolated values for ERA5 observation and models. The two models BCC-CSM2-MR and BCC-CSM2-HR have a cold bias of air temperature that appears near the tropopause and extends to the stratosphere in the subpolar and polar regions. There is also a thicker layer of warm biases in the lower stratosphere over the tropics and mid-latitudes. Those temperature biases are not really reduced in BCC-CSM2-HR with a higher horizontal resolution. The cold bias in the troposphere was also reported in many CMIP5 models (see Charlton-Perez et al., 2013; Tian et al., 2013),

As shown in Fig. 5, the basic pattern of vertical structures of westerly and easterly zones and their changes in DJF and JJA are generally well simulated by BCC-CSM2-MR and BCC-CSM2-HR. Both models have westerly wind biases of annual means that are located in the upper troposphere and stratosphere near $60^{\circ} \mathrm{S}$ and $60^{\circ} \mathrm{N}$ (Fig. $6 \mathrm{~b}$ and d) and reflect the meridional structure of temperature biases (Fig. 6a and c) in accordance with the temperature-wind relationship.

\subsubsection{Precipitation}

Figure 7 shows the spatial distribution of DJF and JJA mean precipitation for BCC-CSM2-MR and BCC-CSM2HR, compared to GPCP data. The two versions of BCCCSMs were both able to reproduce the global observed precipitation patterns, and there is an evident improvement in the high-resolution model (BCC-CSM2-HR). Improvements are particularly clear in the Pacific, Indian, and Atlantic oceans. The double-ITCZ issue is one of the most significant biases that persists in many climate models (e.g. Hwang and Frierson, 2013; Li and Xie, 2014). It exists in BCC-CSM2-MR, with excessive precipitation in the South Pacific Convergence Zone (SPCZ). This bias almost disappears in BCC-CSM2HR. As shown in Fig. 8, there is too much precipitation along the southern intertropical convergence zone (ITCZ) in BCCCSM2-MR, which is mainly caused by excessive precipitation in the southern intertropical zone in DJF. This systematic bias is evidently reduced in BCC-CSM2-HR, especially with weakened precipitation in the South Pacific Convergence Zone (SPCZ). The improvement of SPCZ precipitation in BCC-CSM2-HR might be attributed to the implementation of the UWMT scheme which improved the simulation of low-level clouds over the tropical eastern South Pacific (Lu et al., 2020b) and reduced warm biases there (Fig. 10c). But the intensity of precipitation in the northern intertropical convergence zone in BCC-CSM2-HR is stronger than that from GPCP, which is partly attributed to the excessive precipitation in the tropical oceans, especially in the eastern tropical North Pacific (Fig. 7e). A strong negative bias of JJA precipitation over the Amazon region exists in the two models. In Fig. 7f, we also noted that the amount of JJA precipitation in the east of the Philippines and near the Pacific warm pool is worsened, since it is smaller in BCC-CSM2-HR than in BCC-CSM2-MR and GPCP data. This bias of lacking precipitation in BCC-CSM2-HR may partly be caused by a cold-SST bias over the western Pacific warm pool (Fig. 10c).

Figure 9 shows the probability density of 3-hourly precipitation between $40^{\circ} \mathrm{S}$ and $40^{\circ} \mathrm{N}$ as a function of precipitation 

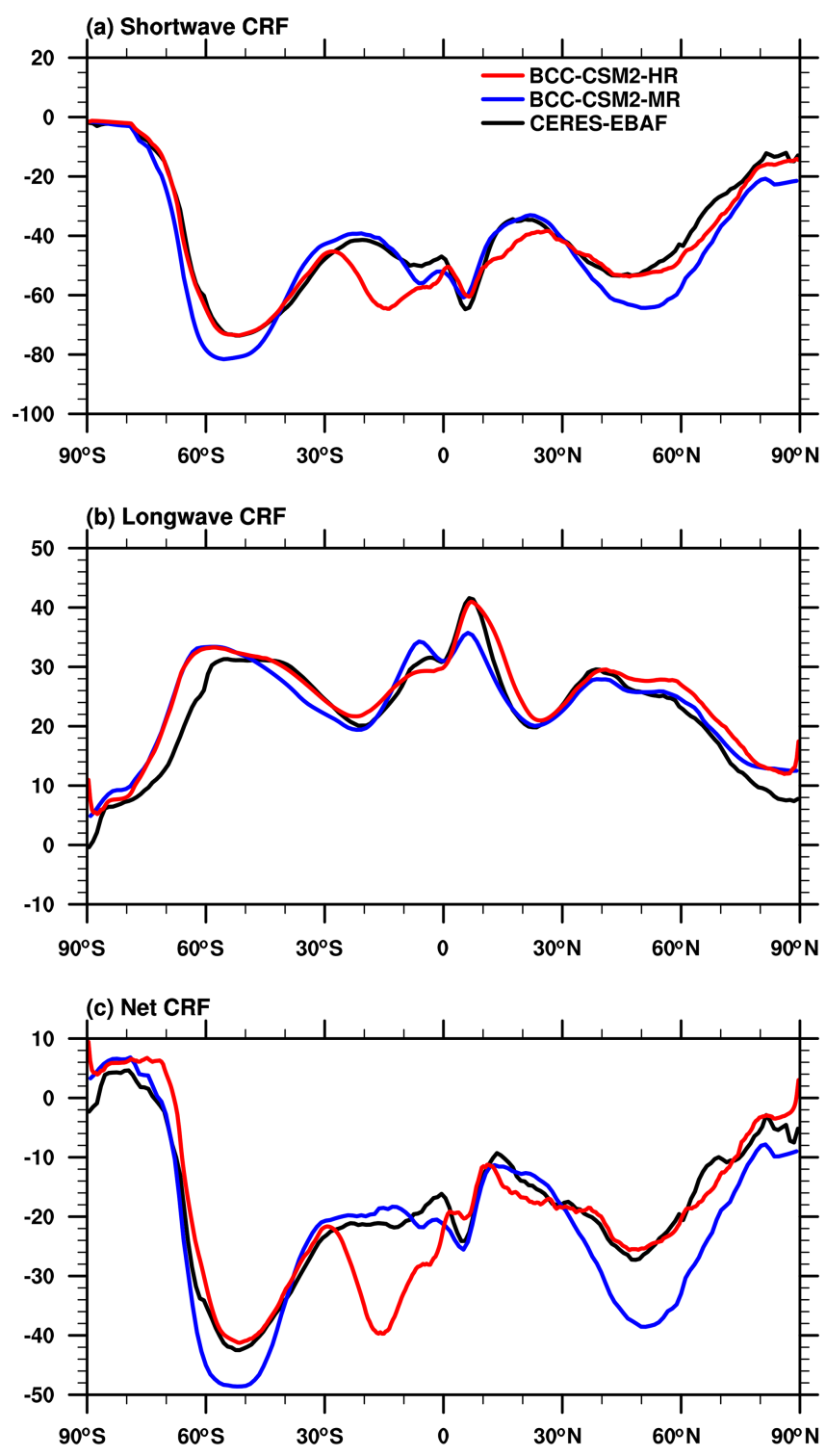

Figure 3. Zonal averages of (a) shortwave, (b) longwave, and (c) net cloud radiative forcing ( $\mathrm{CRF}$, in $\mathrm{W} \mathrm{m}^{-2}$ ) for the historical simulations (2001-2014) of BCC-CSM2-MR (blue lines) and BCCCSM2-HR (red lines), compared to the 2001-2014 CERES-EBAF observations (black lines).

intensity with intervals of $1 \mathrm{~mm} \mathrm{~h}^{-1}$. The frequency of light rainfall events, smaller than $1 \mathrm{~mm} \mathrm{~h}^{-1}$, in BCC-CSM2-MR is higher than in IMERG. But strong precipitation events exceeding $10 \mathrm{~mm} \mathrm{~h}^{-1}$ are clearly insufficient. This is a common bias in many global climate models, raising concerns for any studies on precipitation extremes. Compared to BCC-CSM2MR, BCC-CSM2-HR with resolution increased shows substantial improvements for its precipitation spectrum: reduced light rainfall and enhanced heavy rainfall events. The spectral distribution of precipitation in BCC-CSM2-HR is much closer to IMERG.

\subsubsection{SST}

Figure 10 shows a spatial-distribution map of the 19952014 annual mean SST for HadISST and the biases for BCC-CSM2-MR and BCC-CSM2-HR relative to HadISST. BCC-CSM2-MR is generally warmer, while BCC-CSM2HR is colder than what was observed. A warm SST bias in BCC-CSM2-MR spreads throughout most oceans, except the North Pacific and North Atlantic. Such warm biases do not appear in BCC-CSM2-HR, and the cold SST biases in the eastern subtropical South Pacific are possibly attributable to excessive clouds there, also manifested by strong cloud shortwave radiative forcing (Fig. 4e). The warm biases in the eastern tropical ocean basins in BCC-CSM2-MR are associated with a deficit of stratiform low-level clouds, a common and systematic bias for many climate models (Richter, 2015). The cold biases there in BCC-CSM2-HR, similarly, are associated with too much low cloud, except over the tropical North Pacific. We also noted a belt of warm SST biases in the Kuroshio extension and in the North Atlantic in both models (Fig. 10b and c), especially in the high-resolution model. This bias may be partly a result of the coarse resolution of HadISST data used, as SST near the Kuroshio shows strong temperature gradients with filamentous structures (Shi and Wang, 2020).

\subsubsection{Land-surface air temperature}

Figure 11 shows the simulation biases of annual mean land-surface air temperature from BCC-CSM2-MR and BCC-CSM2-HR. The near-surface air temperature over land in BCC-CSM2-MR is generally colder than that in the CRUTEM observations, particularly exhibiting severe cold biases in northern Europe. As there are no physical (but only resolution) changes in the land modelling component in the two models, the systematic biases of near-surface air temperature over land are very similar to each other. Increasing atmospheric resolution in BCC-CSM2-HR does not seem to show amelioration, and the surface air temperatures in BCCCSM2-HR exhibit rather similar patterns to those in BCCCSM2-MR with biases of -2 to $2 \mathrm{~K}$ in most land regions between $50^{\circ} \mathrm{N}$ and $50^{\circ} \mathrm{S}$ compared to CRU data.

\subsubsection{Sea ice}

Figure 12 shows the annual mean sea-ice concentration simulated by BCC-CSM2-MR and BCC-CSM2-HR over the period 1995-2014, compared to HadISST observation data. The simulated geographic distribution of sea ice in the Arctic is overall realistic, except that the sea-ice concentration in the Atlantic is slightly overestimated in both models. This overestimation of sea ice possibly has a consequence for the severe cold biases of surface air temperature in northern Europe (Fig. 11). In the Antarctic, sea-ice concentration simulated by BCC-CSM2-MR is smaller than that in HadISST data, es- 

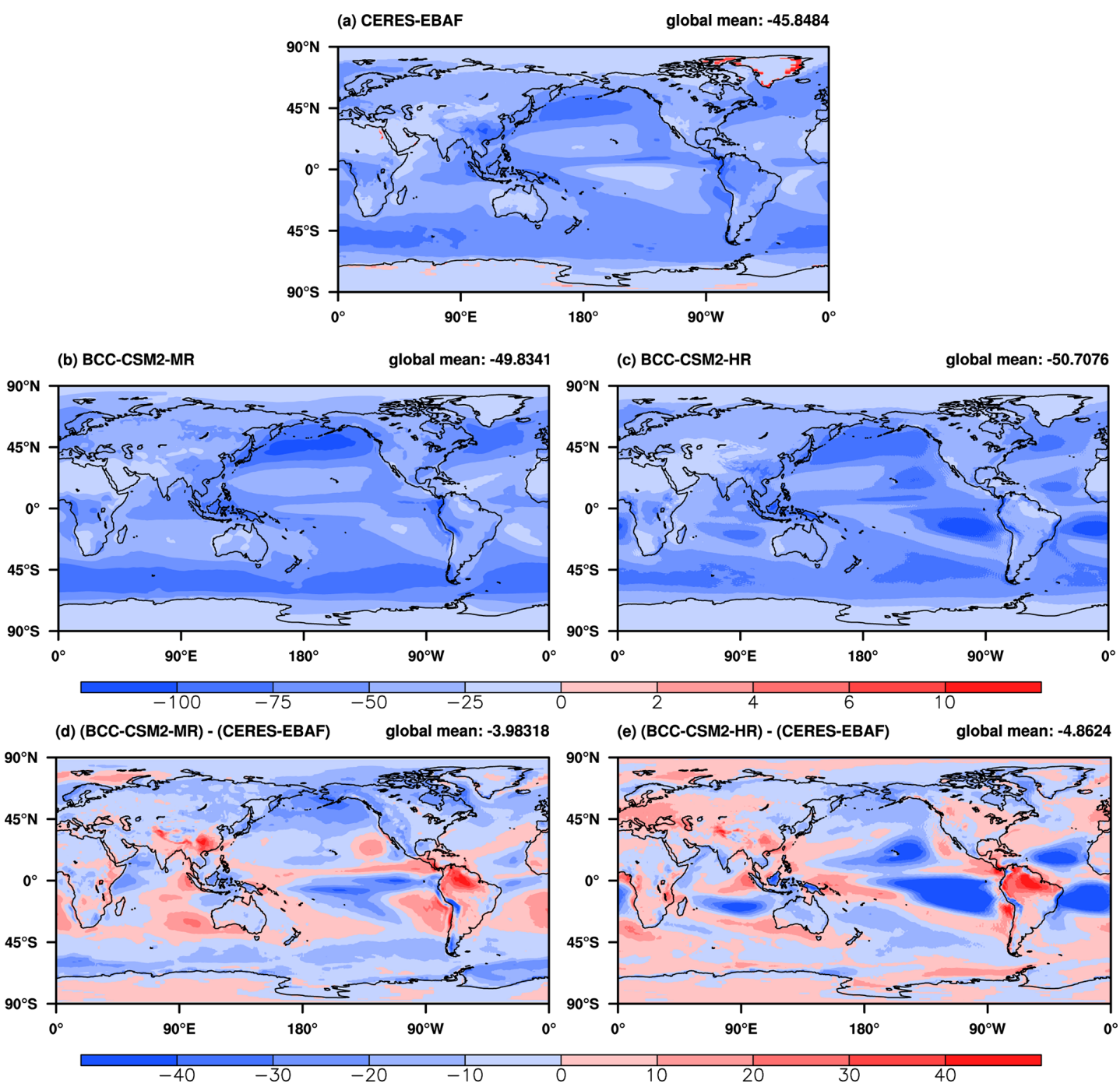

Figure 4. The 2001-2014 averaged annual-mean shortwave cloud radiative forcing for (a) the CERES-EBAF observations, the historical simulations from (b) BCC-CSM2-MR and (c) BCC-CSM2-HR and their biases (d, e) against CERES-EBAF data. Units: W m ${ }^{-2}$.

pecially from $60^{\circ} \mathrm{W}$ to $60^{\circ} \mathrm{E}$ in the subpolar region where the simulated SST is warmer compared to HadISST data (Fig. 10b). Those deficiencies in BCC-CSM2-MR (Fig. 12e) are largely reduced in BCC-CSM2-HR (Fig. 12f).

Figure 13 shows the monthly sea-ice covers for the Arctic and Antarctic from BCC-CSM2-MR and BCC-CSM2-HR. HadISST observations show that the Arctic sea-ice cover reaches a minimum extent of $6.9 \times 10^{6} \mathrm{~km}^{2}$ in September and rises to a maximum extent of $16.0 \times 10^{6} \mathrm{~km}^{2}$ in March, and the Antarctic sea-ice cover reaches a minimum extent in February and a maximum extent in September. The seasonal cycle amplitude and phase of sea-ice area are well captured by the two models, and their biases are mostly smaller than $1 \times 10^{6} \mathrm{~km}^{2}$ compared to HadISST observations. We note that the extents of the Arctic sea ice for each month in BCC-CSM2-MR are slightly but systematically smaller than HadISST, and in the Antarctic are smaller in February and March but larger in other months than HadISST. BCCCSM2-HR slightly overestimated sea-ice concentration by about $1 \times 10^{6} \mathrm{~km}^{2}$ in both hemispheres with reference to HadISST.

\subsection{Variabilities in the tropics}

The tropical cyclone (TC), also known as typhoon or hurricane, is among the most destructive weather phenomena. The Madden-Julian Oscillation (MJO) is the dominant mode of sub-seasonal variability in the tropical troposphere (Madden and Julian, 1971), and the quasi-biennial oscillation (QBO) is a quasi-periodic oscillation of the equatorial zonal wind between easterlies and westerlies in the tropical stratosphere. $\mathrm{TC}$, MJO, and QBO are very important variabilities in the tropics, with consequences for global weather and climate. 


\section{DJF}
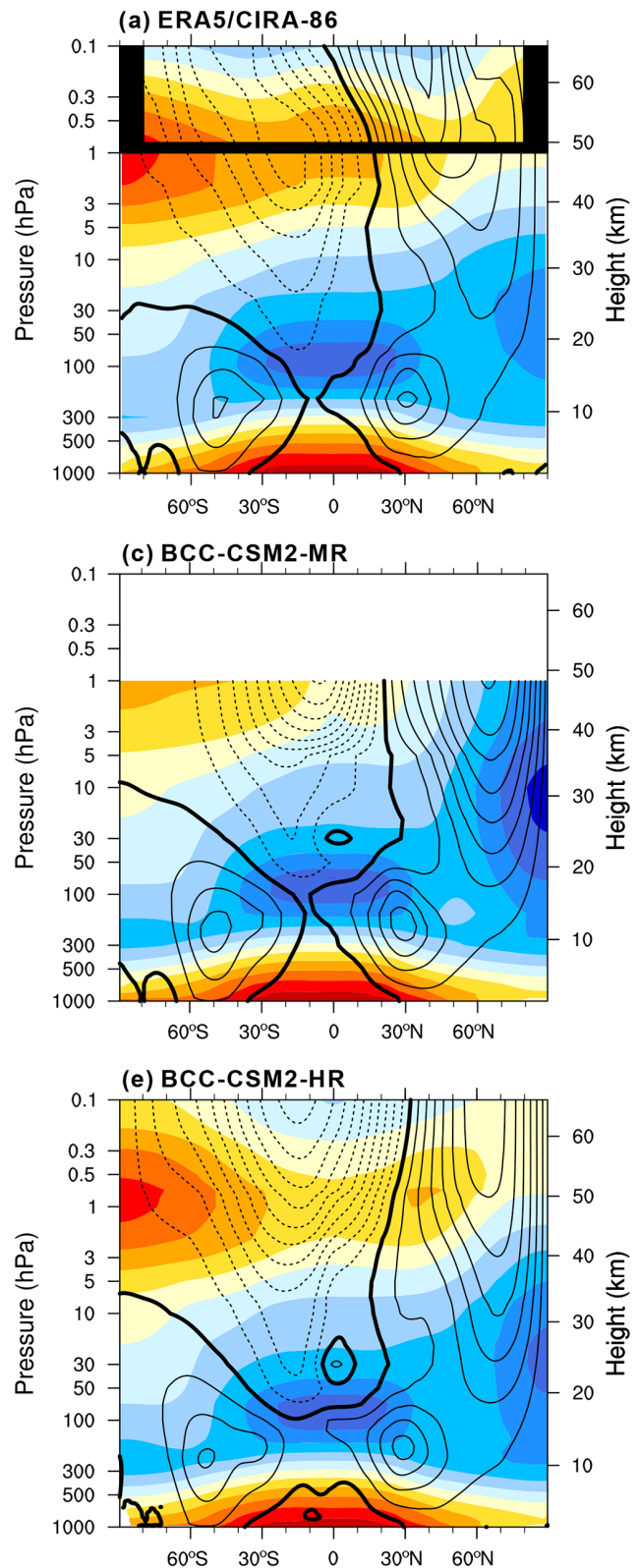

JJA

(b) ERA5/CIRA-86

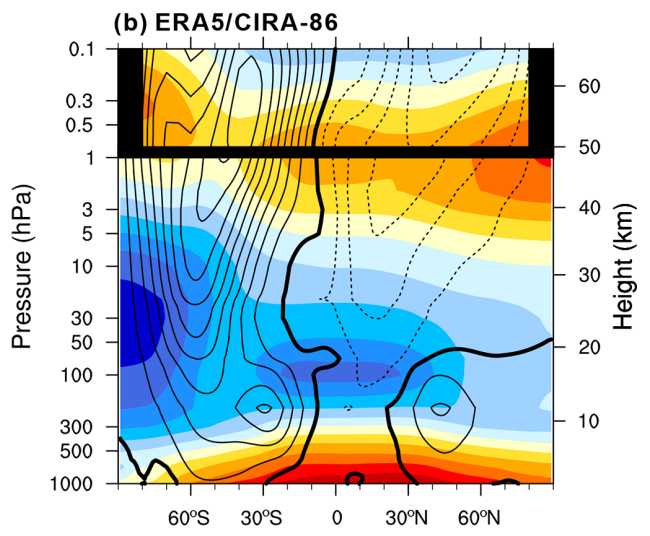

(d) BCC-CSM2-MR
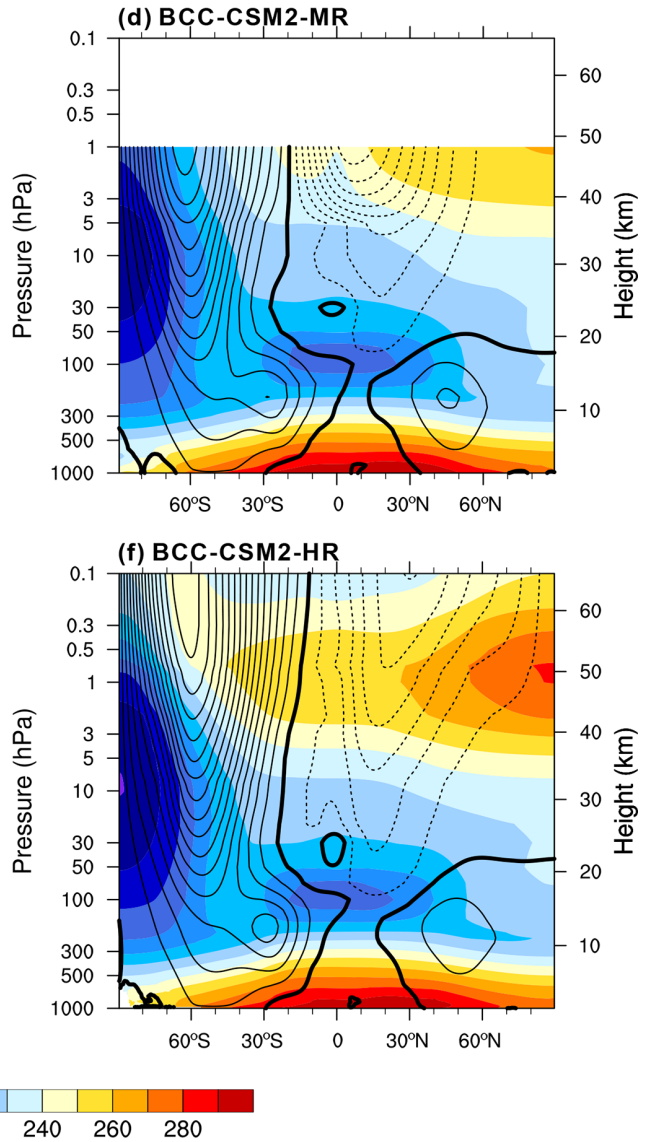

Figure 5. The zonal means of temperature (colours; $\mathrm{K}$ ) and zonal wind (contours; $\mathrm{m} \mathrm{s}^{-1}$ ) averaged for December-January-February (a, c, e) and June-July-August (b, d, f) from 1995 to 2014 for (a, b) ERA5/CIRA86, (c, d) BCC-CSM2-MR, and (e, f) BCC-CSM2-HR. Positive (negative) zonal winds are plotted with solid (dashed) lines with a contour interval of $10 \mathrm{~m} \mathrm{~s}^{-1}$. Thick contour lines denote zero zonal wind speed. In (a) and (b), the values above $1 \mathrm{hPa}$ from the COSPAR International Reference Atmosphere (CIRA86, Fleming et al., 1990) and below $1 \mathrm{hPa}$ from the ERA5 reanalysis.

\subsubsection{Tropical cyclones}

In Fig. 14, we evaluate the average TC frequency over 20 years (1995-2014) from BCC-CSM2-MR and BCCCSM2-HR, in contrast to the climatology of 1995-2014 observations from International Best Track Archive for Climate
Stewardship (IBTrACS; Knapp et al., 2010). It is clear that TC activity is increased with resolution enhanced. The averaged total global TC numbers per year are 49.6 in BCCCSM2-MR and 94.4 in BCC-CSM2-HR, and the global TC numbers in BCC-CSM2-HR are much closer to the IBTrACS 
(a) BCC-CSM2-MR minus ERA5

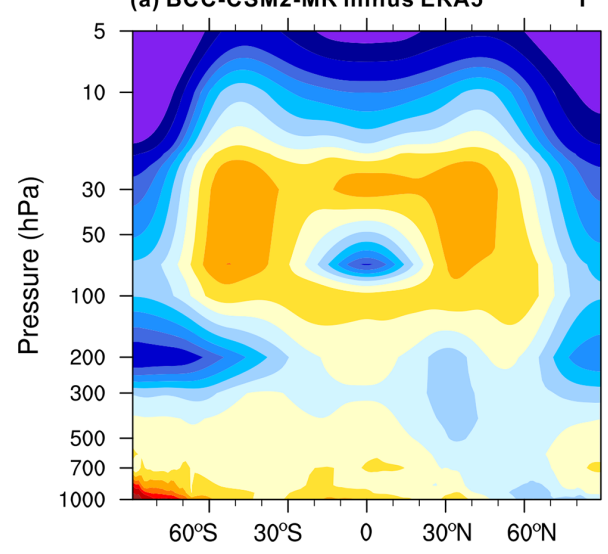

(c) BCC-CSM2-HR minus ERA5 T

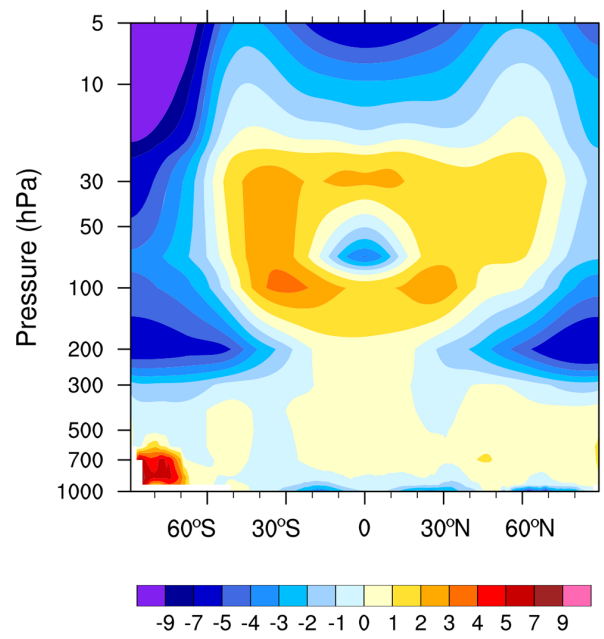

(b) BCC-CSM2-MR minus ERA5

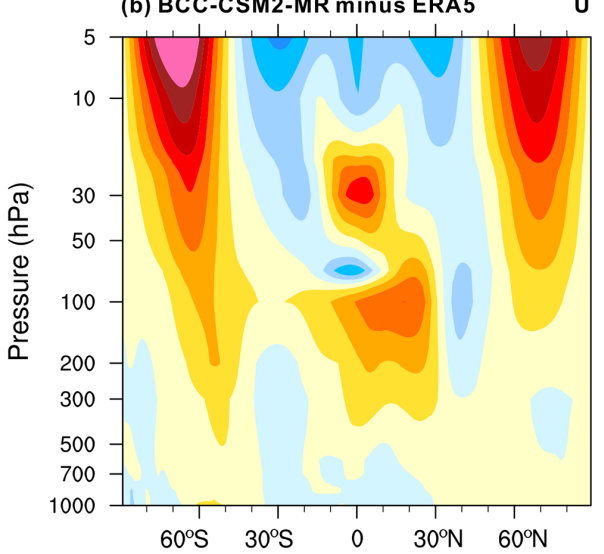

(d) BCC-CSM2-HR minus ERA5 U

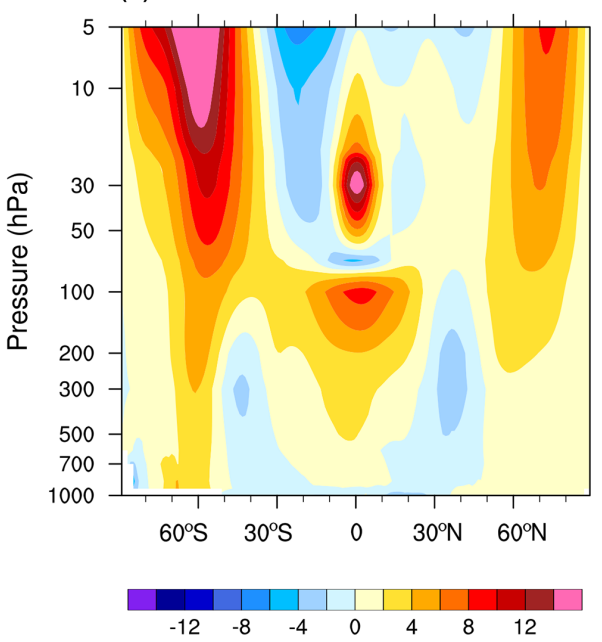

Figure 6. Zonally averaged annual mean temperature biases $(\mathbf{a}, \mathbf{c}$, in $\mathrm{K})$ and zonal wind biases $\left(\mathbf{b}, \mathbf{d}\right.$, in $\left.\mathrm{m} \mathrm{s}^{-1}\right)$ averaged for the period from 1995 to 2014 for $(\mathbf{a}, \mathbf{b})$ BCC-CSM2-MR and (c, d) BCC-CSM2-HR, with respect to the ERA5 reanalysis data.

observation (90.2). The global TC number is slightly influenced by the threshold $\left(15 \times 10^{-5} \mathrm{~s}^{-1}\right.$ in Fig. 14) of relative vorticity at $850 \mathrm{hPa}$ used to detect TC. If this threshold gets looser to $5 \times 10^{-5} \mathrm{~s}^{-1}$, the averaged total global TC numbers per year in BCC-CSM2-MR and BCC-CSM2-HR would enhance to 55.9 and 101.5 (not shown), respectively. The low TC number in BCC-CSM2-MR is furthermore explained by the fact that its 6-hourly data used to detect TC are averaged values in the $6 \mathrm{~h}$ interval, while instantaneous values would be more appropriate as in IBTrACS and BCC-CSM2-HR. Spatially, BCC-CSM2-HR generates excess TC activity in the eastern North Pacific, northern Indian Ocean, and Southern Hemisphere. But both models severely underestimate TC activity in the North Atlantic and in the Caribbean Sea. The general overestimation of TC activity in the eastern North Pacific and the opposite in the North Atlantic in BCC-CSM2HR may be related to the warmer SST in the eastern tropical North Pacific and colder SST in the tropical Atlantic in contrast to HadISST data (Fig. 10c), but other factors such as the entrainment in the parameterization of convection (Zhao et al., 2012) and air-sea coupling (Li and Sriver, 2018) may also have an influence. The study of Li and Sriver (2018) showed that ocean coupling influences simulated TC frequency, geographical distributions, and storm intensity, and TC tracks are relatively sparse in the coupled simulations compared to un-coupled simulations.

Figure 15 shows the maximum surface wind speed versus minimum sea level pressure for the tropical cyclones that are derived from the 1995-2014 IBTrACS observation (black dots and line) and simulations of BCC-CSM2-MR and BCCCSM2-HR. Here, the maximum surface wind speed (minimum sea level pressure) of a given TC was defined as the instantaneous maximum (minimum) of the $6 \mathrm{~h}$ interval in IBTrACS and BCC-CSM2-HR, but the averaged value in BCCCSM2-MR for wind speed at $10 \mathrm{~m}$ (sea level pressure). Instantaneous values of wind speed and sea level pressure were not recorded as output in BCC-CSM2-MR. Maximum wind speeds for TC lifetime in BCC-CSM2-MR are consistently weaker than BCC-CSM2-HR and IBTrACS, which is understandable given the coarser resolution. BCC-CSM2-MR 
(a) GPCP

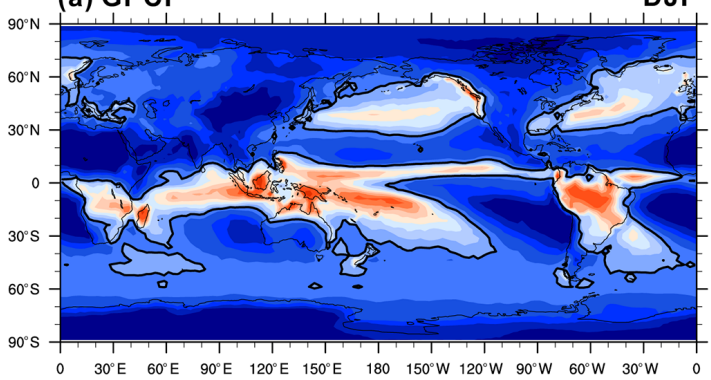

(c) BCC-CSM2-MR

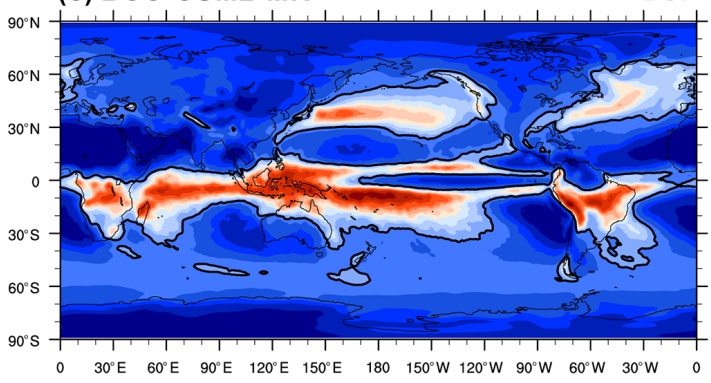

(e) BCC-CSM2-HR

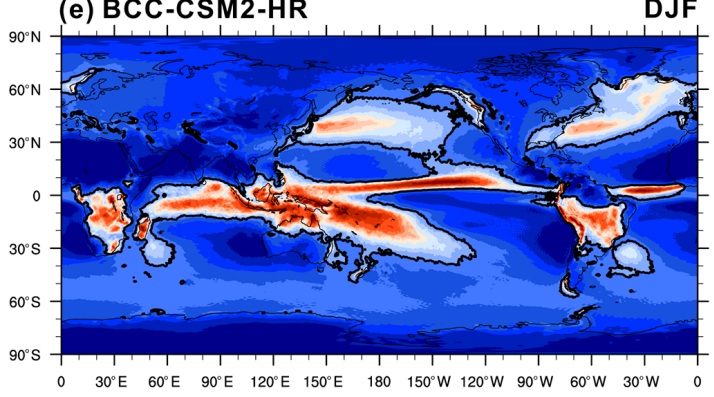

(b) GPCP

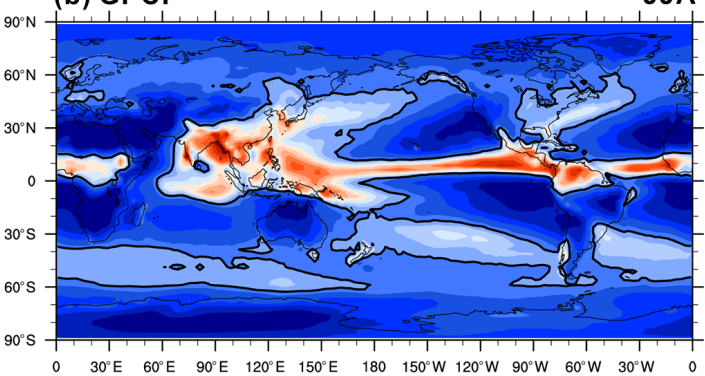

(d) BCC-CSM2-MR

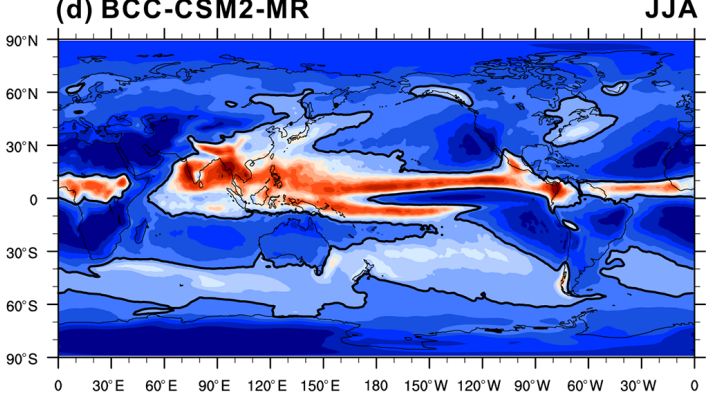

(f) BCC-CSM2-HR

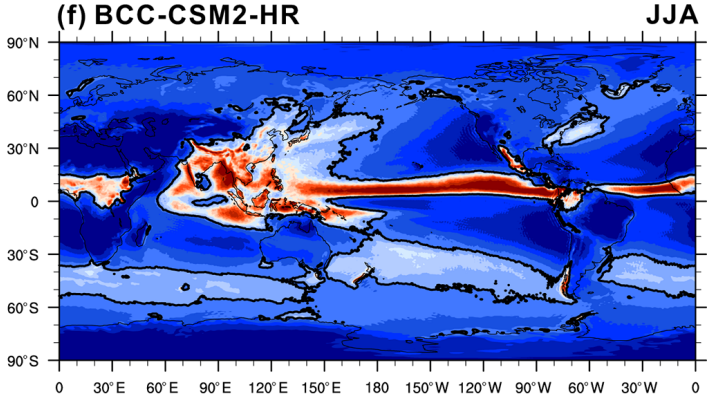

$\begin{array}{lllllllllllllll}0.2 & 0.5 & 1 & 2 & 3 & 4 & 5 & 6 & 7 & 8 & 9 & 10 & 12 & 14 & 17\end{array}$

Figure 7. The 1995-2014 averaged mean precipitation rate of December-January-February (a, c, e) and June-July-August (b, d, f) for (a, b) GPCP observations, (c, d) BCC-CSM2-MR, and (e, f) BCC-CSM2-HR. Units: $\mathrm{mm} \mathrm{d}^{-1}$. The $3 \mathrm{~mm} \mathrm{~d}^{-1}$ contour line is in bold as a reference to facilitate the visual inspection.

cannot capture strong storms, and maximum wind speeds at $10 \mathrm{~m}$ only reach $30 \mathrm{~m} \mathrm{~s}^{-1}$. BCC-CSM2-HR, as expected, can reproduce those strong $\mathrm{TCs}$ for which minimum pressure of TC lifetime may reach $960 \mathrm{hPa}$ and maximum wind speed at $10 \mathrm{~m}$ may reach $50 \mathrm{~m} \mathrm{~s}^{-1}$. The fitting line of maximum wind speeds with minimum centre pressures in BCC-CSM2-HR almost matches that from IBTrACS observation (Fig. 15). The BCC-CSM2-HR simulations demonstrate, just as previous studies have shown (e.g. Murakami et al., 2012; Sugi et al., 2017; Vecchi et al., 2019), that the maximum wind speed of TC simulated by a model with approximately $50 \mathrm{~km}$ resolution can reach up to $50-60 \mathrm{~m} \mathrm{~s}^{-1}$.

\subsubsection{Madden-Julian Oscillation}

MJO is the dominant mode of sub-seasonal variability in the tropical troposphere (Madden and Julian, 1971) and characterized by eastward propagation of deep convective structures along the Equator with an average phase speed of around $5 \mathrm{~m} \mathrm{~s}^{-1}$ at the intraseasonal timescale of 20 $100 \mathrm{~d}$ (Wheeler and Kiladis, 1999). MJO generally forms over the Indian Ocean, strengthens over the Pacific Ocean, and weakens due to interaction with South America and cooler eastern Pacific SSTs (Madden and Julian, 1971). Figure 16 gives the time-lag-longitude evolution of $10^{\circ} \mathrm{S}-$ $10^{\circ} \mathrm{N}$-averaged intraseasonal precipitation anomalies in panels (a)-(c) and time-lag-longitude evolution of $80-100^{\circ} \mathrm{E}$ averaged intraseasonal precipitation anomalies correlated against the precipitation over the equatorial eastern Indian Ocean in panels (d)-(f). Both versions of BCC-CSMs reasonably reproduce the eastward propagating feature of convection from the Indian Ocean across the Maritime Continent to the Pacific (Fig. 16b and c), as well as the apparent poleward propagations from the equatorial Indian Ocean 
(a) ANN

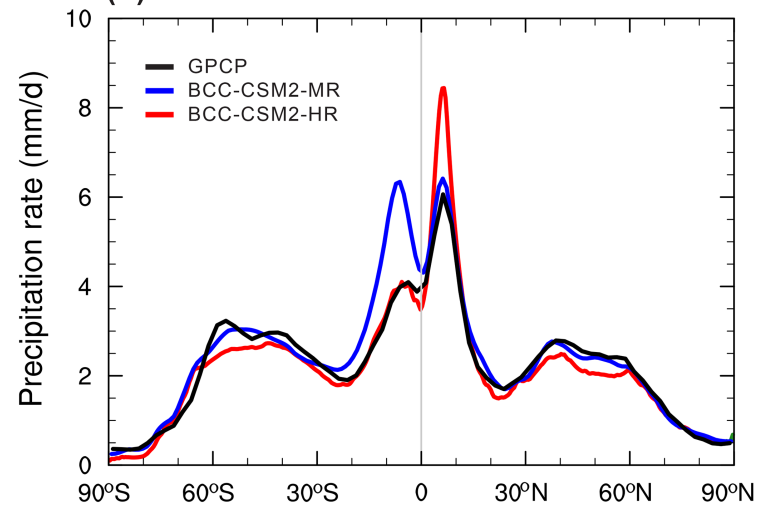

(b) DJF

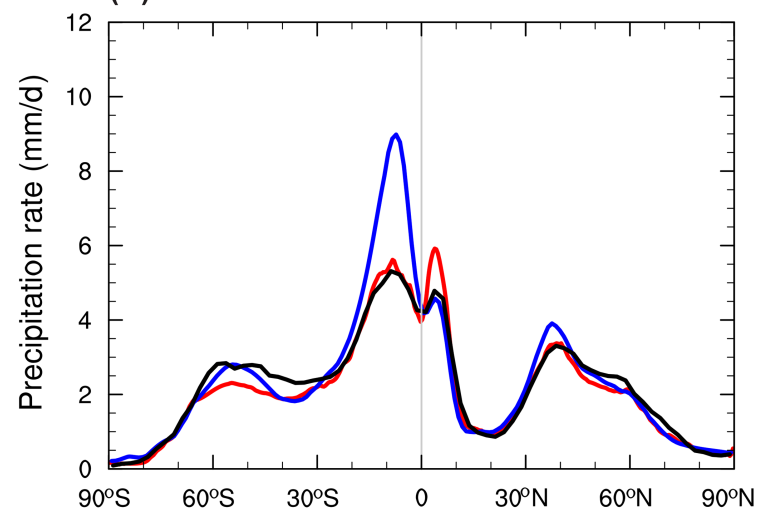

(c) JJA

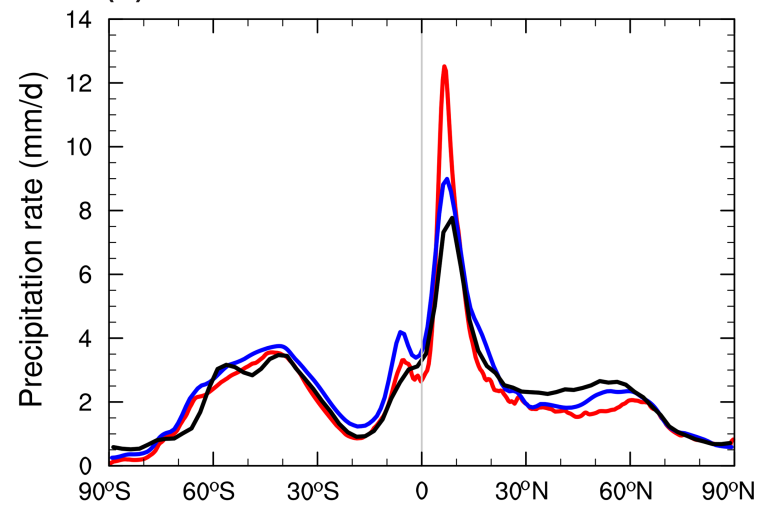

Figure 8. The 1995-2014 averaged zonal mean precipitation rate $\left(\mathrm{mm} \mathrm{d}^{-1}\right)$ for (a) the annual mean, (b) December-JanuaryFebruary, and (c) June-July-August. The solid black lines denote GPCP data, and the colour lines show BCC-CSM2-MR (blue) and BCC-CSM2-HR (red) simulations. Units: $\mathrm{mm} \mathrm{d}^{-1}$.

into the Northern Hemisphere and the Southern Hemisphere (Fig. 16e and f). The signal of northward propagation is more evident in BCC-CSM2-HR than in BCC-CSM2-MR. The average phase speed of eastward propagation of deep convection in BCC-CSM2-HR is much closer to GPCP data, denoted by the dashed line in Fig. 16c. Figure 16b shows that

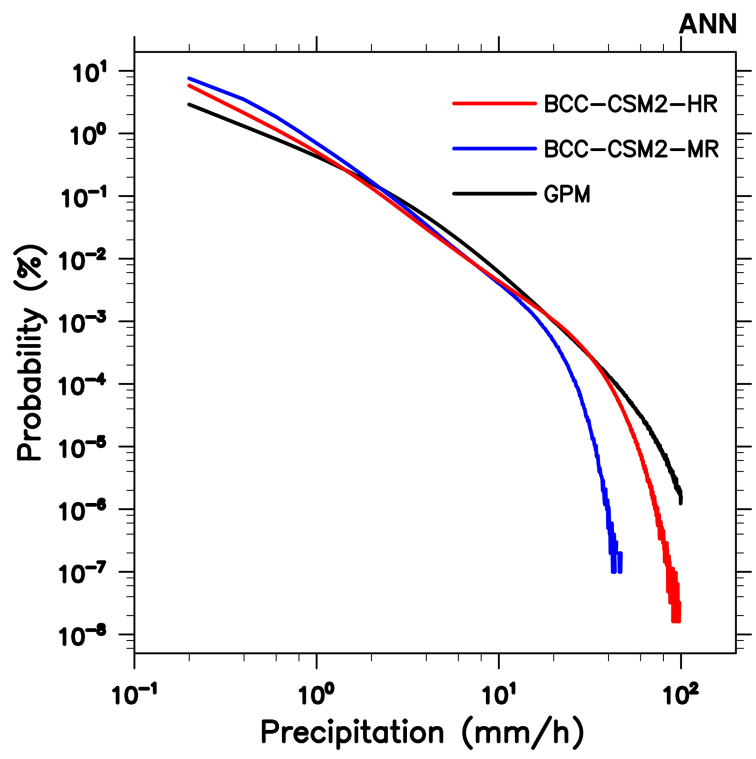

Figure 9. The probability density of 3-hourly precipitation between $40^{\circ} \mathrm{S}$ and $40^{\circ} \mathrm{N}$ and during the period from 2001 to 2014 , as a function of precipitation intensity with intervals of $1 \mathrm{~mm} \mathrm{~h}^{-1}$, for IMERG precipitation (black line), BCC-CSM2-MR (blue line), and BCC-CSM2-HR (red line). The two simulations were re-gridded to the grid of IMERG before processing.

the eastward propagation of deep convection in BCC-CSM2MR is too fast, compared to GPCP data.

MJO activity can be generally featured by a life cycle of eight phases (Wheeler and Hendon, 2004). Intensity of outgoing longwave radiation (OLR) is often used for this purpose to represent the activity of convection. Figure 17 shows the MJO phase-latitude diagram of composited outgoing longwave radiation (OLR) and $850 \mathrm{hPa}$ zonal wind anomalies averaged over $10^{\circ} \mathrm{S}-10^{\circ} \mathrm{N}$. In observations, MJO convection initiated from Africa and the western Indian Ocean at phases 1-2, propagates eastward from the Indian Ocean across the Maritime Continent to the western Pacific at phases 3-6, and finally disappears in the western hemisphere at phases 7-8. BCC-CSM2-MR generally captures the evolution of convection with MJO phases but shows faster propagative speed and apparently underestimates the intensity compared to the observation. In contrast, BCC-CSM2-HR shows an obviously improved MJO phase transition and convection intensity.

\subsubsection{The stratospheric quasi-biennial oscillation}

The alternative oscillation between westerly and easterly winds in the tropical stratosphere constitutes the characteristic feature of the quasi-biennial oscillation (QBO). A good simulation of QBO still remains a challenge nowadays for all state-of-the-art climate models. In a recent work, Kim et al. (2020) showed that only half (15 out of 30) of the CMIP6 models can internally generate QBO (BCC-CSM2-MR was 

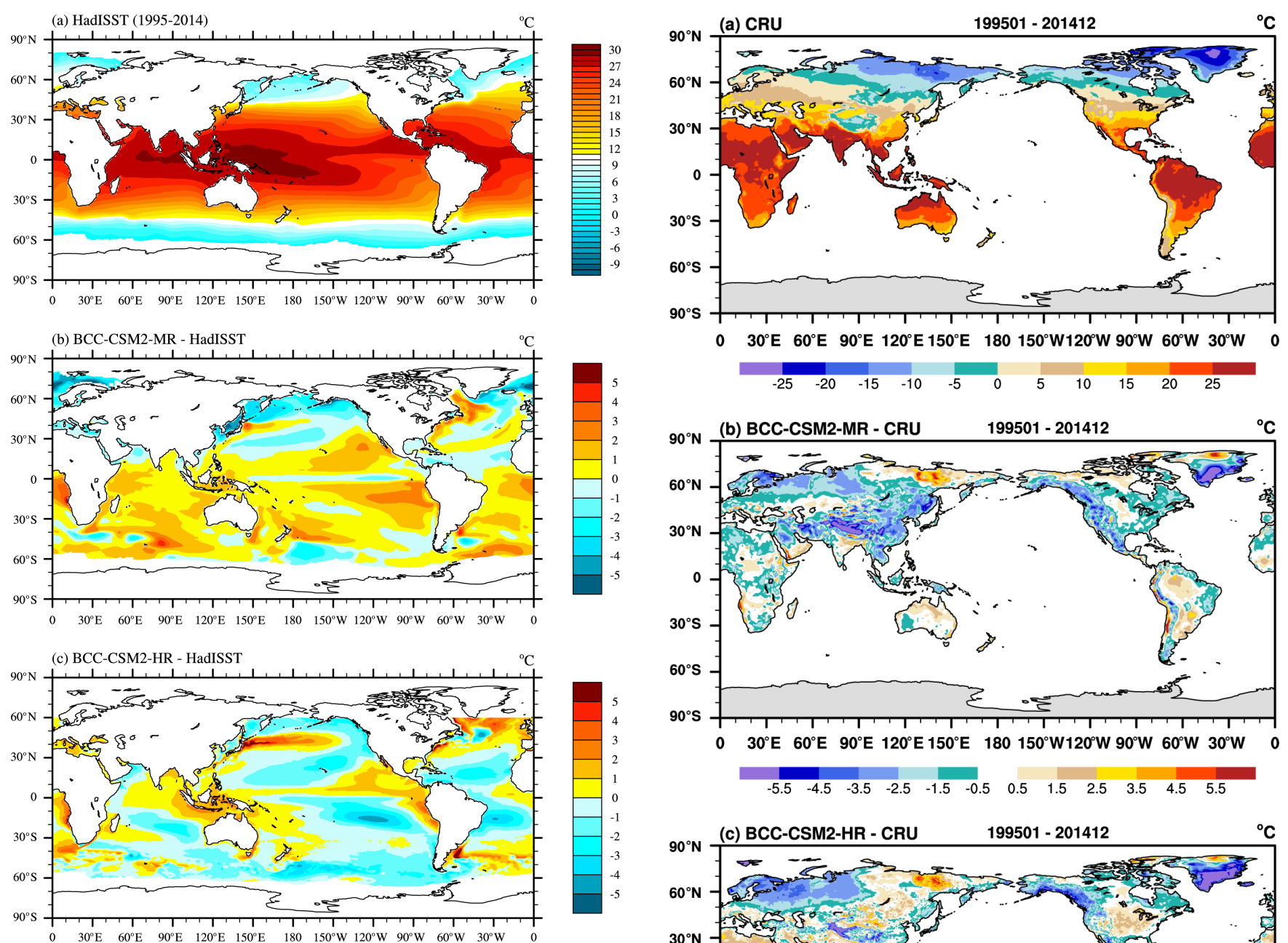

Figure 10. The global distributions of the 1995-2014 annual mean sea surface temperature for (a) the observations from HadISST, and the simulation biases in (b) BCC-CSM2-MR and (c) BCC-CSM2HR.

in the good half). We should, however, recognize that there was huge progress in CMIP6, since in CMIP5 only five models (about $10 \%$ of the total) were able to simulate a realistic QBO (Schenzinger et al., 2017).

To evaluate model performance in simulating the QBO, the time-height cross sections of the tropical zonal winds averaged from $5^{\circ} \mathrm{S}$ to $5^{\circ} \mathrm{N}$ for BCC-CSM2-MR and BCCCSM2-HR are compared to the ERA5 reanalysis. As shown in Fig. 18, ERA5 shows alternative westerlies and easterlies in the lower stratosphere with a mean periodicity of about 28 months. The two BCC models are both able to generate a reasonable $\mathrm{QBO}$, and the observed asymmetry with the easterlies being stronger than the westerlies is also well reproduced. The general performance of QBO in BCC-CSM2MR was evaluated in Wu et al. (2019b). A detailed assessment of the underlying mechanism involving wave dynamics and the associated forcing to drive QBO is presented in
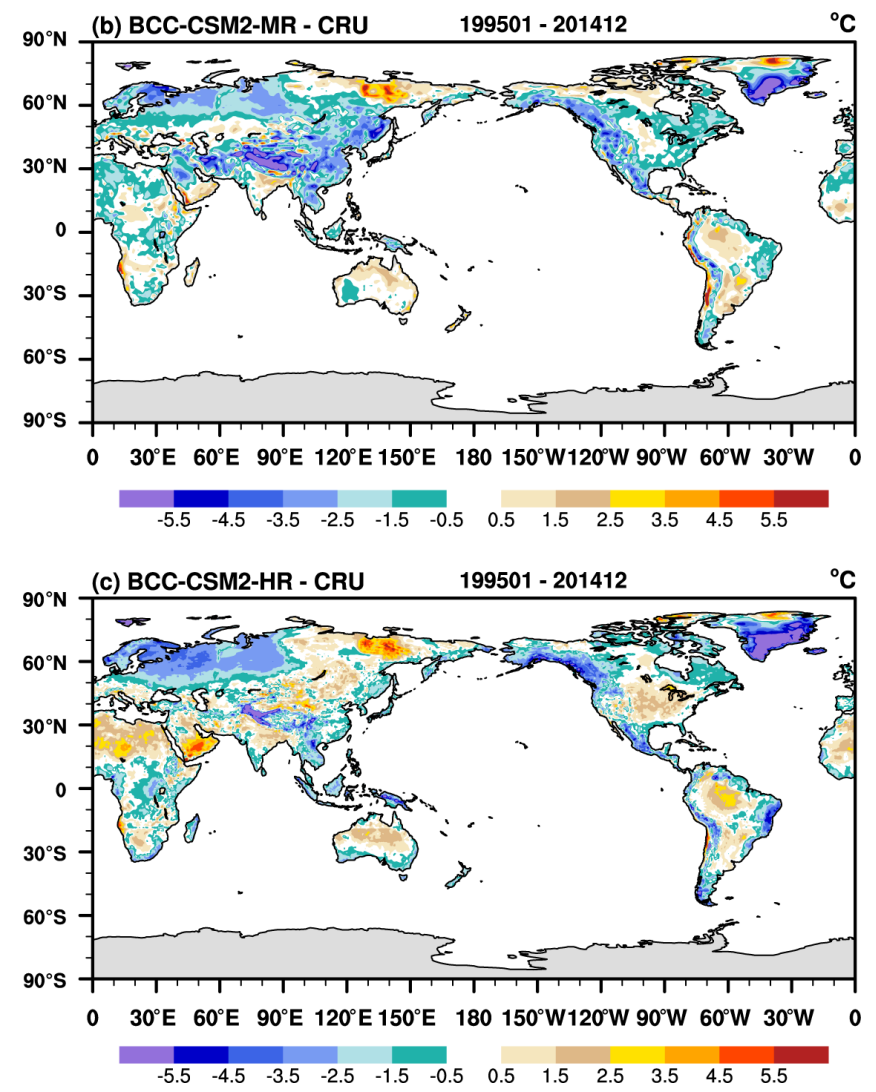

Figure 11. The 1995-2014 averaged global land-surface air temperature for (a) CRUTEM observations, and simulation biases in (b) BCC-CSM2-MR and (c) BCC-CSM2-HR.

Lu et al. (2020a). The simulated QBO has stronger amplitudes in BCC-CSM2-HR than in BCC-CSM2-MR. As the horizontal resolution and physics package are changed from BCC-CSM2-MR to BCC-CSM2-HR, the parameterized convective gravity wave forcing for $\mathrm{QBO}$ could be potentially enhanced in BCC-CSM2-HR. On the other hand, changes in the convective cumulus parameterization can also affect the simulation of the resolved convectively coupled equatorial waves (i.e. the Kelvin wave) driving the QBO and lead to stronger QBO amplitudes in BCC-CSM2-HR. 
(a) HadISST

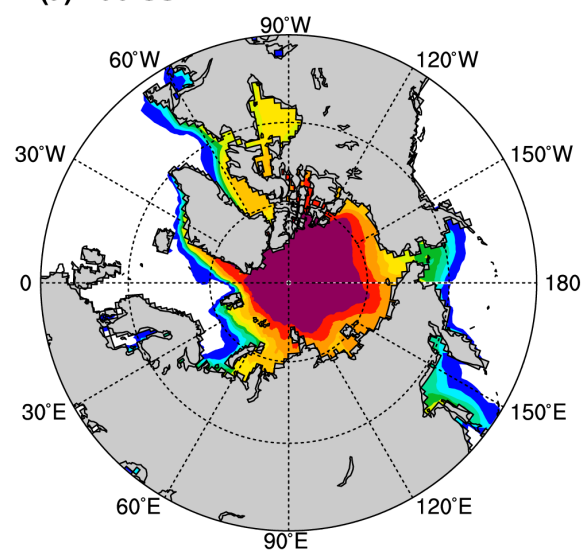

(b) BCC-CSM2-MR

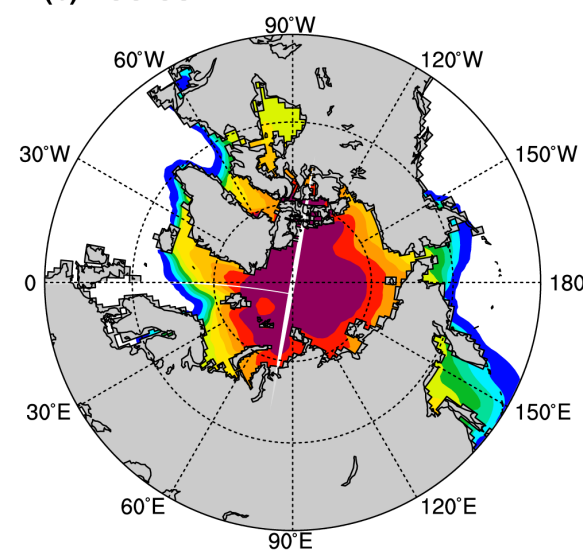

(c) BCC-CSM2-HR

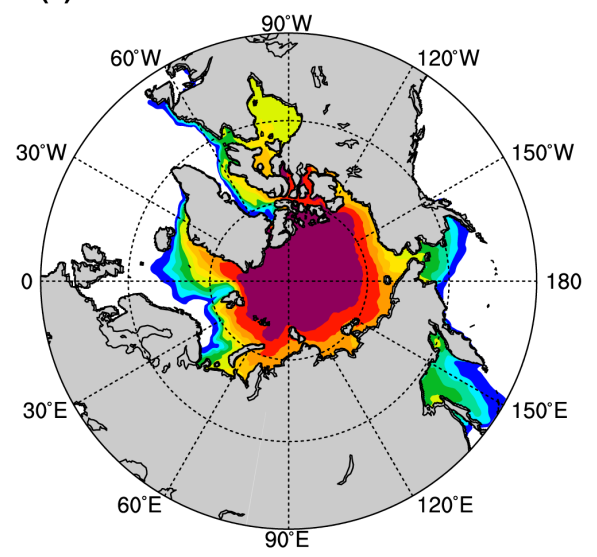

(d) HadISST

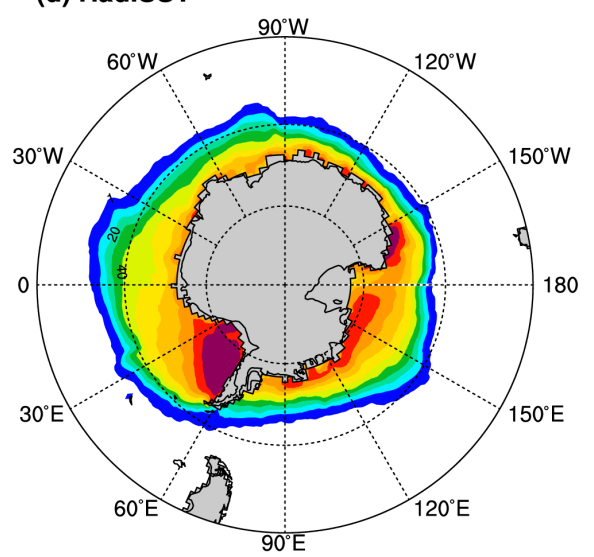

(e) BCC-CSM2-MR

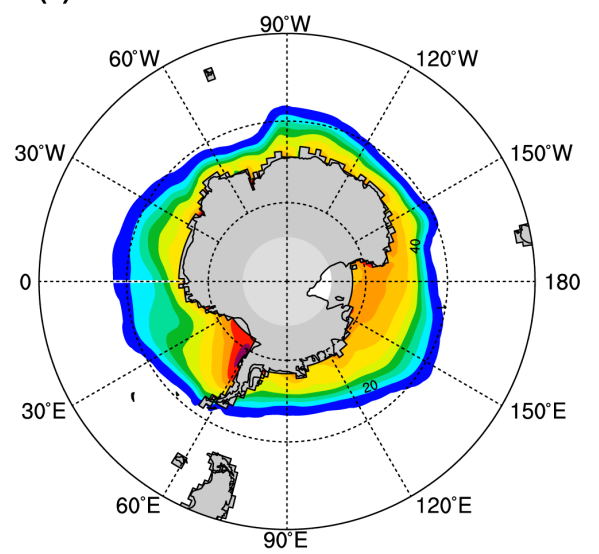

(f) BCC-CSM2-HR

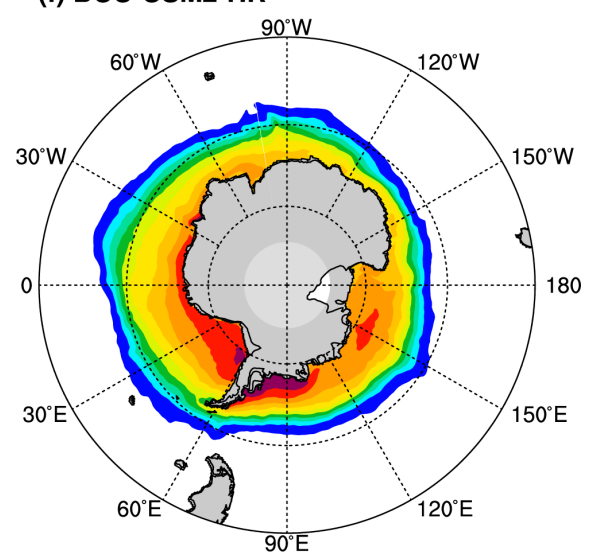

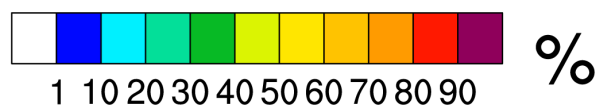

Figure 12. The spatial distribution of annual mean sea-ice concentration from BCC-CSM2-MR and BCC-CSM2-HR in contrast to the observations from the Hadley Centre Sea Ice dataset from 1995 to 2014. 

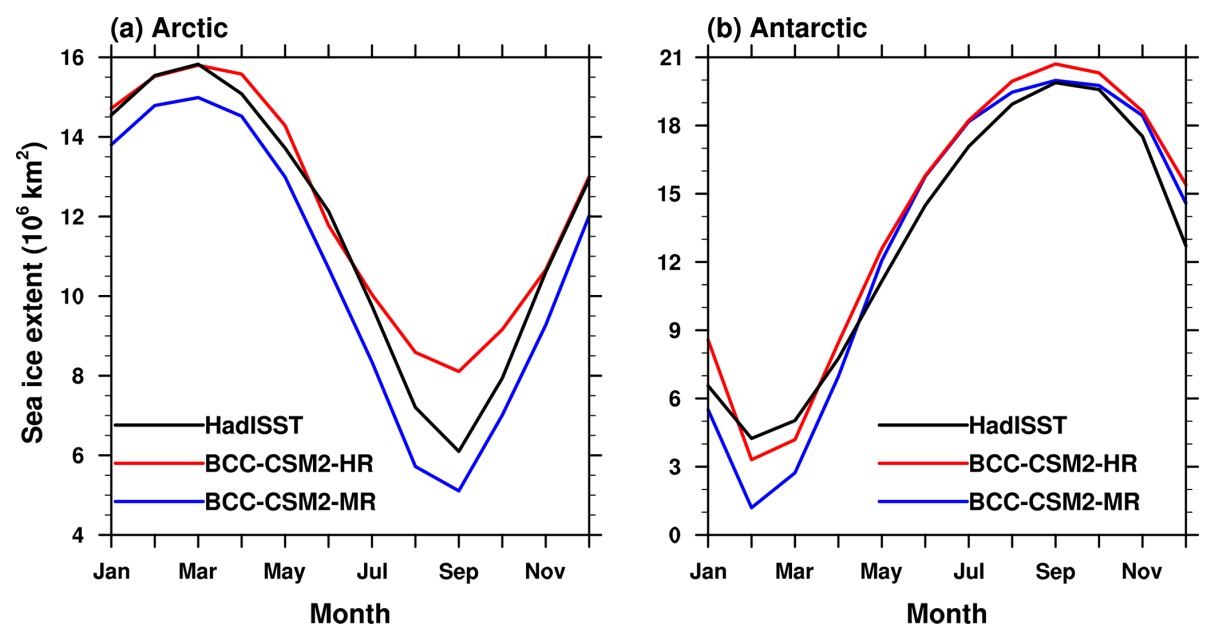

Figure 13. The mean (1995-2014) seasonal cycle of sea-ice extent (with a sea-ice concentration of at least $15 \%$ ) in (a) the Northern Hemisphere and (b) the Southern Hemisphere for the observations from the Hadley Centre Sea Ice and Sea Surface Temperature dataset (black lines) and the simulations from BCC-CSM2-MR (blue lines) and BCC-CSM2-HR (red lines).

In the two BCC models, the downward propagation of QBO occurs in a regular manner but does not sufficiently penetrate to low altitudes below $50 \mathrm{hPa}$. The vertical resolution is similar below $\sim 10 \mathrm{hPa}$ in both BCC-CSM2-MR and BCC-CSM2-HR (Fig. 1). A further downward propagation to lower altitudes can be expected by increasing the vertical resolution finer than $500 \mathrm{~m}$ to adequately resolve the wave-mean flow interaction in the upper troposphere and lower stratosphere (Geller et al., 2016; Garcia and Richter 2019).

\subsubsection{Niño3.4 SST variability}

Figure 19 presents time series of the monthly Niño3.4 SST $\left(5^{\circ} \mathrm{N}-5^{\circ} \mathrm{S}, 170-120^{\circ} \mathrm{W}\right)$ anomalies from BCC-CSM2-MR and BCC-CSM2-HR, with reference to HadISST data from 1950 to 2014. The amplitude of interannual variation of the Niño3.4 index in BCC-CSM2-HR and BCC-CSM2-MR are both stronger than in HadISST. Those strong amplitudes may partly come from the slight warming trends in both models. The power spectrum analysis of the Niño3.4 index from the HadISST observations shows significant peaks at 4-6 and 23 years. The periodicity of the ENSO cycle in BCC-CSM2MR is mainly at 2-3 years. It is prolonged to 3-6 years in BCC-CSM2-HR. As in Fig. 19h, the Niño3.4 SST variability from HadISST data reaches its maximum in the period from November to January. The phase locking (i.e. the preferred timing in the year for the peak of ENSO) simulated by BCCCSM2-MR occurs in autumn. The simulated ENSO phase locking in BCC-CSM2-HR is partly improved, since ENSO events tend to reach their maximum toward winter.

Recent studies of Hayashi et al. (2020) showed that the ability to simulate the asymmetry between warm (El Niño) and cold (La Niña) phases as recorded in observations is still very poor for most CMIP5 and CMIP6 models. This imperfection also exists in both BCC-CSM2-HR and BCC-CSM2-
MR. The asymmetry in SST anomalies is often measured by the normalized third statistical moment, i.e. skewness (Burgers and Stephenson, 1999). Figure 19d-f show spatial maps of the skewness of monthly SST anomalies (SSTA) in the tropical Pacific that are calculated following the methodology in Burgers and Stephenson (1999). In the eastern Pacific, the ENSO signal from HadISST data is the strongest and the observed SSTA skewness is highly positive (Fig. 19d) due to the presence of extreme El Niño events and absence of extreme La Niña events. The skewness values of SSTA in both models (Fig. 19e and f) are underestimated in contrast to HadISST observation, and the area of positive skewness in the eastern tropical Pacific from BCC-CSM2-HR simulations is much closer to HadISST data.

Figure 20 presents the spatial patterns of correlation coefficients between the Niño3.4 index and the corresponding global SST anomalies from 1950 to 2014 for the HadISST observation and the two BCC models. Both BCC-CSM2-HR and BCC-CSM2-MR simulate a positive correlation structure over the equatorial region of the central and eastern $\mathrm{Pa}$ cific, which is consistent with the analysis from HadISST despite an over-extension into the western Pacific. The HadISST data show clearly that the zone of positive correlation of SST with the Niño3.4 index in the equatorial eastern Pacific expands to the extra-tropics. Especially along the eastern border of the Pacific, the areas of high values of positive correlations in BCC-CSM2-HR are larger than BCC-CSM2-MR, and much closer to HadISST. Compared to BCC-CSM2-MR, BCC-CSM2-HR improves the simulation in the equatorial Indian Ocean and the eastern tropical Atlantic where there are also remarkable areas of positive correlation. We also note that areas of negative correlation of SST with the Niño3.4 index in the western equatorial Pacific 
(a) IBTrACKS

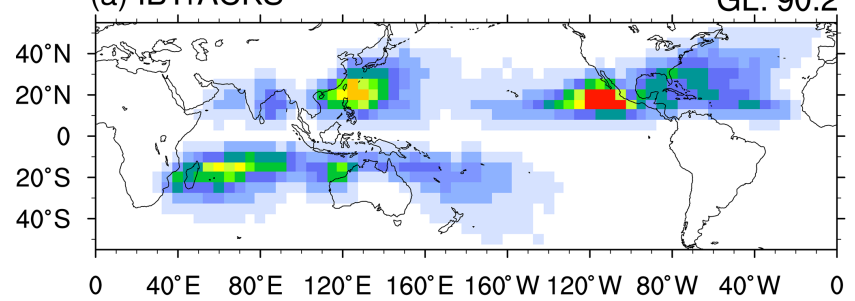

(b) BCC-CSM2-MR

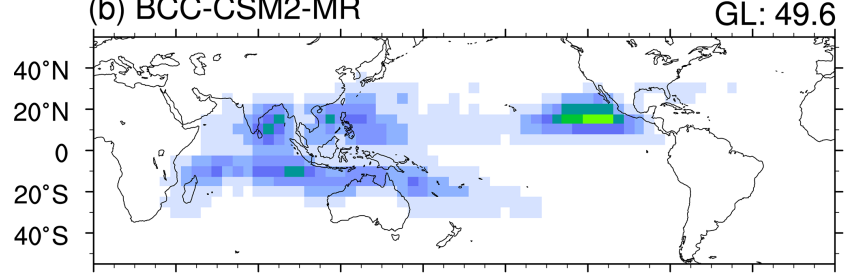

$040^{\circ} \mathrm{E} \quad 80^{\circ} \mathrm{E} \quad 120^{\circ} \mathrm{E} 160^{\circ} \mathrm{E} 160^{\circ} \mathrm{W} 120^{\circ} \mathrm{W} \quad 80^{\circ} \mathrm{W} \quad 40^{\circ} \mathrm{W} \quad 0$

(c) BCC-CSM2-HR

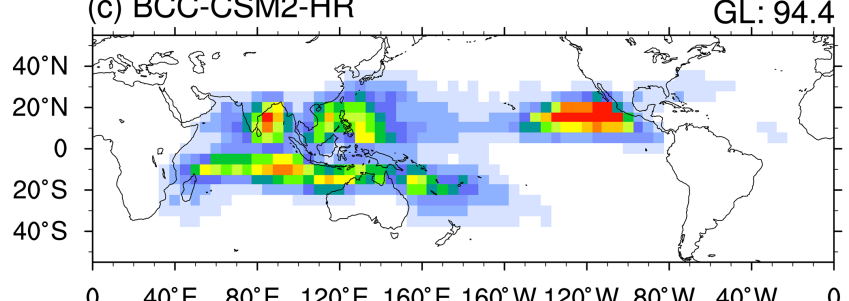

$0 \quad 40^{\circ} \mathrm{E} \quad 80^{\circ} \mathrm{E} \quad 120^{\circ} \mathrm{E} 160^{\circ} \mathrm{E} 160^{\circ} \mathrm{W} 120^{\circ} \mathrm{W} \quad 80^{\circ} \mathrm{W} \quad 40^{\circ} \mathrm{W} \quad 0$

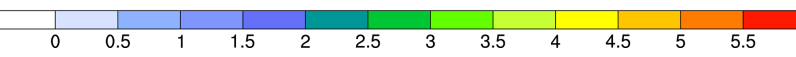

Figure 14. The global distribution of tropical cyclone (TC) densities (number per year) averaged for the period of 1995-2014 from (a) the IBTrACS_wmo observations, and the simulations of (b) BCC-CSM2-MR and (c) BCC-CSM2-HR. The value in the upper-right corner denotes the total number of global TCs on $5^{\circ} \times 5^{\circ}$ grid box.

extend to the South and North Pacific in HadISST, which is clearer in BCC-CSM2-HR than in BCC-CSM2-MR.

\section{Conclusions and discussions}

This paper was devoted to the presentation of the highresolution version BCC-CSM2-HR and to the description of its climate simulation performance. We focused on its updates and differential characteristics from its predecessor, the medium-resolution version BCC-CSM2-MR. BCC-CSM2HR is our model version participating in HighResMIP, while BCC-CSM2-MR is our basic model version participating in other CMIP6-endorsed MIPs (Wu et al., 2019b; Xin et al., 2019).

The atmosphere resolution is increased from T106L46 in BCC-CSM2-MR to T266L56 in BCC-CSM2-HR, and the ocean resolution from $1^{\circ} \times 1^{\circ}$ to $1 / 4^{\circ} \times 1 / 4^{\circ}$. A few novel developments were implemented in BCC-CSM2-HR for both the dynamical core and model physics in the atmospheric

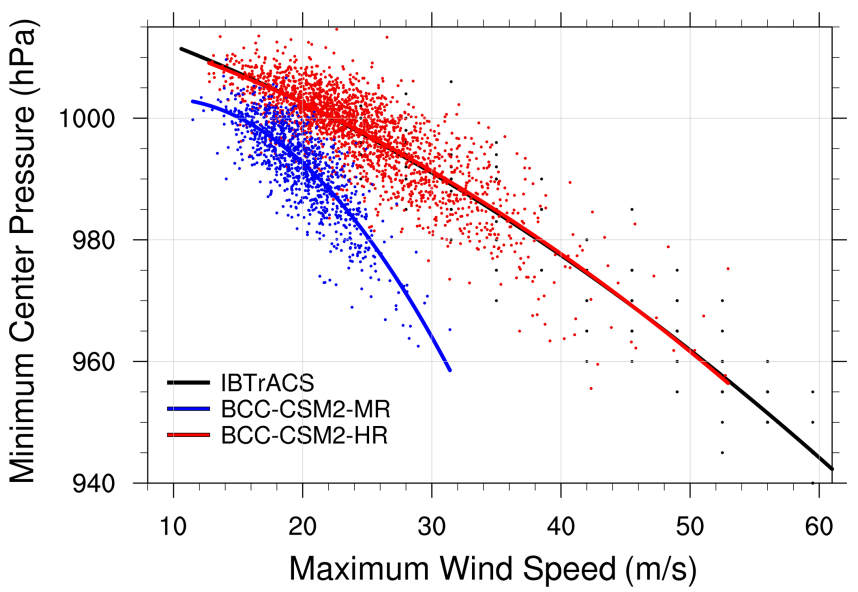

Figure 15. Maximum surface wind speed $\left(\mathrm{m} \mathrm{s}^{-1}\right)$ versus minimum sea level pressure $(\mathrm{hPa})$ for tropical cyclones from 6-hourly data for 1995-2014 IBTrACS observation (black dots and fitting line), and simulations from BCC-CSM2-HR (red dots and fitting line) and BCC-CSM2-MR (blue dots and fitting line). Each dot denotes the maximum surface wind speed and its corresponding minimum sea level pressure for a tropical cyclone during its lifetime.

component: first, a spatially varying damping for the divergence field was used to improve the atmospheric temperature simulation in the stratosphere at polar areas - it helps to control high-frequency noise in the stratosphere and above; second, the deep cumulus convection scheme originally described in $\mathrm{Wu}$ (2012) was further ameliorated to allow detrained cloud water be transported to adjacent grids and downward to lower troposphere; third, we modified the relevant schemes for the boundary layer turbulence and shallow cumulus convection to improve the simulation of ITCZ precipitation; fourth, the UWMT scheme is used to improve the simulation of low-level clouds over eastern basins of subtropical oceans. The land model configuration in BCC-CSM2$\mathrm{HR}$ is the same as in BCC-CSM2-MR. Major land surface biophysical and plant physiological processes of BCCAVIM2 implemented in BCC-CSM2-MR and BCC-CSM2HR were kept the same, and the only differences are in the sub-grid surface classification. The ocean component of BCC-CSM2-HR is upgraded from MOM4 in BCC-CSM2MR to MOM5. The sea-ice component is also updated from SIS4 to SIS5.

For the sake of a rigorous comparison, historical simulations with fully coupled BCC-CSM2-MR and BCCCSM2-HR are analysed over a 65-year period from 1950 to 2014. The long-term trends of 1950-2014 globally averaged annual-mean surface air temperature from both BCCCSM2-MR and BCC-CSM2-HR are highly correlated to HadCRUT4 observation. The global warming in the latter half of the 20th century is well simulated, and the observed global warming hiatus or slowdown in the period from 1998 to 2013 is generally captured by both model versions. 

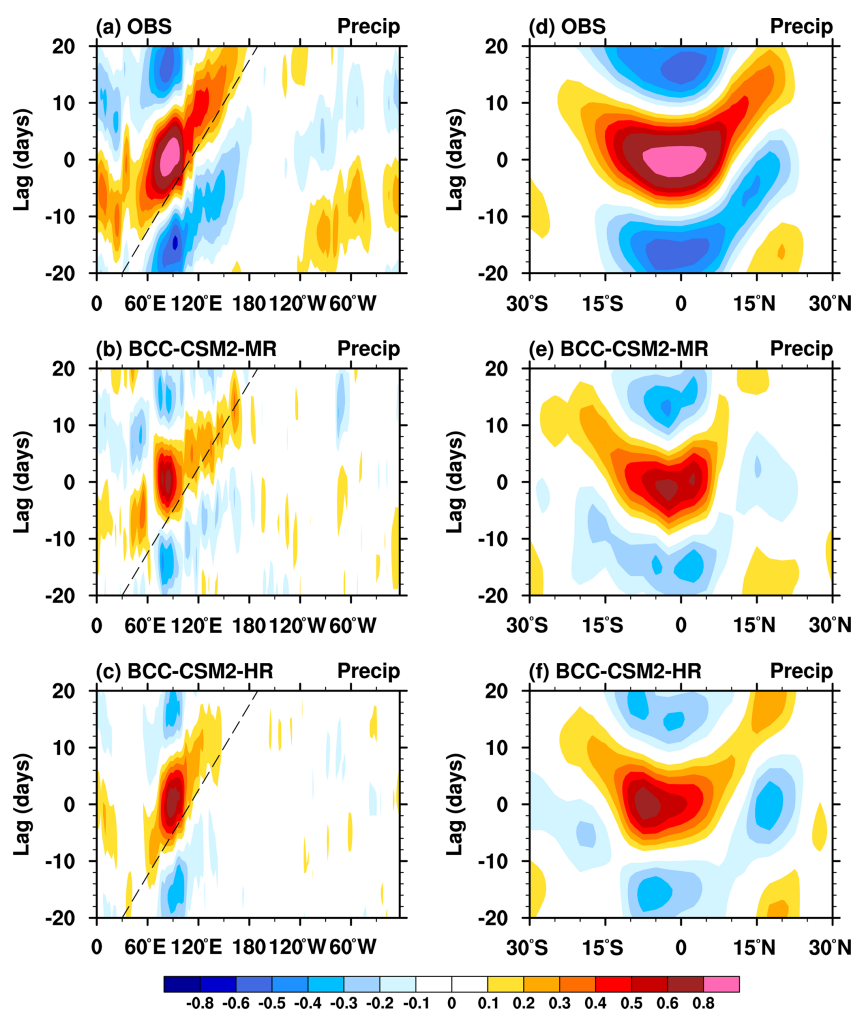

Figure 16. (a, b, c) Longitude-time evolution of lagged correlation coefficient for the $20-100 \mathrm{~d}$ band-pass-filtered precipitation anomaly (averaged over $10^{\circ} \mathrm{S}-10^{\circ} \mathrm{N}$ ) against regionally averaged precipitation over the equatorial eastern Indian Ocean $\left(80-100^{\circ} \mathrm{E}\right.$, $\left.10^{\circ} \mathrm{S}-10^{\circ} \mathrm{N}\right)$. (c, d, e) Same as the left panels, but for the latitudetime evolution of lagged correlation coefficients for filtered precipitation anomaly (averaged over $80-100^{\circ} \mathrm{E}$ ) against the regionally averaged precipitation over the equatorial eastern Indian Ocean. Dashed lines in each panel denote the $5 \mathrm{~m} \mathrm{~s}^{-1}$ eastward propagation speed. The observations in (a) and (b) are derived from GPCP data and the simulations are from (c, d) BCC-CSM2-MR, and (e, f) BCC-CSM2-HR for the period from 1995 to 2014.

We compared the 1995-2014 basic climate features in relation to atmospheric temperature, circulation, precipitation, surface temperature, and sea ice between the two simulations and we evaluated them against observation-based and reanalysis data. With contrast to the medium-resolution BCC-CSM2-MR, the high-resolution BCC-CSM2-HR has slightly improved energy equilibrium for the whole Earth system. The global mean TOA net energy balance is about $1.51 \mathrm{~W} \mathrm{~m}^{-2}$ in BCC-CSM2-HR for the period from 1995 to 2014, showing an evident improvement compared to $2.12 \mathrm{~W} \mathrm{~m}^{-2}$ in BCC-CSM2-MR. The longwave and net cloud radiative forcing are overall consistent with CERESEBAF at most latitudes, but excessive cloud radiative forcing for shortwave radiation is found over the eastern tropical Pacific and tropical Atlantic in BCC-CSM2-HR. Temperature biases in the low- to mid-troposphere below $300 \mathrm{hPa}$ in BCC-CSM2-HR are relatively small, within the range of -1
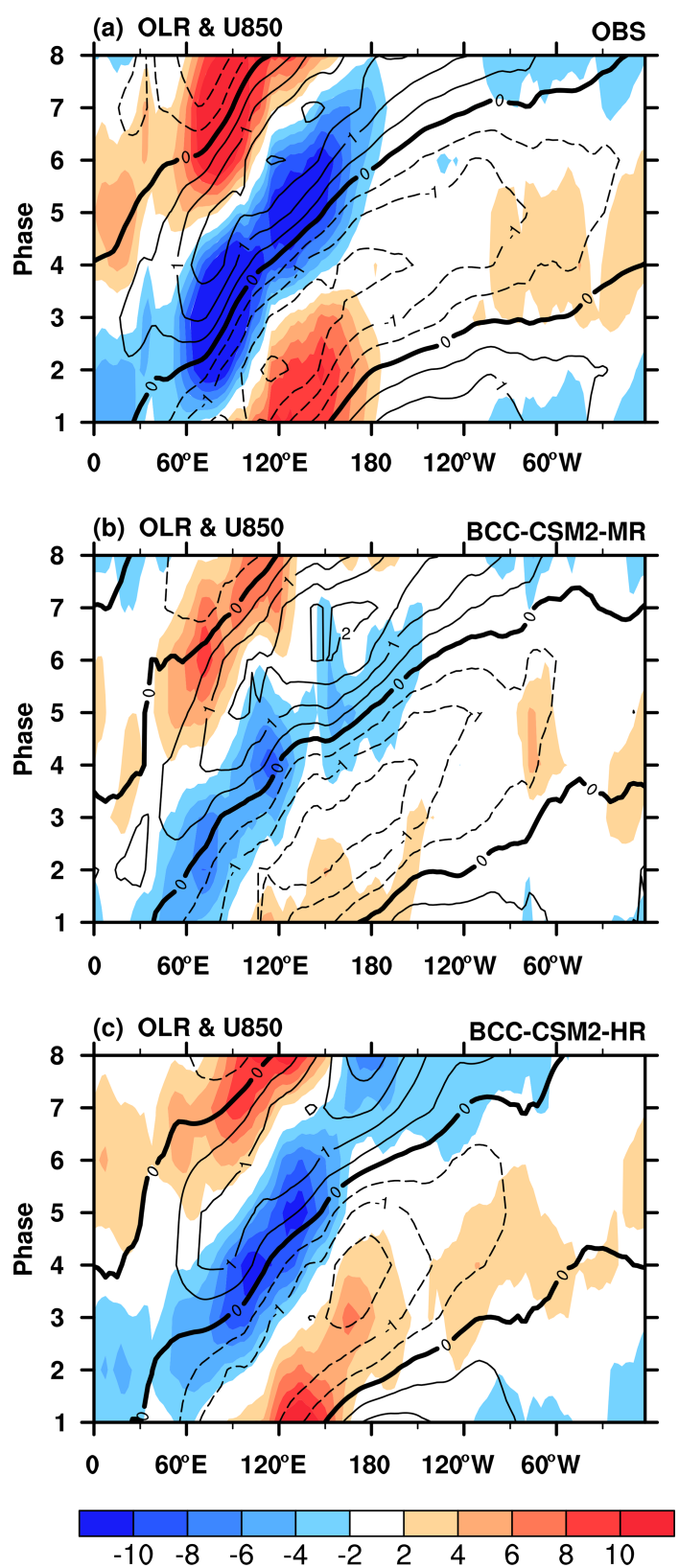

Figure 17. Hovmøller diagrams of MJO phase-composited OLR (shaded) and $850 \mathrm{hPa}$ zonal wind anomalies (contour lines) averaged between $10^{\circ} \mathrm{S}$ and $10^{\circ} \mathrm{N}$ from (a) ERA5 wind and NOAA OLR reanalyses, (b) BCC-CSM2-MR, and (c) BCC-CSM2-HR simulations for the period from 1995 to 2014. The MJO phase is defined by the two principal components corresponding to leading multivariate EOFs of OLR, 850 and $200 \mathrm{hPa}$ zonal wind anomalies as in Wheeler and Hendon (2004).

to $1 \mathrm{~K}$. Both versions of BCC-CSMs have a cold air temperature bias that appears above $250 \mathrm{hPa}$ in the subpolar and polar region, and a warm bias in the upper stratosphere at the mid-latitudes, which caused westerly wind biases in the upper troposphere and in the stratosphere. Although those 
(a) ERA5

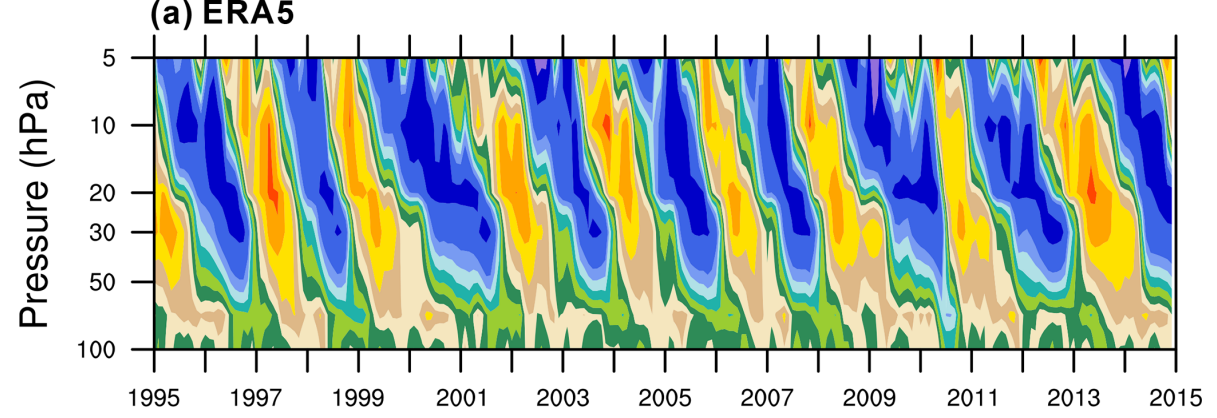

(b) BCC-CSM2-MR

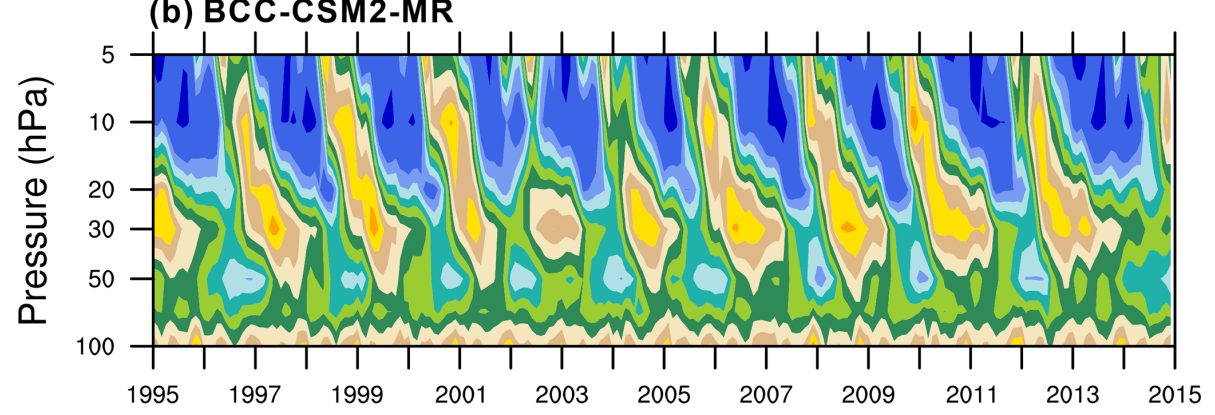

(c) BCC-CSM2-HR

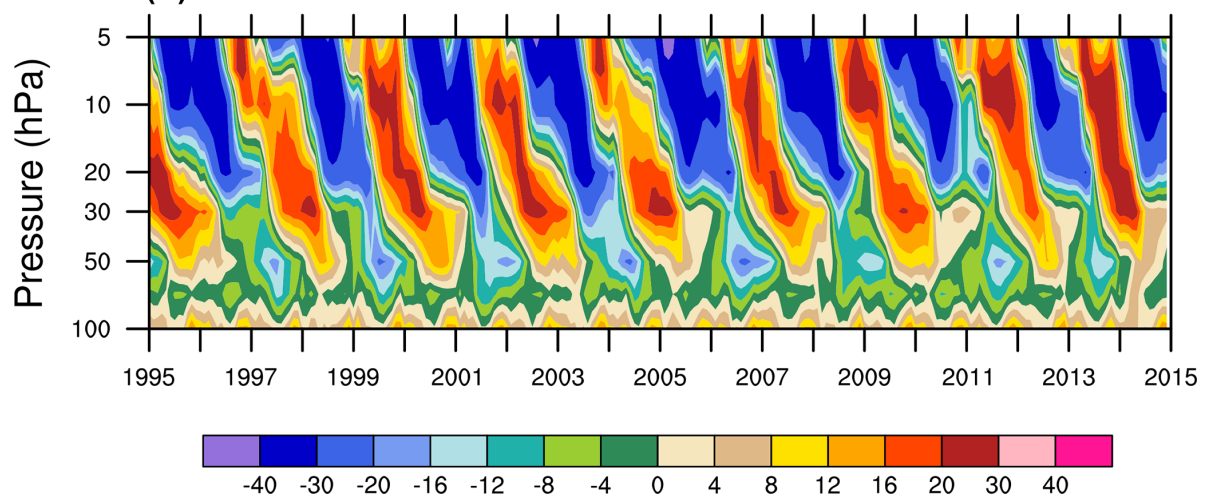

Figure 18. Tropical zonal winds $\left(\mathrm{m} \mathrm{s}^{-1}\right)$ between $5^{\circ} \mathrm{S}$ and $5^{\circ} \mathrm{N}$ in the lower stratosphere for (a) ERA5 reanalysis, (b) BCC-CSM2-MR, and (c) BCC-CSM2-HR during the period from 1995 to 2014.

prominent systematic biases in temperature and wind seem relatively insensitive to changes in atmospheric resolution, the ability to capture the winter-to-summer seasonal transition in the vertical structure of temperature and wind in the upper stratosphere is strengthened in BCC-CSM2-HR.

The two versions of BCC-CSM were both able to reproduce the observed global precipitation patterns, and there is a remarkable improvement in precipitation centres over the Pacific, Indian, and Atlantic oceans in the high-resolution model. The double-ITCZ biases in BCC-CSM2-MR are reduced in BCC-CSM2-HR, and excessive precipitation in the South Pacific Convergence Zone is also strongly reduced in BCC-CSM2-HR. The climatological SST in BCCCSM2-HR, relative to the observation-based HadISST data, shows cold but reduced biases compared to BCC-CSM2-
MR. Such SST cold biases are partly attributable to different ocean components, MOM4 in BCC-CSM2-MR and MOM5 in BCC-CSM2-HR. The seasonal cycles of amplitude and phase of sea ice in both hemispheres are generally well captured in BCC-CSM2-HR, but with a small excess all year round in the Northern Hemisphere, especially in the Atlantic.

We also conducted an assessment on a few important phenomena of the tropical climate, such as TC (tropical cyclone), MJO (Madden-Julian oscillation), QBO (quasibiennial oscillation), and ENSO (El Niño-Southern Oscillation). The averaged total number of global TC in BCCCSM2-HR is a bit larger than in IBTrACS observation. BCCCSM2-HR can simulate main TC activities in the eastern North Pacific, Northern Indian, and in the Southern Hemisphere but misses the TC activities in the North Atlantic. 

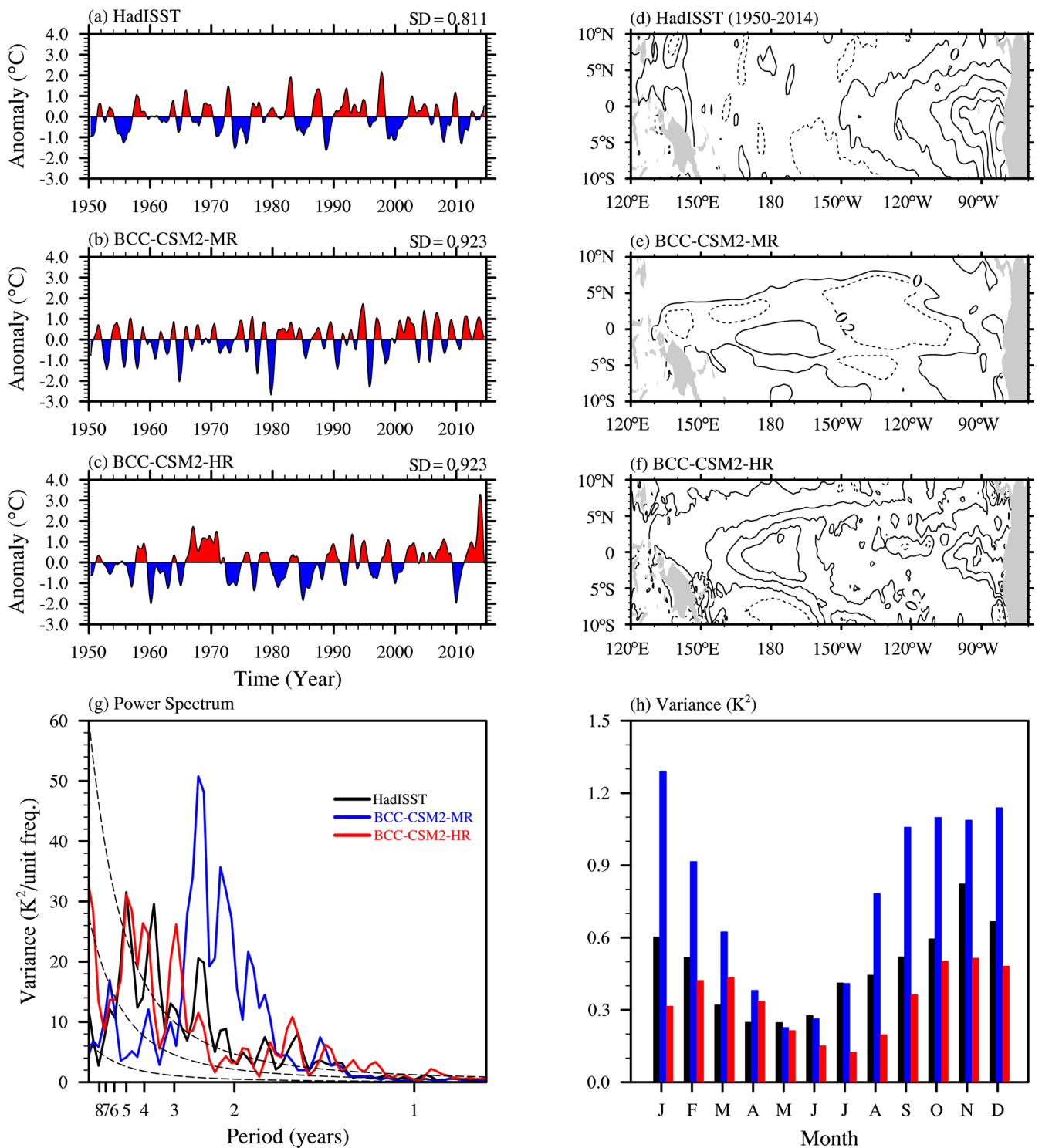

Figure 19. The time series of monthly Niño3.4 SST $\left(5^{\circ} \mathrm{N}-5^{\circ} \mathrm{S}, 170-120^{\circ} \mathrm{W}\right)$ anomalies and spatial distribution of their skewness for (a, d) HadISST observation, (b, e) BCC-CSM2-MR, and (c, f) BCC-CSM2-HR during the period 1950-2014. Panels (g) and (h) show their power spectrums and variances, respectively, and the black, blue, and red solid lines denote the results from HadISST, BCC-CSM2-MR, and BCC-CSM2-HR.

BCC-CSM2-HR is able to capture a realistic MJO signal including the eastward-propagating behaviour of MJO and its phase speed. The QBO-related alternative westerlies and easterlies in the tropical lower stratosphere with a mean periodicity of about 28 months are well simulated. The weakness in downward propagation of the simulated QBO (insufficient penetration of the signal to low altitudes) in BCC-CSM2-MR is slightly improved in BCC-CSM2-HR. Main features of the ENSO cycle such as the periodicity and phase locking are captured by BCC-CSM2-HR although its main ENSO periodicity of 3-6 years is still shorter compared to HadISST observations.
Our work shows that enhancing resolution does not noticeably improve climate mean state, and deterioration is even possible. For example, the decrease in JJA precipitation over the warm pool in our high-resolution model is still an important issue which certainly deserves further investigations with multiple models and simulations. Actually, other studies also reported similar issues. Haarsma et al. (2020) shows that increasing resolution in the EC-Earth model deteriorated the wet bias over the western Pacific warm pool. Bacmeister et al. (2014) analysed the high-resolution climate simulations performed with the Community Atmosphere Model (CAM) and showed that dry bias over the same region with enhanced resolution. Over the western Pacific warm pool, the atmo- 

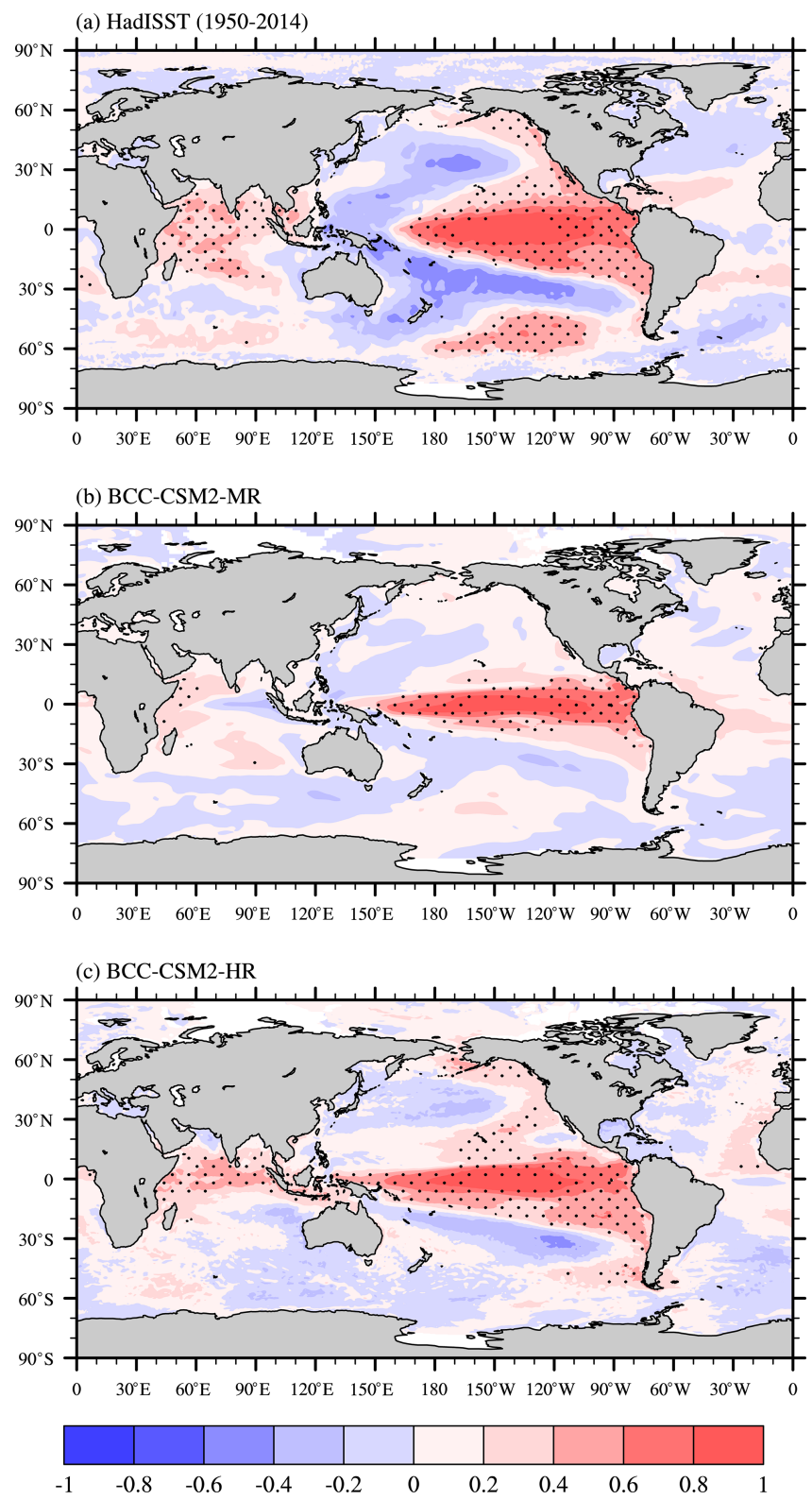

Figure 20. Correlation coefficients between SST and the Niño3.4 index from 1950 to 2014 for (a) HadISST data, (b) BCC-CSM2MR, and (c) BCC-CSM2-HR. Contour intervals are 0.2. Values significant at the $99 \%$ level using a Student's $t$ test are stippled.

spheric circulation and precipitation undergoes not only the impact of tropical variations such as MJO and TC, but also strong regional air-sea coupling.

We finally should note that there exist some systematic biases in our high-resolution model, such as the excessive cloud radiative forcing for shortwave radiation over the eastern tropical Pacific, cold biases in the near-surface temperature over northern Europe and over the tropical Atlantic, and insufficient TC activities over the North Atlantic and the Caribbean Sea. These are all important issues motivating us to develop and implement more physically based parameterizations in our future work. For the lack of sufficient TC activities in the North Atlantic, it seems that this bias also exists in other models (e.g. Bell et al., 2013; Strachan et al., 2013; Small et al., 2014) and still remains a challenging issue for the climate modelling community. A recent study reported by Davis (2018) showed that models with horizontal grid spacing of $1 / 4^{\circ}$ or coarser could not produce a realistic number of category 4 and 5 storms in the tropical Atlantic. The spatial resolution even in our current high-resolution model seems too coarse.

Code and data availability. Source codes of the BCCCSM-HR model can be accessed at a DOI repository https://doi.org/10.5281/zenodo.4127457 (Wu et al., 2020b). The model output of BCC models for CMIP6 simulations described in this paper is distributed through the Earth System Grid Federation (ESGF) and freely accessible through the ESGF data portals after registration (https://doi.org/10.22033/ESGF/CMIP6.2921, Jie et al., 2020). Details about ESGF are presented on the CMIP Panel website at http://www.wcrp-climate.org/index.php/wgcm-cmip/about-cmip (last access: 1 May 2019). All source code and data can also be accessed by contacting the corresponding author Tongwen $\mathrm{Wu}$ (twwu@cma.gov.cn).

Author contributions. TW led the BCC-CSM development, and all other co-authors contributed to it. TW, WJ, XX, and JZ designed the reported experiments and carried them out. TW, LL, YL, JY, and FW wrote the final document with contributions from all other authors.

Competing interests. The authors declare that they have no conflict of interest.

Acknowledgements. Three anonymous reviewers are acknowledged for their constructive comments on earlier versions of the paper.

Financial support. This research has been supported by the The National Key Research and Development Program of China (2016YFA0602100).

Review statement. This paper was edited by Richard Neale and reviewed by three anonymous referees.

\section{References}

Adler, R. F., Huffman, G. J., Chang, A., Ferraro, R., Xie, P., Janowiak, J., Rudolf, B., Schneider, U.,Curtis, S., Bolvin, D., 
Gruber, A., Susskind, J., Arkin, P., and Nelkin, E.: The version 2 Global Precipitation Climatology Project (GPCP) monthly precipitation analysis (1979-present), J. Hydrometeor, 4, 11471167, 2003.

Bacmeister, J. T., Wehner, M. F., Neale, R. B., Gettelman, A., Hannay, C. E., Lauritzen, P. H., Caron, J. M., and Truesdale, J. E.: Exploratory high-resolution climate simulations using the Community Atmosphere Model (CAM), J. Climate, 27, 3073-3099, https://doi.org/10.1175/JCLI-D-13-00387.1, 2014.

Bates, J. R., Moorthi, S., and Higgins, R. W.: A global multilevel atmospheric model using a vector semi-Lagrangian finite difference scheme, Part I: Adiabatic formulation, Mon. Weather Rev., 121, 244-263, 1993.

Bell, R. J., Strachan, J., Vidale, P. L., Hodges, K. I., and Roberts, M.: Response of tropical cyclones to idealized climate change experiments in a global high resolution coupled general circulation model, J. Climate, 26, 7966-7980, 2013.

Beres, J. H., Alexander, M. J., and Holton, J. R.: A method of specifying the gravity wave spectrum above convection based on latent heating properties and background wind, J. Atmos. Sci., 61, 324-337, 2004

Birch, C. E., Marsham, J. H., Parker, D. J., and Taylor, C. M.: The scale dependence and structure of convergence fields preceding the initiation of deep convection, Geophys. Res. Lett., 41, 47694776, https://doi.org/10.1002/2014GL060493, 2014.

Bretherton, C. S. and Park, S.: A new moist turbulence parameterization in the Community Atmosphere Model, J. Climate, 22, 3422-3448, 2009.

Bretherton, C. S. and Wyant, M. C.: Moisture transport, lower tropospheric stability, and decoupling of cloud-topped boundary layers, J. Atmos. Sci., 54, 148-167, 1997.

Burgers, G. and Stephenson D. B.: The "normality" of El Niño, Geophys. Res. Lett., 26, 1027-1039, https://doi.org/10.1029/1999GL900161, 1999.

Charlton-Perez, A. J., Baldwin, M. P., Birner, T., Black, R. X., Butler, A. H., Calvo, N., Davis, N. A., Gerber, E. P., Gillett, N., Hardiman, S., Kim, J., Krüger, K., Lee, Y.-Y., Manzini, E., McDaniel, B. A., Polvani, L., Reichler, T., Shaw, T. A., Sigmond, M., Son, S.-W., Toohey, M., Wilcox, L., Yoden, S., Christiansen, B., Lott, F., Shindell, S., Yukimoto, S., and Watanabe, S.: On the lack of stratospheric dynamical variability in low-top versions of the CMIP5 models, J. Geophys. Res.-Atmos., 118, 2494-2505, https://doi.org/10.1002/jgrd.50125, 2013.

Collins, W. D., Rasch, P. J., Boville, B. A., Hack, J. J., McCaa, J. R., Williamson, D. L., Kiehl, J. T., Briegleb, B., Bitz, C., Lin, S. J., Zhang, M. H., and Dai, Y. J.: Description of the NCAR community atmosphere model (CAM3), Technical Report NCAR/TN464+STR, National Center for Atmospheric Research, Boulder, Colorado, USA, 226 pp., 2004.

Danabasoglu, G., Yeager, S. G., Bailey, D., Behrens, E., Bentsen, E., Bi, D., Biastoch, A., Böning, C., Bozec, A.,Canuto, V. M., Cassou, C., Chassignet, E., Coward, A. C., Danilov, S., Diansky, N., Drange, H., Farneti, R., Fernandez, E., Fogli, P. G., Forget, G., Fujii, Y., Griffies, S. M., Gusev, A., Heimbach, P., Howard, A., Jung, T., Kelley, M., Large, W. G., Leboissetier, A., Lu, J., Simon, G. M., Marsland, J., Masina, S., Navarra, A., Nurser, A. J. G., Pirani, A., Mélia, D. S., Samuels, B. L., Scheinert, M., Sidorenko, D. Treguier, A.-M., Tsujino, H., Uotila, P., Valcke, S., Voldoire, A., and Wang, Q.: North Atlantic simu- lations in Coordinated Ocean-ice Reference Experiments phase II (CORE-II), Part I: Mean States, Ocean Model., 73, 76-107, https://doi.org/10.1016/j.ocemod.2013.10.005, 2014.

Davis, C. A.: Resolving tropical cyclone intensity in models, Geophys. Res. Lett., 45, 2082-2087, https://doi.org/10.1002/2017GL076966, 2018.

Delwortha, T. L., Broccolib, A. J., Rosatia, A., Stouffera, R. J., Balajic, V., Beesleyd, J. A., Cookee, W. F., Dixona, K. W., Dunnea, J., Dunnef, K. A., Durachtae, J. W., Findella, K. L., Ginouxa, P., Gnanadesikana, A., Gordona, C. T., Griffiesa, S. M., Gudgela, R., Harrisona, M. J., Helda, I. M., Hemlera, R. S., Horowitza, L. W., Kleina, S. A., Knutsona, T. R., Kushnerg, P. J., Langenhorste, A. R., Leee, H.-C., Lina, S.-J., Lud, J., Malyshevh, S. L., Millyf, P. C. D., Ramaswamya, V., Russellc, J., Schwarzkopfa, M. D., Shevliakovah, E., Sirutisa, J. J., Spelmana, M. J., Sterna, W. F., Wintona, M., Wittenberga, A. T., Wymana, B., Zenge, F., and Zhang, R.: GFDL's CM2 global coupled climate models, Part I: Formulation and simulation characteristics, J. Climate, 19, 643674, https://doi.org/10.1175/JCLI3629.1, 2006.

Delworth, T. L., Rosati, A., Anderson, W., Adcroft, A. J., Balaji, V., Benson, R., Dixon, K., Griffies, S. M., Lee, H.-C., Pacanowski, R. C., Vecchi, G. A., Wittenberg, A. T., Zeng, F., and Zhang, R.: Simulated climate and climate change in the GFDL CM2.5 high resolution coupled climate model, J. Climate, 25, 2755-2781, https://doi.org/10.1175/JCLI-D-11-00316.1, 2012.

Demory, M.-E., Vidale, P.-L., Roberts, M., Berrisford, P., Strachan, J., Schiemann, R., and Mizielinski, M. S.: The role of horizontal resolution in simulating drivers of the global hydrological cycle, Clim. Dynam., 42, 2201-2225, https://doi.org/10.1007/s00382013-1924-4, 2014.

Dey, C.: Noise suppression in a primitive equation prediction model, Mon. Weather Rev., 106, 159-173, 1978.

Doi, T., Vecchi, G. A., Rosati, A. J., and Delworth, T. L.: Biases in the Atlantic ITCZ in seasonal-interannual variations for a coarseand a high-resolution coupled climate model, J. Climate, 25, 5494-5511, https://doi.org/10.1175/JCLI-D-11-00360.1, 2012.

Endo, H., Kitoh, A., Ose, T., Mizuta, R., and Kusunoki, S.: Future changes and uncertainties in Asian precipitation simulated by multiphysics and multi-sea surface temperature ensemble experiments with high-resolution Meteorological Research Institute atmospheric general circulation models (MRI-AGCMs), J. Geophys. Res.-Atmos., 117, D16118, https://doi.org/10.1029/2012JD017874, 2012.

Eyring, V., Bony, S., Meehl, G. A., Senior, C. A., Stevens, B., Stouffer, R. J., and Taylor, K. E.: Overview of the Coupled Model Intercomparison Project Phase 6 (CMIP6) experimental design and organization, Geosci. Model Dev., 9, 1937-1958, https://doi.org/10.5194/gmd-9-1937-2016, 2016.

Flato, G., Marotzke, J., Abiodun, B., Braconnot, P., Chou, S. C., Collins, W., Cox, P., Driouech, F., Emori, S., Eyring, V., Forest, C., Gleckler, P., Guilyardi, E., Jakob, C., Kattsov, V., Reason, C., and Rummukainen, M.: Evaluation of climate models, in: Climate Change 2013: The Physical Science Basis, Contribution of Working Group I to the Fifth Assessment Report of the Intergovernmental Panel on Climate Change, edited by: Stocker, T. F., Qin, D., Plattner, G.-K., Tignor, M., Allen, S. K., Boschung, J., Nauels, A., Xia, Y., Bex, V., and Midgley, P. M., Cambridge University Press, Cambridge, United Kingdom and New York, USA, 741-866, 2013. 
Fleming, E. L., Chandra, S., Barnett, J. J., and Corney, M.: Zonal mean temperature, pressure, zonal wind, and geopotential height as functions of latitude, COSPAR International Reference Atmosphere: 1986, Part II: Middle Atmosphere Models, Adv. Space Res., 10, 11-59, https://doi.org/10.1016/0273-1177(90)90386-E, 1990.

Fox-Kemper, B., Ferrari, R., and Hallberg, R.: Parameterization of mixed layer eddies, I: Theory and diagnosis, J. Phys. Oceanogr., 38, 1145-1165, 2008.

Fox-Kemper, B., Danabasoglu, G., Ferrari, R., Griffies, S. M., Hallberg, R. W., Holland, M., Peacock, S., and Samuels, B.: Parameterization of mixed layer eddies, III: Global implementation and impact on ocean climate simulations, Ocean Model., 39, 61-78, 2011.

Fyfe, J. C., Meehl, G. A., England, M. H., Mann, M. E. Santer, B. D., Flato, G. M., Hawkins, E., Gillett, N. P., Xie, S.-P., Kosaka, Y., and Swart, N. C.: Making sense of the early-2000's warming slowdown, Nat. Clim. Change, 6, 224-228, 2016.

Garcia, R. R. and Richter, J. H.: On the momentum budget of the quasi-biennial oscillation in the whole atmosphere community climate model, J. Atmos. Sci., 76, 69-87, 2019.

Geller, M. A., Zhou, T., Shindell, D., Ruedy, R., Aleinov, I., Nazarenko, L., Tausnev, N. L., Kelley, M., Sun, S., Cheng, Y., Field, R. D., and Faluvegi, G.: Modeling the QBO - Improvements resulting from higher-model vertical resolution, J. Adv. Model. Earth Sy., 8, 1092-1105, 2016.

Griffies, S. M.: Elements of the Modular Ocean Model (MOM), GFDL Ocean Group, Technical Report No. 7, NOAA/Geophysical Fluid Dynamics Laboratory, Princeton, USA, 620 pp., 2012.

Griffies, S. M., Gnanadesikan, A., Pacanowski, R. C., Larichev, V., Dukowicz, J. K., and Smith, R. D.: Isoneutral diffusion in a zcoordinate ocean model, J. Phys. Oceanogr., 28, 805-830, 1998.

Griffies, S. M., Gnanadesikan, A., Dixon, K. W., Dunne, J. P., Gerdes, R., Harrison, M. J., Rosati, A., Russell, J. L., Samuels, B. L., Spelman, M. J., Winton, M., and Zhang, R.: Formulation of an ocean model for global climate simulations, Ocean Sci., 1, 45-79, https://doi.org/10.5194/os-1-45-2005, 2005.

Haarsma, R. J., Roberts, M. J., Vidale, P. L., Senior, C. A., Bellucci, A., Bao, Q., Chang, P., Corti, S., Fučkar, N. S., Guemas, V., von Hardenberg, J., Hazeleger, W., Kodama, C., Koenigk, T., Leung, L. R., Lu, J., Luo, J.-J., Mao, J., Mizielinski, M. S., Mizuta, R., Nobre, P., Satoh, M., Scoccimarro, E., Semmler, T., Small, J., and von Storch, J.-S.: High Resolution Model Intercomparison Project (HighResMIP v1.0) for CMIP6, Geosci. Model Dev., 9, 4185-4208, https://doi.org/10.5194/gmd-9-4185-2016, 2016.

Haarsma, R., Acosta, M., Bakhshi, R., Bretonnière, P.-A., Caron, L.-P., Castrillo, M., Corti, S., Davini, P., Exarchou, E., Fabiano, F., Fladrich, U., Fuentes Franco, R., García-Serrano, J., von Hardenberg, J., Koenigk, T., Levine, X., Meccia, V. L., van Noije, T., van den Oord, G., Palmeiro, F. M., Rodrigo, M., RuprichRobert, Y., Le Sager, P., Tourigny, E., Wang, S., van Weele, M., and Wyser, K.: HighResMIP versions of EC-Earth: EC-Earth3P and EC-Earth3P-HR - description, model computational performance and basic validation, Geosci. Model Dev., 13, 3507-3527, https://doi.org/10.5194/gmd-13-3507-2020, 2020.

Hack, J. J.: Parameterization of moist convection in the National Center for Atmospheric Research Community Climate Model (CCM2), J. Geophys. Res., 99, 5551-5568, 1994.
Harris, I. C. and Jones, P. D.: CRU TS4.01: Climatic Research Unit (CRU) Time-Series (TS) version 4.01 of high-resolution gridded data of month-by-month variation in climate (January 1901-December 2016) [dataset], Centre for Environmental Data Analysis, available at: https://doi.org/10.5285/58a8802721c94c66ae45c3baa4d814d0, 2017.

Hayashi, M., Jin, F. F., and Stuecker, M. F.: Dynamics for El NiñoLa Niña asymmetry constrain equatorial-Pacific warming pattern, Nat. Commun., 11, 4230, https://doi.org/10.1038/s41467020-17983-y, 2020

Hersbach, H. and Dee, D.: ERA5 reanalysis is in production, ECMWF Newsletter, No. 147, Reading, United Kingdom, 7 pp., available at: http://www.ecmwf.int/sites/default/files/ elibrary/2016/16299-newsletter-no147-spring-2016.pdf (last access: 1 May 2020), 2016.

Hertwig, E., von Storch, J.-S., Handorf, D., Dethloff, K., Fast, I., and Krismer, T.: Effect of horizontal resolution on ECHAM6-AMIP performance, Clim. Dynam., 45, 185-211, https://doi.org/10.1007/s00382-014-2396-x, 2015.

Hewitt, H. T., Roberts, M. J., Hyder, P., Graham, T., Rae, J., Belcher, S. E., Bourdallé-Badie, R., Copsey, D., Coward, A., Guiavarch, C., Harris, C., Hill, R., Hirschi, J. J.-M., Madec, G., Mizielinski, M. S., Neininger, E., New, A. L., Rioual, J.-C., Sinha, B., Storkey, D., Shelly, A., Thorpe, L., and Wood, R. A.: The impact of resolving the Rossby radius at mid-latitudes in the ocean: results from a high-resolution version of the Met Office GC2 coupled model, Geosci. Model Dev., 9, 3655-3670, https://doi.org/10.5194/gmd-9-3655-2016, 2016.

Holtslag, A. A. M. and Boville, B. A.: Local versus nonlocal boundary-layer diffusion in a glocal climate model, J. Climate, 6, 1825-1842, 1993.

Huffman, G. J., Bolvin, D. T., Braithwaite, D., Hsu, K., Joyce, R., Kidd, C., Nelkin, E. J., Sorooshian, S., Tan, J., and Xie, P.: NASA Global Precipitation Measurement (GPM) Integrated Multi-satellitE Retrievals for GPM (IMERG), Algorithm Theoretical Basis Document (ATBD), Version 06, 2019.

Hwang, Y.-T. and Frierson, D. M. W.: Link between the doubleIntertropical Convergence Zone problem and cloud biases over the Southern Ocean, P. Natl. Acad. Sci. USA, 110, 4935-4940, https://doi.org/10.1073/pnas.1213302110, 2013.

Ji, J.: A climate-vegetation interaction model: Simulating physical and biological processes at the surface, J. Biogeogr., 22, 20632069, 1995.

Ji, J., Huang, M., and Li, K.: Prediction of carbon exchange between China terrestrial ecosystem and atmosphere in 21 st century, Sci. China Ser. D, 51, 885-898, 2008.

Jie, W., Zhang, J., Wu, T., Shi, X., Zhang, F., Li, J., Chu, M., Liu, Q., Yan, J., Ma, Q., and Wei, M.: BCC BCC-CSM2HR model output prepared for CMIP6 HighResMIP hist-1950 [dataset], Version 20200921, Earth System Grid Federation, available at: https://doi.org/10.22033/ESGF/CMIP6.2921, 2020.

Jones, P. D., Lister, D. H., Osborn, T. J., Harpham, C., Salmon, M., and Morice, C. P.: Hemispheric and large-scale land surface air temperature variations: an extensive revision and an update to 2010, J. Geophys. Res.-Atmos., 117, D05127, https://doi.org/10.1029/2011JD017139, 2012.

Knapp, K. R., Kruk, M. C., Levinson, D. H., Diamond, H. J., and Neumann, C. J.: The International Best Track 
Archive for Climate Stewardship (IBTrACS): Unifying Tropical Cyclone Data, B. Am. Meteorol. Soc., 91, 363-376, https://doi.org/10.1175/2009BAMS2755.1, 2010.

Kim, H., Caron, J. M., Richter, J. H., and Simpson, I. R.: The lack of QBO-MJO connection in CMIP6 models, Geophys. Res. Lett., 47, e2020GL087295, https://doi.org/10.1029/2020GL087295, 2020.

Kinter, J. L., Cash, B., Achuthavarier, D., Adams, J., Altshuler, E., Dirmeyer, P., Doty, B., Huang, B., Jin, E. K., Marx, L., Manganello, J., Stan, C., Wakefield, T., Palmer, T., Hamrud, M., Jung, T., Miller, M., Towers, P., Wedi, N., Satoh, M., Tomita, H., Kodama, C., Nasuno, T., Oouchi, K., Yamada, Y., Taniguchi, H., Andrews, P., Baer, T., Ezell, M., Halloy, C., John, D., Loftis, B., Mohr, R., and Wong, K.: Revolutionizing Climate Modeling with Project Athena: A Multi-Institutional, International Collaboration, B. Am. Meteorol. Soc., 94, 231-245, https://doi.org/10.1175/BAMS-D-11-00043.1, 2013.

Klein, S. A. and Hartmann, D. L.: The seasonal cycle of low stratiform cloud, J. Climate, 6, 1587-1606, 1993.

Lal, M., Cubasch, U., Perlwitz, J. P., and Waszkewitz, J.: Simulation of the Indian monsoon climatology in ECHAM3 climate model: Sensitivity to horizontal resolution, Int. J. Climatol., 17, 847858, 1997.

Large, W., McWilliams, J., and Doney, S.: Oceanic vertical mixing: a review and a model with a nonlocal boundary layer parameterization, Rev. Geophys., 32, 363-403, 1994.

Li, G. and Xie, S.-P.: Tropical biases in CMIP5 multimodel ensemble: The excessive equatorial Pacific cold tongue and double ITCZ problems, J. Climate, 27, 1765-1780, 2014.

Li, H. and Sriver, R. L.: Tropical Cyclone Activity in the HighResolution Community Earth System Model and the Impact of Ocean Coupling, J. Adv. Model. Earth Sy., 10, 165-186, https://doi.org/10.1002/2017MS001199, 2018.

Li, W., Zhang, Y., Shi, X., Zhou, W., Huang, A., Mu, M., Qiu, B., and Ji, J.: Development of the Land Surface Model BCC_AVIM2.0 and Its Preliminary Performance in LS3MIP/CMIP6, J. Meteorol. Res.-PRC, 33, 851-869, https://doi.org/10.1007/s13351-019-9016-y, 2019.

Liebmann, B. and Smith, C. A.: Description of a Complete (Interpolated) Outgoing Longwave Radiation Dataset, B. Am. Meteorol. Soc., 77, 1275-1277, 1996.

Loeb, N. G., Doelling, D. R., Wang, H., Su, W., Nguyen, C., Corbett, J. G., Liang, L., Mitrescu, C., Rose, F. G., and Kato, S.: Clouds and the Earth's Radiant Energy System (CERES) Energy Balanced and Filled (EBAF) Top-ofAtmosphere (TOA) Edition-4.0 data product, J. Climate, 31, 895-918, https://doi.org/10.1175/JCLI-D-17-0208.1, 2018.

Lu, Y., Wu, T., Jie, W., Scaife, A. A., Andrews, M. B., and Richter, J. H.: Variability of the Stratospheric Quasi-Biennial Oscillation and Its Wave Forcing Simulated in the Beijing Climate Center Atmospheric General Circulation Model, J. Atmos. Sci., 77, 149-165, https://doi.org/10.1175/JAS-D-19-0123.1, 2020a.

Lu, Y., Wu, T., Li, Y., and Yang, B.: Mitigation of the double ITCZ syndrome in BCC-CSM2-MR through improving parameterizations of boundary-layer turbulence and shallow convection, Geosci. Model Dev. Discuss. [preprint], https://doi.org/10.5194/gmd-2020-40, in review, 2020 b.
Madden, R. A. and Julian, P. R.: Detection of a 40-50 Day Oscillation in the Zonal Wind in the Tropical Pacific, J. Atmos. Sci., 28, 702-708, 1971.

Manganello, J. V., Hodges, K. I., Kinter, J. L., Cash, B. A., Marx, L., Jung, T., Achuthavarier, D., Adams, J. M., Altshuler, E. L., Huang, B., Jin, E. K., Stan, C., Towers, P., and Wedi, N.: Tropical Cyclone Climatology in a $10 \mathrm{~km}$ Global Atmospheric GCM: Toward Weather-Resolving Climate Modeling, J. Climate, 25, 3867-3893, https://doi.org/10.1175/JCLI-D-11-00346.1, 2012.

Manizza, M., Le Quere, C., Watson, A. J., and Buitenhuis, E. T.: Bio-optical feedbacks among phytoplankton, upper ocean physics and sea-ice in a global model, Geophys. Res. Lett., 32, L05603, https://doi.org/10.1029/2004GL020778, 2005.

Marshall, J., Hill, C., Perelman, L., and Adcroft, A.: Hydrostatic, quasi-hydrostatic, and nonhydrostatic ocean modeling, J. Geophys. Res., 102, 5733-5752, 1997.

Martin, G. M.: The simulation of the Asian summer monsoon, and its sensitivity to horizontal resolution, in the UK meteorological office unified model, Q. J. Roy. Meteor. Soc., 125, 1499-1525, https://doi.org/10.1002/qj.49712555703, 1999.

Masson, S., Terray, P., Madec, G., Luo, J.-J., Yamagata, T., and Takahashi, K.: Impact of intra-daily SST variability on ENSO characteristics in a coupled model, Clim. Dynam., 39, 681-707, 2012.

Masumoto, Y., Sasaki, H., Kagimoto, T., Komori, N., Ishida, A., Sasai, Y., Miyama, T., Motoi, T., Mitsudera, H., Takahashi, K., Sakuma, H., and Yamagata, T.: A fifty-year eddy-resolving simulation of the world ocean - Preliminary outcomes of OFES (OGCM for the Earth Simulator), J. Earth Sim., 1, 35-56, 2004.

McFarlane, N. A.: The effect of orographically excited gravity wave drag on the general circulation of the lower stratosphere and troposphere, J. Atmos. Sci., 44, 1775-1800, 1987.

Medhaug, I., Martin, B. S., Erich, M. F., and Knutti, R.: Reconciling controversies about the "global warming hiatus", Nature, 545, 41-47, 2017.

Mizielinski, M. S., Roberts, M. J., Vidale, P. L., Schiemann, R., Demory, M.-E., Strachan, J., Edwards, T., Stephens, A., Lawrence, B. N., Pritchard, M., Chiu, P., Iwi, A., Churchill, J., del Cano Novales, C., Kettleborough, J., Roseblade, W., Selwood, P., Foster, M., Glover, M., and Malcolm, A.: High-resolution global climate modelling: the UPSCALE project, a large-simulation campaign, Geosci. Model Dev., 7, 1629-1640, https://doi.org/10.5194/gmd7-1629-2014, 2014.

Mizuta, R., Oouchi, K., Yoshimura, H., Noda, A., Katayama, K., Yukimoto, S., Hosaka, M., Kusunoki, S., Kawai, H., and Nakagawa, M.: 20 km-Mesh Global Climate Simulations Using JMAGSMModel: Mean Climate States, J. Meteorol. Soc. Jpn., 84, 165-185, 2006.

Morel, A. and Antoine, D.: Heating rate within the upper ocean in relation to its bio-optical state, J. Phys. Oceanogr., 24, 1652$1665,1994$.

Morice, C. P., Kennedy, J. J., Rayner, N. A., and Jones, P. D.: Quantifying uncertainties in global and regional temperature change using an ensemble of observational estimates: The HadCRUT4 data set, J. Geophys. Res. 117, D08101, https://doi.org/10.1029/2011JD017187, 2012.

Murakami, H.: Tropical cyclones in reanalysis data sets, Geophys. Res. Lett., 41, 2133-2141, 2014. 
Murakami, H., Wang, Y., Yoshimura, H., Mizuta, R., Sugi, M., Shindo, E., Adachi, Y., Yukimoto, S., Hosaka, M., Kusunoki, S., Ose, T., and Kitoh, A.: Future Changes in Tropical Cyclone Activity Projected by the New High-Resolution MRI-AGCM, J. Climate, 25, 3237-3260, https://doi.org/10.1175/JCLI-D-1100415.1, 2012.

Murakami, H., Vecchi, G. A., Underwood, S., Delworth, T. L., Wittenberg, A. T., Anderson, W. G., Chen, J.-H., Gudgel, R. G., Harris, L. M., Lin, S.-J., and Zeng, F.: Simulation and Prediction of Category 4 and 5 Hurricanes in the High-Resolution GFDL HiFLOR Coupled Climate Model, J. Climate, 28, 9058-9079, 2015.

Nicholls, S. and Turton, J. D.: An observational study of the structure of stratiform cloud sheets: Part II. Entrainment, Q. J. Roy. Meteor. Soc., 112, 461-480, 1986.

Ohfuchi, W., Nakamura, H., Yoshioka, M. K., Enomoto, T., Takaya, K., Peng, X., Yamane, S., Nishimura, T., Kurihara, Y., and Ninomiya, K.: $10 \mathrm{~km}$ mesh meso-scale resolving simulations of the global atmosphere on the Earth Simulator: Preliminary outcomes of AFES (AGCM for the Earth Simulator), J. Earth Sim., 1, 8-34, 2004.

Oleson, K. W., Dai, Y., Bonan, G., Bosilovich, M., Dickinson, R., Dirmeyer, P., Hoffman, F., Houser, P., Levis, S., Niu, G.-Y., Thornton, P., Vertenstein, M., Yang, Z.-L., and Zeng, X.: Technical description of the Community Land Model (CLM), NCAR Tech. Note TN-461+STR, University Corporation for Atmospheric Research, USA, 174 pp., https://doi.org/10.5065/D6N877R0, 2004.

Oouchi, K., Yoshimura, J., Yoshimura, H., Mizuta, R., Kusunoki, S., and Noda, A.: Tropical Cyclone Climatology in a GlobalWarming Climate as Simulated in a $20 \mathrm{~km}$-Mesh Global Atmospheric Model: Frequency and Wind Intensity Analyses, J. Meteorol. Soc. Jpn., 84, 259-276, 2006.

Park, S. and Bretherton, C. S.: The University of Washington shallow convection and moist turbulence schemes and their impact on climate simulations in the Community Atmosphere Model, J. Climate, 22, 3449-3469, 2009.

Peatman, S. C., Matthews, A. J., and Stevens, D. P.: Propagation of the Madden-Julian Oscillation and scale interaction with the diurnal cycle in a high-resolution GCM, Clim. Dynam., 45, 29012918, https://doi.org/10.1007/s00382-015-2513-5, 2015.

Rackow, T., Goessling, H. F., Jung, T., Sidorenko, D., Semmler, T., Barbi, D., and Handorf, D.: Towards multi-resolution global climate modeling with ECHAM6-FESOM, Part II: climate variability, Clim. Dynam., 50, 2369-2394, https://doi.org/10.1007/s00382-016-3192-6, 2016.

Rasch, P. J. and Kristjánsson, J. E.: A comparison of the CCM3 model climate using diagnosed and predicted condensate parameterizations, J. Climate, 11, 1587-1614, 1998.

Rayner, N. A., Parker, D. E., Horton, E. B., Folland, C. K., Alexander, L. V., Rowell, D. P., Kent, E. C., and Kaplan, A.: Global analyses of sea surface temperature, sea ice, and night marine air temperature since the late nineteenth century, J. Geophys. Res.-Atmos., 108, 4407, https://doi.org/10.1029/2002JD002670, 2003.

Reed, K. A., Bacmeister, J. T., Rosenbloom, N. A., Wehner, M. F., Bates, S. C., Lauritzen, P. H., Truesdale, J. E., and Hannay, C.: Impact of the dynamical core on the direct simulation of tropical cyclones in a high-resolution global model, Geophys. Res. Lett., 42, GL063974, https://doi.org/10.1002/2015GL063974, 2015.

Richter, I.: Climate model biases in the eastern tropical oceans: Causes, impacts and ways forward, WIRES. Clim. Change, 6, 345-358, https://doi.org/10.1002/wcc.338, 2015.

Richter, J. H., Sassi, F., and Garcia, R. R.: Toward a physically based gravity wave source parameterization in a general circulation model, J. Atmos. Sci., 67, 136-156, 2010.

Roberts, C. D., Senan, R., Molteni, F., Boussetta, S., Mayer, M., and Keeley, S. P. E.: Climate model configurations of the ECMWF Integrated Forecasting System (ECMWF-IFS cycle 43r1) for HighResMIP, Geosci. Model Dev., 11, 3681-3712, https://doi.org/10.5194/gmd-11-3681-2018, 2018.

Roberts, M. J., Hewitt, H. T., Hyder, P., Ferreira, D., Josey, S. A., Mizielinski, M., and Shelly, A.: Impact of ocean resolution on coupled air-sea fluxes and large-scale climate, Geophys. Res. Lett., 43, 10430-10438, https://doi.org/10.1002/2016GL070559, 2016.

Roberts, M. J., Baker, A., Blockley, E. W., Calvert, D., Coward, A., Hewitt, H. T., Jackson, L. C., Kuhlbrodt, T., Mathiot, P., Roberts, C. D., Schiemann, R., Seddon, J., Vannière, B., and Vidale, P. L.: Description of the resolution hierarchy of the global coupled HadGEM3-GC3.1 model as used in CMIP6 HighResMIP experiments, Geosci. Model Dev., 12, 4999-5028, https://doi.org/10.5194/gmd-12-4999-2019, 2019.

Sakamoto, T. T., Komuro, Y., Nishimura, T., Ishi, M., Tatebe, H., Shiogama, H., Hasegawa, A., Toyoda, T., Mori, M., Suzuki, T., Imada, Y., Nozawa, T., Takata, K., Mochizuki, T., Ogochi, K., Emori, S., Hasumi, H., and Kimoto, M.: MIROC4h - A New High-Resolution Atmosphere-Ocean Coupled General Circulation Model, J. Meteorol. Soc. Jpn., 90, 325-359, 2012.

Sato, T., Miura, H., Satoh, M., Takayabu, Y. N., and Wang, Y. Q.: Diurnal cycle of precipitation in the tropics simulated in a global cloud-resolving model, J. Climate, 22, 4809-4826, 2009.

Satoh, M., Tomita, H., Yashiro, H., Miura, H., Kodama, C., Seiki, T., Noda, A. T., Yamada, Y., Goto, D., Sawada, M., Miyoshi, T., Niwa, Y., Hara, M., Ohno, Y., Iga, S., Arakawa, T., Inoue, T., and Kubokawa, H.: The Non-hydrostatic Icosahedral Atmospheric Model: Description and development, Progress in Earth and Planetary Science, 1, 18, https://doi.org/10.1186/s40645014-0018-1, 2014.

Schenzinger, V., Osprey, S., Gray, L., and Butchart, N.: Defining metrics of the Quasi-Biennial Oscillation in global climate models, Geosci. Model Dev., 10, 2157-2168, https://doi.org/10.5194/gmd-10-2157-2017, 2017.

Schiemann, R., Demory, M.-E., Mizielinski, M. S., Roberts, M. J., Shaffrey, L. C., Strachan, J., and Vidale, P. L.: The sensitivity of the tropical circulation and Maritime Continent precipitation to climate model resolution, Clim. Dynam., 42, 2455-2468, https://doi.org/10.1007/s00382-013-1997-0, 2014.

Semtner, A. J.: A model for the thermodynamic growth of sea ice in numerical investigations of climate, J. Phys. Oceanogr., 6, 379389, 1976.

Shaevitz, D., Camargo, S. J., Sobel, A. H., Jonas, J. A., Kim, D., Kumar, A., LaRow, T. E., Lim, Y.-K., Murakami, H., Reed, K., Roberts, M. J., Scoccimarro, E., Vidale, P. L., Wang, H., Wehner, M. F., Zhao, M., and Henderson, N.: Characteristics of tropical cyclones in high-resolution models in 
the present climate, J. Adv. Model. Earth Sy., 6, 1154-1172, https://doi.org/10.1002/2014MS000372, 2014.

Shaffrey, L. C., Stevens, I., Norton, W. A., Roberts, M. J., Vidale, P. L., Harle, J. D., Jrrar, A., Stevens, D. P., Woodage, M. J., Demory, M. E., Donners, J., Clark, D. B., Clayton, A., Cole, J. W., Wilson, S. S., Connolley, W. M., Davies, T. M., Iwi, A. M., Johns, T. C., King, J. C., New, A. L., Slingo, J. M., Slingo, A., Steenman-Clark, L., and Martin, G. M.: UK HiGEM: the new UK High-resolution Global Environment Model - model description and basic evaluation, J. Climate, 22, 1861-1896, https://doi.org/10.1175/2008JCLI2508.1, 2009.

Shi, Q. and Wang, G.: ObservedWarm Filaments from the Kuroshio Associated with Mesoscale Eddies, Remote Sens.-Basel, 12, 3090, https://doi.org/10.3390/rs12183090, 2020.

Small, R. J., Bacmeister, J., Bailey, D. A., Baker, A., Bishop, S., Bryan, F. O., Caron, J., Dennis, J., Gent, P. R., Hsu, H.-M., Jochum, M., Lawrence, D. M., Munoz Acevedo, E., diNezio, P., Scheitlin, T., Tomas, R., Tribbia, J., Tseng, Y., and Vertenstein, M.: A new synoptic scale resolving global climate simulation using the Community Earth System Model, J. Adv. Model. Earth Sy., 6, 1065-1094, https://doi.org/10.1002/2014MS000363, 2014

Small, R. J., Curchitser, E., Hedstrom, K., Kauffman, B., and Large, W. G.: The Benguela upwelling system: Quantifying the sensitivity to resolution and coastal wind representation in a global climate model, J. Climate, 28, 9409-9432, https://doi.org/10.1175/JCLI-D-15-0192.1, 2015.

Smith, R. D., Maltrud, M. E., Bryan, F. O., and Hecht, M. W.: Numerical Simulation of the North Atlantic Ocean at $1 / 10^{\circ}$, J. Phys. Oceanogr., 30, 1532-1561, 2000.

Sperber, K. R., Sultan, H., Potter, G. L., and Boyle, J. S.: Simulation of the Northern summer monsoon in the ECMWF model: sensitivity to horizontal resolution, Mon. Weather Rev., 122, 24612481, 1994.

Stevens, B., Fiedler, S., Kinne, S., Peters, K., Rast, S., Müsse, J., Smith, S. J., and Mauritsen, T.: MACv2-SP: a parameterization of anthropogenic aerosol optical properties and an associated Twomey effect for use in CMIP6, Geosci. Model Dev., 10, 433452, https://doi.org/10.5194/gmd-10-433-2017, 2017.

Strachan, J., Vidale, P. L., Hodges, K., Roberts, M., and Demory, M.-E.: Investigating global tropical cyclone activity with a hierarchy of AGCMs: The role of model resolution, J. Climate, 26, 133-152, 2013.

Sugi, M., Murakami, H., and Yoshida, K.: Projection of future changes in the frequency of intense tropical cyclones, Clim. Dynam., 49, 619-632, 2017.

Sweby, P. K.: High resolution schemes using flux limiters for hyperbolic conservation laws, SIAM J. Numer. Anal., 21, 995-1011, 1984.

Taylor, K. E., Stouffer, R. J., and Meehl, G. A.: An Overview of Cmip5 and the Experiment Design, B. Am. Meteorol. Soc., 93, 485-498, 2012.

Tian, B., Fetzer, E. J., Kahn, B. H., Teixeira, J., Manning, E., and Hearty, T.: Evaluating CMIP5 models using AIRS tropospheric air temperature and specific humidity climatology, J. Geophys. Res.-Atmos., 118, 114-134, https://doi.org/10.1029/2012JD018607, 2013.
Turton, J. D. and Nicholls, L.: A study of the diurnal variation of stratocumulus using a multiple mixed-layer model, Q. J. Roy. Meteor. Soc., 113, 969-1009, 1987.

Vecchi, G. A., Delworth, T., Murakami, H., Underwood, S., Wittenberg, A. T., Zeng, F., Zhang, W., Baldwin, J. W., Bhatia, K., Cooke, W., He, J., Kapnick, S. B., Knutson, T., Villarini, G., van der Wiel, K., Anderson, W., Balaji, V., Chen, J., Dixon, K., Gudgel, R., Harris, L., Jia, L., Johnson, N., Lin, S., Liu, M., Ng, J., Rosati, A., Smith, J., and Yang, X.: Tropical cyclone sensitivities to $\mathrm{CO}_{2}$ doubling: Roles of atmospheric resolution, synoptic variability and background climate changes, Clim. Dynam., 53, 5999-6033, 2019.

Vellinga, M., Roberts, M., Vidale, P. L., Mizielinski, M., Demory, M.-E., Schiemann, R., Strachan, J., Bain, C., Kettleborough, J., Good, P., Edmond, I., and Hibling, E.: Organised convection as the main carrier of Sahel rainfall variability at multi-annual timescales, Geophys. Res. Lett., 43, 326-333, https://doi.org/10.1002/2015GL066690, 2016.

Walsh, K., Lavender, S., Scoccimarro, E., and Murakami, H.: Resolution dependence of tropical cyclone formation in CMIP3 and finer resolution models, Clim. Dynam., 40, 585-599, 2012.

Wehner, M. F., Smith, R. L., Bala, G., and Duffy, P.: The effect of horizontal resolution on simulation of very extreme US precipitation events in a global atmosphere model, Clim. Dynam., 34, 241-247, 2010.

Wehner, M. F., Prabhat, Reed, K. A., Stone, D., Collins, W. D., and Bacmeister, J. T.: Resolution dependence of future tropical cyclone projections of CAM5.1 in the US CLIVAR Hurricane Working Group idealized configurations, J. Climate, 28, 39053925, https://doi.org/10.1175/JCLI-D-14-00311.1, 2015.

Wheeler, M. and Kiladis, G. N.: Convectively coupled equatorial waves: Analysis of clouds and temperature in the wavenumberfrequency domain, J. Atmos. Sci., 56, 374-399, 1999.

Wheeler, M. C. and Hendon, H. H.: An all-season real-time multivariate MJO index: Development of an index for monitoring and prediction, Mon. Weather Rev., 132, 1917-1932, 2004.

Whitehead, J. P., Jablonowski, C., Rood, R. B., and Lauritzen, P. H.: A stability analysis of divergence damping on a latitudelongitude grid, Mon. Weather Rev., 139, 2976-2993, 2011.

Wielicki, B. A., Barkstrom, B. R., Harrison, E. F., Lee, R. B., Smith, G. L., and Cooper, J. E.: Clouds and the earth's radiant energy system (CERES): an earth observing system experiment, B. Am. Meteorol. Soc., 77, 853-868, 1996.

Winton, M.: A reformulated three-layer sea ice model, J. Atmos. Ocean. Tech., 17, 525-531, 2000.

Wood, R. and Bretherton, C. S.: Boundary-layer depth, entrainment, and decoupling in the cloud-capped subtropical and tropical marine boundary layer, J. Climate, 17, 3576-3588, 2004.

Wu, T.: A Mass-Flux Cumulus Parameterization Scheme for Largesistercale Models: Description and Test with Observations, Clim. Dynam., 38, 725-744, https://doi.org/10.1007/s00382011-0995-3, 2012.

Wu, T., Yu, R., and Zhang, F.: A modified dynamic framework for atmospheric spectral model and its application, J. Atmos. Sci., 65, 2235-2253, 2008.

Wu, T., Yu, R., Zhang, F., Wang, Z., Dong, M., Wang, L., Jin, X., Chen, D., and Li, L.: The Beijing Climate Center atmospheric general circulation model: description and its perfor- 
mance for the present-day climate, Clim. Dynam., 34, 123-147, https://doi.org/10.1007/s00382-008-0487-2, 2010.

Wu, T., Li, W., Ji, J., Xin, X., Li, L., Wang, Z., Zhang, Y., Li, J., Zhang, F., Wei, M., Shi, X., Wu, F., Zhang, L., Chu, M., Jie, W., Liu, Y., Wang, F., Liu, X., Li, Q., Dong, M., Liang, X., Gao, Y., and Zhang, J.: Global carbon budgets simulated by the Beijing climate center climate system model for the last century, J. Geophys. Res.-Atmos., 118, 4326-4347, https://doi.org/10.1002/jgrd.50320, 2013.

Wu, T., Song, L., Li, W., Wang, Z., Zhang, H., Xin, X., Zhang, Y., Zhang, L., Li, J., Wu, F., Liu, Y., Zhang, F., Shi, X., Chu, M., Zhang, J., Fang, Y., Wang, F., Lu, Y., Liu, X., Wei, M., Liu, Q., Zhou, W., Dong, M., Zhao, Q., Ji, J., Li, L., and Zhou, M.: An overview of BCC climate system model development and application for climate change studies, J. Meteorol. Res.-PRC, 28, 34-56, 2014.

Wu, T., Hu, A., Gao, F., Zhang, J., and Meehl, G. A.: New insights into natural variability and anthropogenic forcing of global/regional climate evolution, npj Climate and Atmospheric Science, 2, 18, https://doi.org/10.1038/s41612-0190075-7, 2019a.

Wu, T., Lu, Y., Fang, Y., Xin, X., Li, L., Li, W., Jie, W., Zhang, J., Liu, Y., Zhang, L., Zhang, F., Zhang, Y., Wu, F., Li, J., Chu, M., Wang, Z., Shi, X., Liu, X., Wei, M., Huang, A., Zhang, Y., and Liu, X.: The Beijing Climate Center Climate System Model (BCC-CSM): the main progress from CMIP5 to CMIP6, Geosci. Model Dev., 12, 1573-1600, https://doi.org/10.5194/gmd-121573-2019, 2019b.

Wu, T., Zhang, F., Zhang, J., Jie, W., Zhang, Y., Wu, F., Li, L., Yan, J., Liu, X., Lu, X., Tan, H., Zhang, L., Wang, J., and Hu, A.: Beijing Climate Center Earth System Model version 1 (BCCESM1): model description and evaluation of aerosol simulations, Geosci. Model Dev., 13, 977-1005, https://doi.org/10.5194/gmd13-977-2020, 2020a.

Wu, T., Yu, R., Lu, Y., Jie, W., Fang, Y., Zhang, F., Zhang, J., Zhang, L., Xin, X., Wang, Z., Liu, Y., Wu, F., Chu, M., Li, J., Li, W., Zhang, Y., Shi, X., Yao, J., Liu, X., Yan, J., Zhao, H., Wei, M., Zhou, W., Li, L., Xue, W., Huang, A., Zhang, Y., Zhang, Y., and Shu, Q.: Source code for Wu et al., "BCC-CSM2-HR: A High-Resolution Version of the Beijing Climate Center Climate System Model", Geosci. Model Dev. publication, Zenodo, https://doi.org/10.5281/zenodo.4127457, 2020b.

Xin, X., Wu, T., and Zhang, J.: Introduction of CMIP5 experiments carried out with the climate system models of Beijing Climate Center, Advances in Climate Change Research, 4, 41-49, https://doi.org/10.3724/SP.J.1248.2013.041, 2013.
Xin, X., Wu, T., Zhang, J., Zhang, F., Li, W., Zhang, Y., Lu, Y., Fang, Y., Jie, W., Zhang, L., Dong, M., Shi, X., Chu, M., Liu, Q., and Yan, J.: Introduction of BCC models and its participation in CMIP6, Climate Change Research, 15, 533-539, https://doi.org/10.12006/j.issn.1673-1719.2019.039, 2019.

Yao, J., Zhou, T., Guo, Z., and Chen, X.: Improved Performance of High-Resolution Atmospheric Models in Simulating the East Asian Summer Monsoon Rain Belt, J. Climate, 30, 8825-8840, https://doi.org/10.1175/JCLI-D-16-0372.1, 2017.

Yu, R., Zhou, T., Wu, T., Xue, W., and Zhou, G.: Development and Evaluation of High Resolution Climate System Models, Springer, Singapore, 258 pp., https://doi.org/10.1007/978-98110-0033-1, 2016.

Zarzycki, C. M., Reed, K. A., Bacmeister, J. T., Craig, A. P., Bates, S. C., and Rosenbloom, N. A.: Impact of surface coupling grids on tropical cyclone extremes in high-resolution atmospheric simulations, Geosci. Model Dev., 9, 779-788, https://doi.org/10.5194/gmd-9-779-2016, 2016.

Zhang, L., Zhou, T., Klingaman, N. P., Wu, P., and Roberts, M.: Effect of Horizontal Resolution on the Representation of the Global Monsoon Annual Cycle in AGCMs, Adv. Atmos. Sci., 35, 10031020, https://doi.org/10.1007/s00376-018-7273-9, 2018.

Zhang, M., Lin, W., Bretherton, C. S., Hack, J. J., and Rasch, P. J.: A modified formulation of fractional stratiform condensation rate in the NCAR community atmospheric model CAM2, J. Geophys. Res., J. Geophys. Res., 108, 4035, https://doi.org/10.1029/2002JD002523, 2003.

Zhang, Y., Gao, Z., Li, D., Li, Y., Zhang, N., Zhao, X., and Chen, J.: On the computation of planetary boundary-layer height using the bulk Richardson number method, Geosci. Model Dev., 7, 2599_ 2611, https://doi.org/10.5194/gmd-7-2599-2014, 2014.

Zhao, M., Held, I. M., Lin, S. J., and Vecchi, G. A.: Simulations of Global Hurricane Climatology, Interannual Variability, and Response to Global Warming Using a $50 \mathrm{~km}$ Resolution GCM, J. Climate, 33, 6653-6678, 2009.

Zhao, M., Held, I. M., and Lin, S.-J.: Some counterintuitive dependencies of tropical cyclone frequency on parameters in a GCM, J. Atmos. Sci., 69, 2272-2283, 2012.

Zhou, T., Chen, Z., Zou, L., Chen, X., Yu, Y., Wang, B., Bao, Q., Bao, Y., Cao, J., He, B., Hu, S., Li, L., Li, J., Lin, Y., Ma, L., Qiao, F., Rong, X., Song, Z., Tang, Y., Wu, B., Wu, T., Xin, X., Zhang, H., and Zhang, M.: Development of climate and earth system models in China: Past achievements and new CMIP6 results, J. Meteorol. Res.-PRC, 34, 1-19, https://doi.org/10.1007/s13351020-9164-0, 2020. 